\title{
Anais do I Congresso Internacional de Saúde Única (Interface Mundial)
}

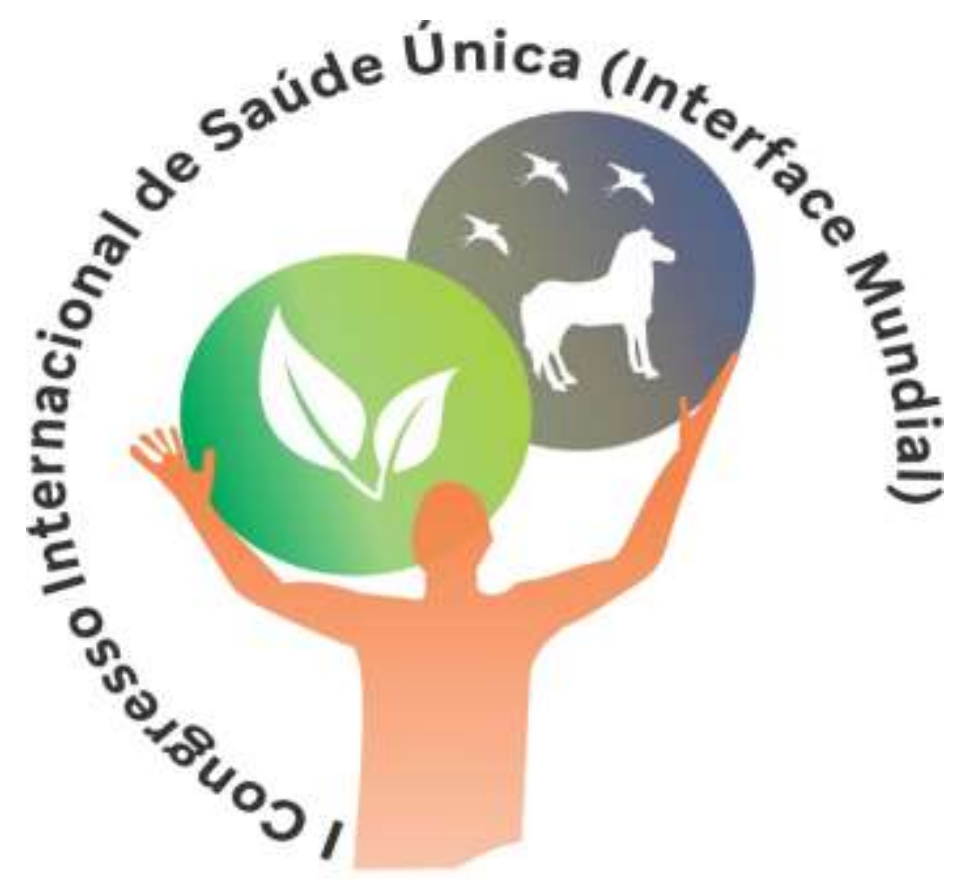

Apoio:

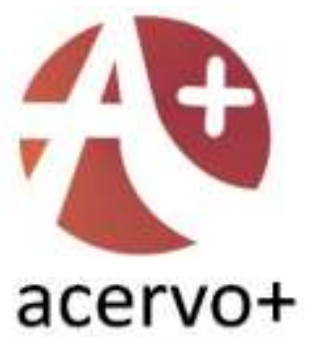

Eventos

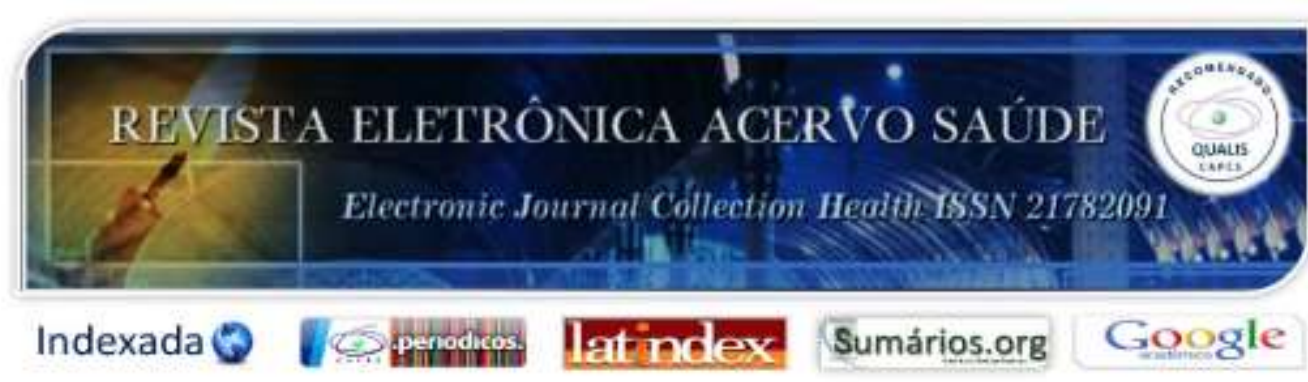




\section{SUMÁRIO}

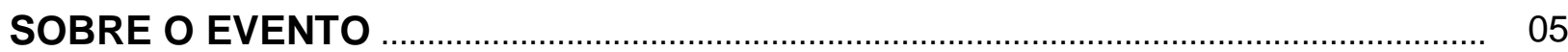

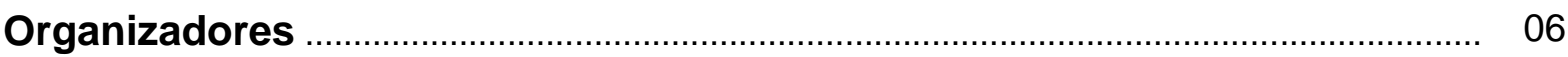

Presidência / Diretoria …....................................................................................... 06

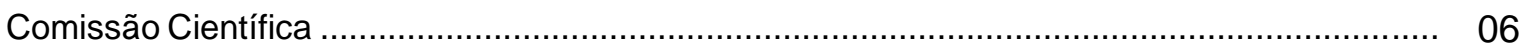

Estrutura Administrativa ......................................................................................... 06

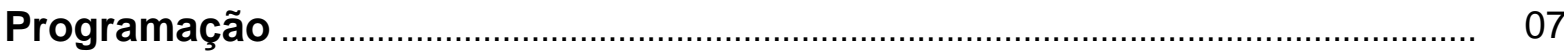

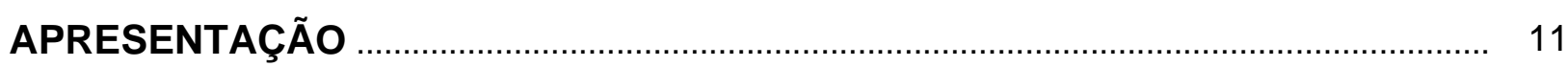

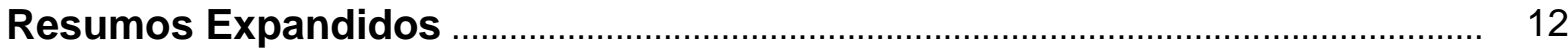

Perfil de medicamentos com potencial risco de quedas em idosos nefropatas hospitalizados.

Rennaly Sabrina da Silva Santana / Geovanna Oliveira Carneiro / Isabel Cristina Oliveira

Fernandes / Bruno Sant'Anna Rodrigues da Silva / Jordan Carlos Silva de Medeiros

Análise do estado nutricional de estudantes do curso de nutrição

Marcos Garcia Costa Morais/ Maysla Rayssa Silva Costa/ Joerika Batista Ciqueira / Cássia

Thaís Pessoa de Albuquerque Ferreira/ José Thiago Alves de Sousa

Análise parcial da presença de lectinas em extratos das cascas de Mimosa tenuiflora (Jurema-preta)

Nabuêr Francieli da Silva / Rosângela Estevão Alves Falcão / Maria Tereza dos Santos Correia

A utilização da fitoterapia e de plantas medicinais na atenção primária à saúde

Rayane Rodrigues Brasil / Clara Mirelle Oliveira Sales / Antonio Rodrigues da Silva Neto /

Diane Sousa Sales

Perfil epidemiológico da sífilis congênita no estado da Bahia, no período de 2010 a 2019

Augusto Cesar Costa Cardoso / Manoela Borges Pereira Lacerda

Levantamento epidemiológico das internações por tripanossomíase no Brasil durante o período de 2009 a 2019

Vanessa Aparecida Pivatto /Gabriela Araujo Moreira /Bárbara Tisse da Silva /Rodrigo Antonio Pivatto

ITAMs e suas funções no sistema imune: uma breve revisão

Melaine Lopes / Camilla Lazzaretti

Ação antimicrobiana do citronelal

David Vitor da Silva Anjos / Paulo Henrique Silva / Suyla Manuelle Leite / Renata Janaína Carvalho de Souza 
Ácido Mandélico voltado ao tratamento de manchas e hiperpigmentação da pele

Ana Tamires Alves dos Santos / David Pablo Cavalcanti da Fonseca / Marconi Rego Barros Júnior / Maria Luiza Carneiro Moura Gonçalves Rego Barros / Ana Carolina Messias de Souza Ferreira da Costa

Impacto dos serviços clínicos farmacêuticos na adesão de pacientes renais crônicos a terapia

Izadora Gomes Rodrigues Silva / Jordan Carlos Silva de Medeiros / Ana Carolina Messias de Souza Ferreira da Costa / Marconi Rego Barros Junior / Maria Luiza Carneiro Moura Gonçalves Rego Barros

Importância do controle da coleta de amostras de refeições fornecidas por unidades hospitalares

Cássia Thaís Pessoa de Albuquerque Ferreira / Joerika Batista Ciqueira / Marcos Garcia Costa Morais / Maysla Rayssa Silva Costa /José Thiago Alves de Sousa

Os impactos e desafios da COVID-19 em gestantes, lactantes e recém-nascidos durante a pandemia

Izadora Gomes Rodrigues Silva / Geovanna Oliveira Carneiro / Rennaly Sabrina da Silva Santana / Ana Carolina Messias de Souza Ferreira da Costa / Maria Luiza Carneiro Moura Gonçalves Rego Barros

O acesso da pessoa idosa aos serviços de saúde da atenção básica

Cidianna Emanuelly Melo do Nascimento

Políticas Públicas de saúde e ações estratégicas na erradicação da Tuberculose Pulmonar

Izadora Gomes Rodrigues Silva / Bruno Sant'Anna Rodrigues da Silva / Ana Carolina Messias de Souza Ferreira da Costa / Marconi Rego Barros Júnior / Maria Luiza Carneiro Moura Gonçalves Rego Barros

Síndrome de Peutz-Jeghers: um acometimento raro

Cleber Queiroz Leite / Laís Silva Sousa / Kimberlly Nava Flores / Grícia Aparecida Rodrigues de Souza

O risco da automedicação em meio a uma pandemia

Suyla Manuelle da Silva Leite / Paulo Henrique da Silva / David Vitor da Silva Anjos / Maria Luiza Carneiro Moura Gonçalves Rego Barros / Ana Carolina Messias de Souza Ferreira da Costa

Uso do canabidiol como auxílio ou alternativa terapêutica para manejo da dor em pacientes com câncer

David Pablo Cavalcanti da Fonseca / Ana Tamires Alves dos Santos / Marconi Rego Barros Junior / Maria Luiza Carneiro Moura Gonçalves Rego Barros / Ana Carolina Messias de Souza Ferreira da Costa

Utilização da Calendula officinalis L. e Punica granatum L. na saúde bucal .... 
Bianka Carlla Vicente da Silva, Suzana de Paula Figueiredo, Renata Janaína Carvalho de Souza

Atividades biológicas das cascas da Aroeira do sertão (Myracrodruon urundeuva)

Elvis Bezerra Santos / Jessica Alves de Lima / Vanessa da Silva Rocha / Nabuêr Francieli da Silva / Rosângela Estevão Alves Falcão

Atividades biológicas dos frutos do noni (Morinda citrifolia Linn)

Elvis Bezerra Santos / Jessica Alves de Lima / Vanessa da Silva Rocha / Nabuêr Francieli da Silva / Rosângela Estevão Alves Falcão

Sarcopenia e seus impactos no estado nutricional em pacientes oncológicos em cuidados paliativos

Joerika Batista Ciqueira/ Cássia Thaís Pessoa de Albuquerque Ferreira / Marcos Garcia Costa Morais / Maysla Rayssa Silva Costa / José Thiago Alves de Sousa

Uso de benzodiazepínicos em área rural

Carine Machado Pereira / Stéphane Rossi de Melo / Denise Krieger

Impacto do seguimento farmacoterapêutico realizado em pacientes com insuficiência renal crônica

Adriana Araújo de Oliveira Souza / Alan Damião Queiroz / Renata Freitas de Araujo-Calumby Biocurativo de selante de fibrina no tratamento de úlceras dos membros inferiores e venosa

Suyla Manuelle da Silva Leite / Paulo Henrique da Silva Santos / David Vitor da Silva Anjos / Maria Luiza Carneiro Moura Gonçalves Rego Barros / Ana Carolina Messias

Alterações anatômicas na mulher gestante versus infecção urinária: uma estratégia de educação em saúde

Thaise Farias Rodrigues / Beatriz Mella Pessoa Soares / Carlos Eduardo Colares Soares / Janaína de Oliveira e Castro / Quelly Christina Alves Schiave

Resumos Simples 74

Epidemiologia dos casos de câncer de gengiva no Brasil de 2016 a 2020 74

Pedro Henrique Batista da Silva / Renaly Gabriely de Araujo Rodrigues

Causas relacionadas à pielonefrite com ênfase no seu diagnóstico e tratamento 76

Paulo Henrique Santos da Silva / David Vitor da Silva Anjos / Suyla Manuelle da Silva Leite / Ana Carolina Messias de Souza Ferreira da Costa / Ruany Cristyne de Oliveira Silva

AGRADECIMENTOS 78

Patrocinadores 78 


\section{SOBRE O EVENTO}

Saúde Única surge como uma forma de traduzir a visão integrada entre a saúde animal, humana e ambiental através da multidisciplinaridade no contexto da educação, torna-se possível atingir melhores resultados na saúde como um todo, elevando a qualidade de vida dos indivíduos e proporcionando um meio ambiente mais sustentável. Por isso, o objetivo desse evento foi "criar um ambiente de aprendizado e discussão científica na área de Saúde Única”. O evento tem como tema: As diversas faces da atuação profissional na Saúde Única. Teve início às 08:00 horas da manhã no dia 16 de julho e término no dia 18 de julho de 2020 às 16:00 horas. O evento foi on-line, por isso, utilizamos palestras gravadas para ir ao ar em horário pré-determinado. Os palestrantes também se disponibilizaram em diversas ferramentas on-line para retirar dúvidas. Resumos de trabalhos foram submetidos e avaliados pela comissão científica. Alguns destes resumos foram escolhidos para apresentação oral com Menção Honrosa. Nosso evento foi extraordinário e pessoas de todo o país e até de outros países participaram. 


\section{Organizadores do Evento}

\section{Presidência/Diretoria}

Ana Carolina Messias de Souza Ferreira da Costa (Presidente).

Francisco Ferreira da Costa de Souza

Marconi Rego Barros Júnior

Maria Luiza Carneiro Moura Gonçalves

\section{Comissão Científica}

Ana Carolina Messias de Souza Ferreira da Costa

Edenilze Teles Romeiro

Francisco Ferreira da Costa de Souza

Marconi Rego Barros Júnior

Maria Luiza Carneiro Moura Gonçalves

Renata Janaína Carvalho de Souza

\section{Estrutura Administrativa}

Ana Carolina Messias de Souza Ferreira da Costa

Ana Tamires Alves dos Santos

David Pablo Cavalcanti da Fonseca

Felipe dos Santos Souza

Francisco Ferreira da Costa de Souza

Marconi Rego Barros Júnior

Maria Luiza Carneiro Moura Gonçalves

Renata Janaína Carvalho de Souza 
Programação

\begin{tabular}{|c|c|c|c|c|}
\hline \multicolumn{5}{|c|}{ Dia 1 - 16/07/2020 } \\
\hline Horário & Evento & & & \\
\hline 08:00 - 9:00 & Palestra & $\begin{array}{l}\text { Nome da } \\
\text { palestra } \\
\text { Fitoterapia e sua } \\
\text { Importância na } \\
\text { Saúde Pública }\end{array}$ & $\begin{array}{l}\text { Dra. Renata } \\
\text { Janaína Carvalho } \\
\text { de Souza }\end{array}$ & Online \\
\hline 09:30 - 10:30 & Palestra & $\begin{array}{l}\text { Desafio da } \\
\text { Saúde Pública } \\
\text { no Contexto das } \\
\text { Doenças } \\
\text { Zoonóticas }\end{array}$ & $\begin{array}{l}\text { Dra. Silvia Rafaelli } \\
\text { Marques }\end{array}$ & Online \\
\hline $11: 00-12: 00$ & Palestra & $\begin{array}{l}\text { Resistência } \\
\text { Bacteriana }\end{array}$ & $\begin{array}{l}\text { Dra. Amanda } \\
\text { Rafaela Carneiro } \\
\text { de Mesquita }\end{array}$ & Online \\
\hline $13: 00-14: 00$ & Palestra & $\begin{array}{l}\text { A importância } \\
\text { das técnicas } \\
\text { moleculares em } \\
\text { situação de } \\
\text { pandemia }\end{array}$ & $\begin{array}{l}\text { Dr. Marconi Rego } \\
\text { Barros Júnior }\end{array}$ & \\
\hline $15: 00-16: 00$ & Palestra & $\begin{array}{l}\text { O Farmacêutico } \\
\text { como profissional } \\
\text { "coringa" no SUS }\end{array}$ & $\begin{array}{l}\text { Dra. Maria Luíza } \\
\text { Carneiro Moura } \\
\text { Gonçalves Rego } \\
\text { Barros }\end{array}$ & Online \\
\hline $17: 00-18: 00$ & Palestra & $\begin{array}{l}\text { A epidemia } \\
\text { oculta: saúde } \\
\text { mental na era do } \\
\text { Covid-19 }\end{array}$ & $\begin{array}{l}\text { Psicóloga Laise } \\
\text { Andrade }\end{array}$ & Online \\
\hline
\end{tabular}




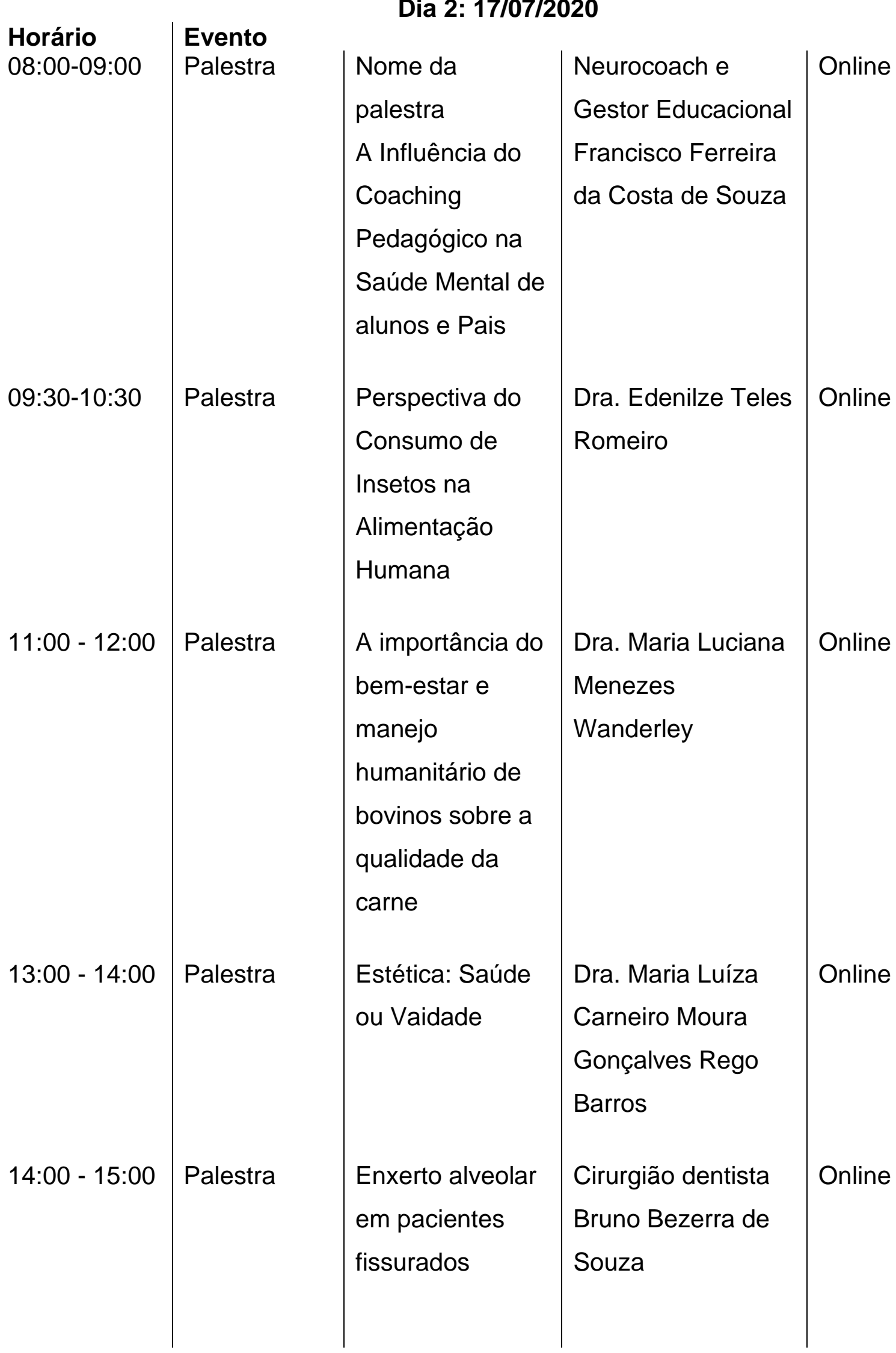




\begin{tabular}{|c|c|c|c|c|}
\hline $15: 00-16: 00$ & Palestra & $\begin{array}{l}\text { O Médico } \\
\text { Veterinário na } \\
\text { Saúde Pública }\end{array}$ & $\begin{array}{l}\text { Dra. Ana Carolina } \\
\text { Messias de Souza } \\
\text { Ferreira da Costa }\end{array}$ & Online \\
\hline $17: 00-18: 00$ & Palestra & $\begin{array}{l}\text { Quando e como } \\
\text { administrar } \\
\text { anestésicos } \\
\text { locais com } \\
\text { vasoconstrictores } \\
\text { em pacientes } \\
\text { com doenças do } \\
\text { sistema } \\
\text { cardiovascular }\end{array}$ & $\begin{array}{l}\text { Cirurgião dentista } \\
\text { Dr. Martinho Dinoá } \\
\text { Medeiros Júnior }\end{array}$ & Online \\
\hline $18: 00-19: 00$ & Palestra & $\begin{array}{l}\text { Inserção do } \\
\text { Farmacêutico } \\
\text { esteta no } \\
\text { mercado de } \\
\text { trabalho. }\end{array}$ & & Online \\
\hline
\end{tabular}

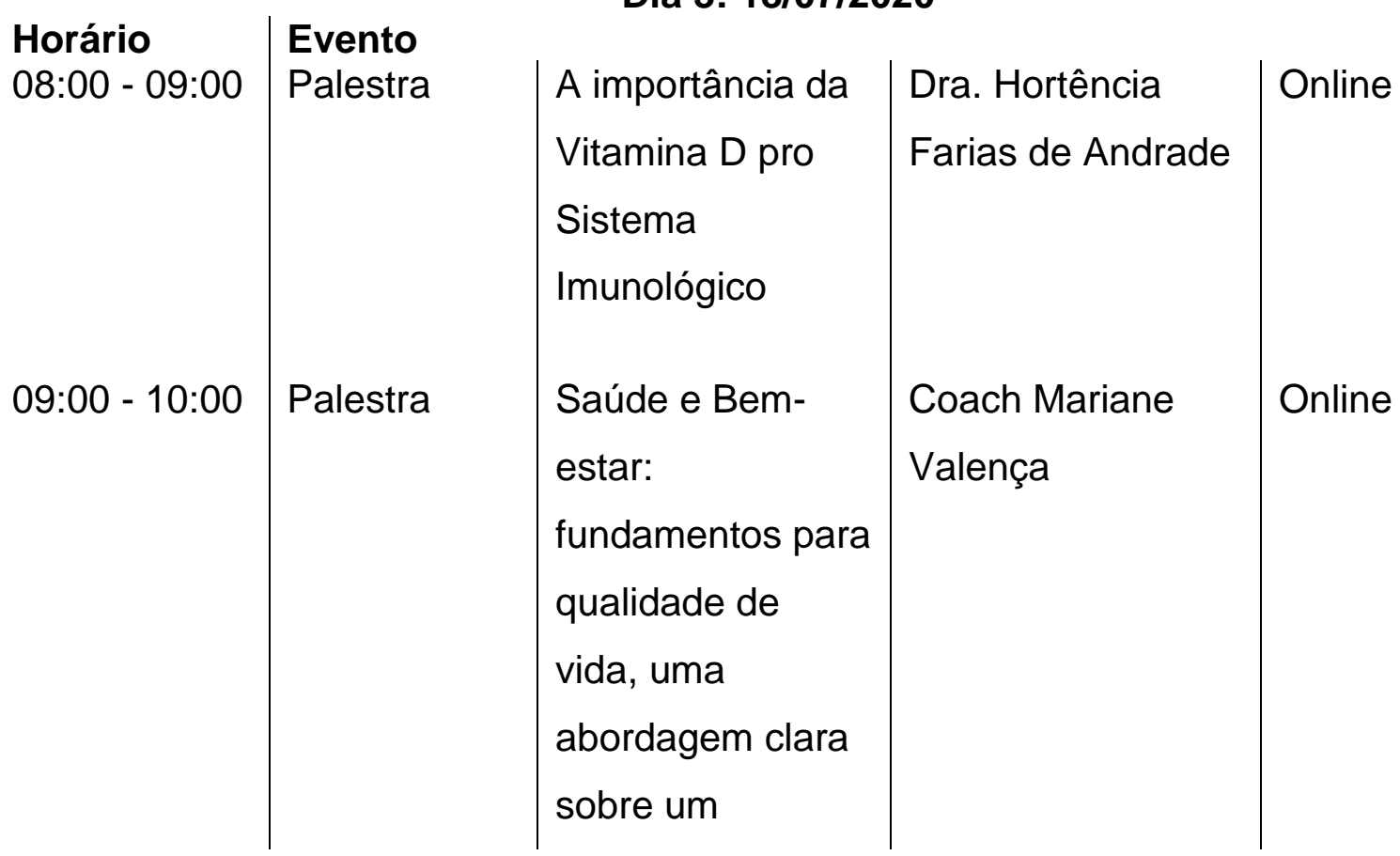




\begin{tabular}{|c|c|c|c|c|}
\hline & & $\begin{array}{l}\text { conjunto de } \\
\text { conceitos e } \\
\text { práticas que } \\
\text { condicionam a } \\
\text { vida de um ser } \\
\text { humano. }\end{array}$ & & \\
\hline $11: 00-12: 00$ & Palestra & $\begin{array}{l}\text { O Ensino da Área } \\
\text { de Saúde em } \\
\text { tempos de } \\
\text { Pandemia: Quais } \\
\text { estratégias } \\
\text { podem ser } \\
\text { desenvolvidas? }\end{array}$ & $\begin{array}{l}\text { Neurologista e } \\
\text { Msc. Felipe César } \\
\text { Gomes de } \\
\text { Andrade }\end{array}$ & Online \\
\hline $14: 00-15: 00$ & Palestra & $\begin{array}{l}\text { Bioinvasões } \\
\text { marinhas: Riscos } \\
\text { e Gestão }\end{array}$ & $\begin{array}{l}\text { Msc. Everthon de } \\
\text { Albuquerque } \\
\text { Xavier }\end{array}$ & Online \\
\hline $15: 00-16: 00$ & Palestra & $\begin{array}{l}\text { Análise da } \\
\text { acessibilidade a } \\
\text { áreas verdes para } \\
\text { manutenção da } \\
\text { qualidade de vida } \\
\text { em recursos a } \\
\text { SIG. }\end{array}$ & $\begin{array}{l}\text { Especialista } \\
\text { Pollyanna Marsi de } \\
\text { Lucena }\end{array}$ & Online \\
\hline
\end{tabular}




\section{APRESENTAÇÃO}

Em um momento que a população passa por uma pandemia pelo Covid-19 e diversas pessoas precisam estar isoladas, evitando-se, desta forma, contato social, o I Congresso Internacional de Saúde Única (Interface Mundial) trouxe a possibilidade de várias pessoas poderem assistir palestras gravadas de profissionais extremamente qualificados e de diversas áreas da saúde e meio ambiente, sem sair de casa. Trazendo assim uma maior conscientização das pessoas acerca do conceito de Saúde Única, que surge como uma forte união entre a saúde animal, humana e ambiental. Neste contexto, analisar e entender o todo são de suma importância para garantir melhores resultados na promoção da saúde e assim poder prevenir e tratar muitas doenças, através da atuação integrada dos diversos profissionais das várias áreas da saúde humana e animal e profissionais que estudam o meio ambiente em um contexto mais amplo. Incentivando pesquisas e programas voltados para a integração dos diversos saberes que possam permitir gestão de ações e ligadas à saúde pública, bem estar animal, manuseio seguro de produtos vegetais e animais, segurança alimentar e uso sustentável dos recursos naturais como um todo. O congresso contou com a participação de estudantes de graduação, pós-graduação e profissionais da saúde e meio ambiente. O evento também possibilitou a submissão de resumos simples e expandidos, na forma de estudo original, estudo de caso, relato de experiência e revisão bibliográfica, nas mais variadas áreas de saúde dentro do conceito de Saúde Única, com temas que abordam todas as dimensões de bem-estar animal e humano. A publicação traz 27 trabalhos, incluindo 25 resumos expandidos e 2 resumos simples. E um dos trabalhos foi aprovado pelo Comitê de Ética em Pesquisa, por ser realizado com seres humanos. As avaliações dos trabalhos para publicação levaram em consideração a originalidade, fundamentação teórica, metodologias aplicadas, apresentação dos dados e discussão dos resultados e contextualização dos assuntos abordados. O evento mostrou-se importante na abordagem de assuntos relevantes para a saúde e bem-estar geral de humanos, animais e meio ambiente. 


\section{Resumos Expandidos}

\section{RESUMO EXPANDIDO: Estudo Original}

Título: Perfil de medicamentos com potencial risco de quedas em idosos nefropatas hospitalizados

Autor/coautores: Rennaly Sabrina da Silva Santana ${ }^{1}$, Geovanna Oliveira Carneiro ${ }^{1}$, Isabel Cristina Oliveira Fernandes ${ }^{2}$, Bruno Sant'Anna Rodrigues da Silva ${ }^{2}$, Jordan Carlos Silva de Medeiros ${ }^{3}$.

Instituição: ${ }^{1}$ Graduanda na Universidade Federal de Pernambuco (UFPE), Recife-Pernambuco; ${ }^{2}$ Graduando no Centro Universitário Maurício de Nassau (UNINASSAU), Recife-Pernambuco; ${ }^{3}$ Mestrando no Programa de Pós graduação em Ciências Farmacêuticas da Universidade Federal de Pernambuco (PPGCF/UFPE), Recife-Pernambuco.

Palavras-chave: Acidentes por Queda, Idosos, Hospitais.

\section{INTRODUÇÃO}

Estabelecidas pela Joint Commission International ( $\mathrm{JCl}$ ), em parceria com a Organização Mundial da Saúde (OMS), as seis Metas Internacionais de Segurança do Paciente se consistem em identificar os pacientes corretamente, melhorar a comunicação efetiva, melhorar a segurança de medicamentos de alta vigilância, assegurar cirurgias com local de intervenção correto, procedimento correto e paciente correto, reduzir o risco de infecção associada aos cuidados de saúde, e reduzir o risco de lesões ao paciente, decorrente de quedas (NEVES, et al., 2017).

Alguns requisitos são observados para se chegar a essa meta, como: utilizar de algum instrumento ou método para se reduzir os riscos de lesões aos pacientes; realizar avaliações e reavaliações de risco de queda com os pacientes e aplicar métodos diferenciados aos pacientes que possuem esse risco (NEVES, et al., 2017).

O uso de determinados medicamentos pode contribuir para a queda de pacientes, principalmente na população idosa, sendo esta a segunda maior causa de morte acidental no mundo, responsável por 424 mil óbitos/ano. Em um estudo canadense, identificou-se que $95,4 \%$ dos pacientes internados que sofreram quedas em unidades de clínica geral de um hospital geral utilizavam, pelo menos, um medicamento associado à ocorrência de quedas (ISPM, 2017).

\section{OBJETIVO}

Analisar o perfil de medicamentos potenciais que juntamente com outros fatores, possam atuar de forma sinérgica para elevação do risco de queda em idosos internados na enfermaria de Nefrologia em um Hospital Universitário.

\section{MÉTODO}

Trata-se de um estudo descritivo, observacional transversal de caráter quantitativo, no período de janeiro a junho de 2019, na enfermaria de Nefrologia de um Hospital Universitário, por meio de análise das prescrições, seguindo a publicação referente aos Medicamentos Associados à Ocorrência de Quedas para Práticas Seguras no Uso de Medicamentos, com intuito de analisar a presença de medicamentos, que elevam riscos de queda no ambiente hospitalar, aplicando-se dados obtidos por uma pesquisa realizada pelo ISMPCanadá, juntamente com uma escala (Medication Fall Risk Score) disponibilizada pelo ISMP- Brasil, desenvolvida pela Agency for Healthcare Research and Quality (AHRQ). A coleta dos dados ocorreu após 
aprovação do projeto pelo CEP do hospital, com o número do parecer: 3.307.272. CAAE:12045019.1.0000.8807.

\section{RESULTADOS}

Foi realizado uma análise nas prescrições de 62 idosos, sendo composta em sua maioria por mulheres e pardos (53,22\% e 70,96\% respectivamente), com idades indo dos 60 aos 83 anos e insuficiência renal crônica em fase terminal como principal causa de internação (51,61\%), a qual girou em torno de 11,1 dias. A média de medicamentos por paciente foi de 8,37 fármacos.

Dos 78 diferentes medicamentos verificados e prescritos no intervalo de 520 vezes, 30 se enquadraram como susceptíveis para queda (38,46\%), sendo incluídos de acordo com seus efeitos no organismo (hipotensão ortostática, tontura, sonolência, parkinsonismo, disfunções motoras e cognitivas e alterações visuais) ou pela classe farmacológica (opióides; psicotrópicos; usados no tratamento de distúrbios cardiovasculares, incluindo diuréticos; e hipoglicemiantes, abarcando as insulinas).

Dentre as classes, fármacos indicados no tratamento das doenças cardiovasculares foram os mais utilizados $(61,6 \%)$, enquanto dexclorfeniramina e metoclopramida (antieméticos), tiveram um menor número de prescrições, total de 6 vezes (3,2\%).

No contexto dos medicamentos que predispõem à queda, com 20 ocorrências cada, as insulinas (Regular e NPH), foram as que mais se apresentaram nas prescrições (21\%).

Tabela 1 - Perfil dos medicamentos $(n=30)$ referentes a cada classe medicamentosa e quantidade de vezes que foram prescritos $(n=190)$.

\begin{tabular}{ccc}
\hline Classes & $\mathrm{N}$ & $\%$ \\
\hline Opióides & 3 & 6,3 \\
Psicotrópicos & 7 & 7,9 \\
Tratamento de distúrbios cardiovasculares & 16 & 61,6 \\
Hipoglicemiantes & 2 & 21 \\
Antieméticos & 1 & 1,6 \\
Antihistamínico & 1 & 1,6 \\
\hline Medicamentos & 30 & 100 \\
\hline Insulina NPH e Insulina Regular & & \\
Carvedilol, Furosemida e Nifedipina & 20 & 10,5 \\
Anlodipino e Clonidina & 18 & 9,5 \\
Atenolol e Tramadol & 13 & 6,0 \\
Clonazepam e Hidralazina & 8 & 4,2 \\
Losartana & 7 & 3,7 \\
Isossorbida & 6 & 3,1 \\
Metoclopramida & 5 & 2,6 \\
Codeína e Metoprolol & 4 & 2,1 \\
Amiodarona, Amitriptilina, Cilostazol, & 3 & 1,6 \\
Dexclorfeniramina e Diazepam & 2 & 1,05
\end{tabular}




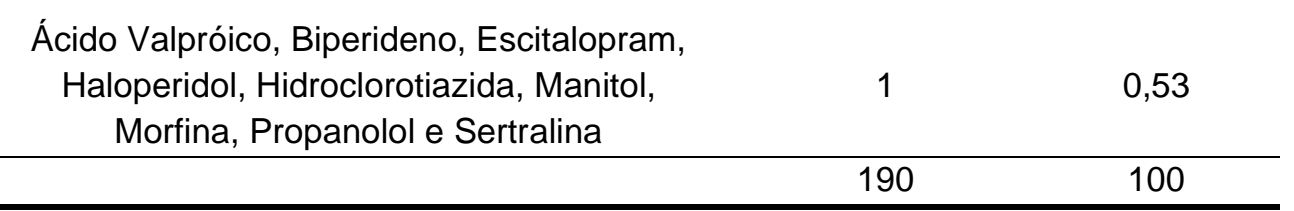

Fonte: Autoria própria.

\section{DISCUSSÃO}

Dentre os 190 medicamentos prescritos, 5 se destacam devido ao número de ocorrências: insulina regular e NPH (10,5\% cada) e carvedilol, furosemida e nifedipina ( $9,5 \%$ cada).

As insulinas representam riscos pelo efeito da hipoglicemia, podendo levar a danos cerebrais irreversíveis, cefaléia, náuseas, fraqueza, diminuição da coordenação e visão distorcida, sendo de grande importância para sucessão de acidentes (MARQUES, 2016).

Os antihipertensivos se fizeram presentes na extensa maioria das prescrições (118 dos 190 medicamentos) logo, o uso de fármacos para seu tratamento tendo a hipotensão ortostática como efeito colateral, é responsável por graves fraturas de quadril nesta população. A furosemida (18 indicações), como diurético traz a depleção de volume através da excreção de sódio, aumentando o fluxo urinário, gerando urgência miccional (MARQUES, 2016).

A indicação de 3 ou mais drogas também é fator de risco, sendo algo comum nas farmacoterapias analisadas, pois 8,37 foi o valor médio de medicamentos por prescrição.

\section{CONSIDERAÇÕES FINAIS}

De acordo com levantamento bibliográfico, fatores como idade avançada dos pacientes internados, alta média de permanência na hospitalização e a polifarmácia, juntamente com o uso de determinados medicamentos, apresentam importante predisposição para as quedas (MARQUES, 2016). Nesse prisma, medidas devem ser implantadas, tais como avaliação de interações que indiquem hipoglicemia, protocolos de checagem e registro de sinais vitais para monitoramento de hipotensão ortostática, alertas nos softwares de prescrição eletrônica que informem riscos identificados ao prescritor, e não menos importante, o papel ativo na prevenção desse evento adverso, por toda equipe multiprofissional (ISMP, 2017).

\section{REFERÊNCIAS}

1. MARQUES LGS, et al. Fatores clínicos, farmacológicos e ambientais que predispõem pacientes hospitalizados ao risco de quedas. Revista Acreditação: ACRED, v. 6, n. 12, p. 21-38, 2016.

2. Medicamentos associados à ocorrência de quedas. Instituto para Práticas Seguras no Uso de Medicamentos - ISMP Brasil. ISSN 2317-2312| VOLUME 6 | NÚMERO 1 | FEVEREIRO DE 2017.

3. NEVES VLS, et al. Risco de queda em idosos: instrumento de avaliação. Revista uningá review, v. 30, n. 2, 2017. 
RESUMO EXPANDIDO: Estudo Original

Título: Análise do estado nutricional de estudantes do curso de nutrição

Autor/coautores: Marcos Garcia Costa Morais, Maysla Rayssa Silva Costa, Joerika Batista Ciqueira, Cássia Thaís Pessoa de Albuquerque Ferreira, José Thiago Alves de Sousa.

Instituição: Centro Universitário Maurício de Nassau (UNINASSAU), Campina Grande -PB; Universidade Federal de Campina Grande (UFCG), Cuité-PB; Universidade de Pernambuco (UPE), Garanhuns-PE.

Palavras-chave: Estudantes, Desnutrição, Eutrófico.

\section{INTRODUÇÃO}

Hodiernamente muitos adolescentes estão em transição para a vida universitária, processo que é caraterizado como um marco de mudanças nas características de vida. Essas mudanças constitui-se como uma etapa primordial do processo de transição da adolescência para a fase adulta, com isso, torna-se necessário adaptar à nova rotina e à nova carga horária de estudos e trabalhos, mudanças estas que podem condicionar alterações no comportamento alimentar e também alterações no estado nutricional, como o ganho ou perda de peso, durante esse período (LOUREIRO, 2016). Estudos recentes mostram que estudantes acadêmicos apresentam risco aumentado para o aparecimento de distúrbios alimentares, devido a suas atividades rotineiras. Além disso, graduandos do curso de Nutrição ainda tem outro fator a considerar, que é o convívio destes com os alimentos e seu pensamento em relação ao aspecto exterior, atribuindo grande relevância à boa aparência e relacionando-a com seu sucesso profissional (CRUZ, et al., 2018).

\section{OBJETIVO}

Estimar o estado nutricional e identificar alterações com a utilização do índice de Massa Corporal (IMC) e Circunferência da Cintura (CC) em estudantes graduandas do curso de Bacharelado em Nutrição em uma instituição privada no estado da Paraíba.

\section{MÉTODO}

Trata-se de um estudo do tipo transversal. A pesquisa foi realizada entre os meses de setembro a novembro, com estudantes do sexo feminino na faixa etária de 18 a 59 anos, de forma aleatória, com seleção por conveniência, sendo incluídas todas aquelas que estavam regularmente matriculadas no curso de Bacharelado em Nutrição, no ano de 2019 em uma instituição privada no estado da Paraíba, no qual aceitaram participar da pesquisa. Foram excluídos homens, idosos ( $>60$ anos), as mulheres que não compareceram para a coleta dos dados no dia previamente agendado, totalizando uma amostra final de 31 participantes. Esta pesquisa foi devidamente aprovada pelo Comitê de Ética da Universidade Estadual da Paraíba, UEPB (CAAE: 24763819.0.0000.5187).

\section{RESULTADOS}

Das 195 alunas matriculadas do curso de nutrição, 31 concordaram em participar da pesquisa, posteriormente foi realizado uma avaliação nutricional antropométrica. Analisando o estado nutricional, segundo a classificação do IMC, descrito na Tabela 1, mais da metade das estudantes apresentou adequação do índice de massa corporal (61,29\%) com média de IMC de $21,20 \mathrm{~kg} / \mathrm{m}^{2}$, em contrapartida, 38,72\% apresentava alguma alteração no estado nutricional, sendo 12,90\% estava abaixo do peso adequado, IMC médio de $17,42 \mathrm{~kg} / \mathrm{m}^{2}$ e $25,81 \%$ com excesso de peso, sendo que $16,13 \%$ estavam com sobrepeso (IMC médio de $27,41 \mathrm{~kg} / \mathrm{m}^{2}$ ) e $9,68 \%$ com obesidade, onde o IMC médio era de $31,96 \mathrm{~kg} / \mathrm{m}^{2}$, configurando obesidade grau $\mathrm{l}$. 
Tabela 1 - Perfil nutricional segundo IMC e CC, $n=31$.

\begin{tabular}{lccc}
\hline Estado nutricional (IMC) & N & $\%$ & (M \pm DP) \\
\hline Baixo peso & 4 & 12,90 & $17,42 \pm 0,16$ \\
Eutrofia & 19 & 61,29 & $21,20 \pm 1,52$ \\
Sobrepeso & 5 & 16,13 & $27,41 \pm 1,07$ \\
Obesidade & 3 & 9,68 & $31,96 \pm 1,74$ \\
\hline Circunferência da cintura (cm) & $\mathbf{N}$ & $\%$ & (M \pm DP) \\
\hline Normal & 20 & 64,51 & $68,17 \pm 4,90$ \\
Risco Elevado & 4 & 12,99 & $82,00 \pm 1,33$ \\
Risco Muito elevado & 7 & 22,5 & $95,43 \pm 4,90$ \\
\hline
\end{tabular}

Fonte: MORAIS, 2019.

Analisando a medida antropométrica da circunferência da cintura, 64,51\% apresentou ausência de risco para doenças cardiovasculares, $12,90 \%$ encontrava-se em risco elevado e $22,5 \%$ estavam em risco muito elevado. Evidenciando que apesar da maioria apresentar valores adequados para circunferência da cintura uma parcela significativa encontra-se em risco.

\section{DISCUSSÃO}

Apesar da rotina de um estudante acadêmico muitas vezes cansativa, no presente estudo, constatou-se que a maioria dos participantes estavam em estado nutricional eutrófico, entretanto uma parcela considerável apresenta alterações no diagnóstico nutricional. Corroborando, em um estudo desenvolvido também na Paraíba, ao analisar estudantes dos cursos de nutrição, enfermagem e farmácia, foi detectado que o diagnóstico nutricional apresentou prevalência para eutrofia, segundo o IMC preconizado pela Organização Mundial da Saúde (OMS) (GONÇALVES, 2019).

\section{CONSIDERAÇÕES FINAIS}

Foi encontrado uma prevalência do estado nutricional desejável (eutrófico), além disso, baixo risco para doenças cardiovasculares em estudantes de nutrição. Em contrapartida, uma parcela significativa manifestou alterações no diagnóstico nutricional como também risco para doenças cardiovasculares. Dessa forma, este estudo chama atenção para parcela de estudantes jovens desenvolvendo precocemente um diagnóstico indesejável. Baseado nisso, a criação de um estudo maior e o aperfeiçoamento de centros de atividades físicas dentro das universidades, auxiliado com influência da mídia em difundir hábitos alimentares adequados e quebrar paradigmas de um padrão inatingível de beleza, são medidas importantes direcionados à prevenção de alterações nutricionais.

\section{REFERÊNCIAS}

1. CRUZ R, et al. Verificação do estado nutricional de estudantes do curso de nutrição das faculdades integradas de bauru-sp com enfoque na ortorexia. Revista Brasileira de Obesidade, Nutrição e Emagrecimento, São Paulo. v. 12. n. 76. Suplementar 2. p.1119-1128. Jan./Dez. 2018.

2. GONÇALVES C. Estado Nutricional e do Comportamento Alimentar dos Estudantes dos Cursos da Saúde do Centro de Educação d Saúde da UFCG - Cuité/PB. 2019 Monografia (Graduação de Nutrição). Universidade Federal de Campina Grande, Cuité. 
3. LOUREIRO MP. Estado nutricional e hábitos alimentares de universitários. Segurança alimentar e nutricional, v.23, n. 2, p., 955-972, 2016. 
RESUMO EXPANDIDO: Estudo Original

Título: Análise parcial da presença de lectinas em extratos das cascas de Mimosa tenuiflora (Jurema-preta)

Autor/coautores: Nabuêr Francieli da Silva, Rosângela Estevão Alves Falcão, Maria Tereza dos Santos Correia.

Instituição: Universidade Federal de Pernambuco (UFPE); Universidade de Pernambuco (UPE), Campus Garanhuns; Recife-Pernambuco.

Financiamento: Fundação de Amparo à Ciência e Tecnologia de Pernambuco (FACEPE).

Palavras-chave: Lectinas, Cascas, Jurema-preta.

\section{INTRODUÇÃO}

O aparato molecular de que dispõem os organismos para o enfretamento de injúrias celulares, é altamente diverso e especializado. Nas plantas, um grupo de proteínas conhecidas como lectinas, merecem especial destaque. Essas biomoléculas são definidas como proteínas ou glicoproteínas de origem não imune, cuja principal função biológica é a interação com moléculas de carboidratos ou glicoconjugados de modo específico e reversível. Nesse contexto, estão associadas a uma diversidade de eventos biológicos a citar, propriedade de hemaglutinação, precipitação de carboidratos e glicoconjugados, e a mecanismos de defesa em plantas, como na interação hospedeiro-planta e proteção contra fitopatógenos; desempenhando, portanto, papel crucial em determinados grupos vegetais quanto a sua resposta à organismos invasores (MISHRA A, 2019).

Dentre as famílias botânicas, a leguminosa registra o maior número de lectinas já isoladas e caracterizadas. Muitas dessas lectinas demonstraram atividades relevantes de interesse médico, exibindo propriedade anticancerígena, ação antimicrobiana e anti-inflamatória (MISHRA A, 2019). Portanto, a identificação de novas lectinas de plantas se apresenta como promissora considerando a gama de aplicações biotecnológicas registradas na literatura científica. Por fim, Mimosa tenuiflora espécie arbórea pertencente à família supracitada, referida popularmente, principalmente, como jurema-preta nos locais de sua ocorrência, será objeto de investigação lectínica do presente estudo.

\section{OBJETIVO}

Investigar a existência de lectinas em extratos das cascas de Mimosa tenuiflora produzidos em solução de $\mathrm{NaCl}$ 0,15 M e tampões citrato-fosfato salino $\mathrm{pH} 5,6$ e fostato salino $\mathrm{pH} 8,0$, utilizando eritrocitos humanos do sistema ABO para verificação da Atividade Hemaglutinante.

\section{MÉTODO}

Previamente a realização do estudo experimental, as cascas foram coletadas em área de Caatinga localizada na divisa entre os municípios de lati e Paranatama, estado de Pernambuco. O material vegetal coletado foi triturado, pesado e solubilizado nos tampões citrato-fosfato salino $(\mathrm{pH} \mathrm{5,6)}$ e fosfato salino $(\mathrm{pH}$ $8,0)$, e em solução de $\mathrm{NaCl} 0,15 \mathrm{M}$, obtendo-se uma solução a $10 \%(\mathrm{~m} / \mathrm{v})$. Na sequência, a solução foi centrifugada a $10.000 \mathrm{rpm}$ por 15 minutos a $4 \stackrel{\circ}{\circ} \mathrm{C}$. O sedimento foi desprezado e o sobrenadante (extrato aquoso) foi coletado e usado para os ensaios de hemaglutinação. A atividade hemaglutinante foi verificada utilizando eritrócitos de diferentes grupos sanguíneos $A, B, A B$ e $O$ humanos.

\section{RESULTADOS}


Os extratos brutos avaliados de Mimosa tenuiflora em diferentes pHs apresentaram atividade hemaglutinante para todos os eritrocitos humanos testados, conforme pode ser observado nos dados do estudo organizados na Tabela 1 a seguir. Verifica-se, contudo, que comparativamente o extrato produzido em $\mathrm{NaCl}$ 0,15 M apresentou maiores valores de aglutinação para ambos os tipos sanguíneos analisados em relação aos demais extratos estudados, e que ainda o extrato fosfato salino e o citrato-fosfato salino apresentaram as menores atividades hemaglutinantes, respectivamente. Dessa forma, estes dados indicam a influência dos três tipos de solventes em diferentes valores de $\mathrm{pH}$ sobre a atividade hemaglutinante, verificando-se que a melhor atividade encontrada foi no extrato em $\mathrm{NaCl} 0,15 \mathrm{M}, \mathrm{pH}$ neutro.

Tabela 1 - Atividade Hemaglutinante $(\mathrm{AH})$ dos extratos de Mimosa tenuiflora em eritrócitos humanos do sistema ABO.

\begin{tabular}{cccc}
\hline Eritrócitos & $\begin{array}{c}\text { Citrato-fosfato } \\
\text { salino }(\mathbf{p H ~ 5 , 6 )}\end{array}$ & $\mathbf{N a C l ~ 0 , 1 5 ~ M}$ & $\begin{array}{c}\text { Fosfato salino } \\
(\mathbf{p H ~ 8 , 0 )}\end{array}$ \\
\hline $\mathrm{AH}\left({ }^{*} \mathrm{UH} / \mathrm{mL}\right)$ & $\mathrm{AH}\left({ }^{*} \mathrm{UH} / \mathrm{mL}\right)$ & $\mathrm{AH}\left({ }^{*} \mathrm{UH} / \mathrm{mL}\right)$ \\
\hline A & 10922 & 54613 & 682 \\
\hline B & 2048 & 27306 & 1706 \\
\hline AB & 16384 & 16384 & 1706 \\
\hline $\mathbf{O}$ & 19114 & 27306 & 10922
\end{tabular}

Fonte: Própria autoria (2020). *Unidade hemaglutinante (quantidade de proteína necessária para causar a aglutinação dos eritrócitos).

A tabela 1 também revela que os eritrócitos do grupo sanguíneo $A$ e $O$ apresentaram aglutinação mais expressiva em relação aos demais eritrócitos humanos, comparando-se os três solventes extratores. Entretanto, os eritrócitos do grupo sanguíneo $O$ apresentou melhor resultado para os extratos testados.

\section{DISCUSSÃO}

Estudos descritos na literatura sobre a potencialidade lectínica de Mimosa tenuiflora são escassos. Constatou-se um único estudo realizado por Feitosa MTL et al. (2015) com extratos das cascas desta espécie, obtendo-se uma atividade hemaglutinante específica em pH 3,5 de 316,74 UH/mg frente a eritrócitos humanos do tipo A. Reforça-se, contudo, que para a espécie em questão ainda não há na literatura científica consultada nenhum estudo descrito com resultados positivos para a atividade hemaglutinante utilizando os tipos sanguíneos $B, A B$ e $O$, ressaltando-se o ineditismo do presente estudo.

Por fim, salientamos que o ensaio de hemaglutinação, embora um teste padronizado para a triagens de lectinas, não é suficientemente conclusivo para a detecção da existência dessas proteínas, uma vez que outras moléculas inerentes ao metabolismo secundário de plantas, por exemplo, podem promover a aglutinação de células, como os taninos, composto fenólico presente nas cascas de $M$. tenuiflora em investigação (DENTINHO MTP e BESSA RJB, 2016).

\section{CONSIDERAÇÕES FINAIS}

Os resultados obtidos demonstraram que $\circ \mathrm{NaCl} 0,15 \mathrm{M}$ permite melhor estabilidade da atividade hemaglutinante verificada para amostras das cascas de Mimosa tenuiflora durante o processo extrativo. Reforça-se, entretanto, que os dados aqui apresentados são preliminares, e que ensaios posteriores de purificação e caracterização lectínica não necessários para confirmar e atribuir a atividade hemaglutinante observada a um tipo específico de lectina. Ademais, os resultados encontrados no presente estudo sugerem que se confirmada em estudos futuros a presença de aglutininas nas cascas da espécie avaliada, estas podem ser utilizadas na tipificação de grupos sanguíneos humanos. 


\section{REFERÊNCIAS}

1. DENTINHO MTP, BESSA RJB. Efeito da fonte e do pH do tanino na estabilidade de complexos de proteínas e taninos da fibra. Revista de Ciências Agrárias, 2016; 1(39).

2. FEITOSA MTL, et al. Inquérito Etnofarmacológico do pH de extração da lectina presente no extrato aquoso de Mimosa tenuiflora. In: Anais do X Simpósio Brasileiro de Farmacognosia, 2015.

3. MISHRA A. Structure-function and application of plant lectins in disease biology and immunity. Food and Chemical Toxicology, 2019; 134: e110827. 
RESUMO EXPANDIDO: Estudo Original

Título: A utilização da fitoterapia e de plantas medicinais na atenção primária à saúde

Autor/coautores: Rayane Rodrigues Brasil ${ }^{1}$, Clara Mirelle Oliveira Sales ${ }^{2}$, Antonio Rodrigues da Silva Neto ${ }^{3}$ Diane Sousa Sales ${ }^{4}$.

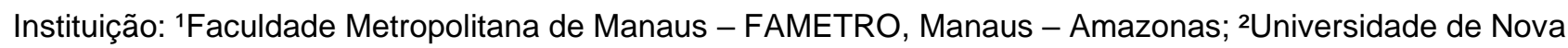
Iguaçu - UNIG, Nova Iguaçu - Rio de Janeiro; ${ }^{3}$ Universidade Estadual do Piauí - UESPI, Teresina - Piauí; ${ }^{4}$ Universidade Estadual Vale do Acaraú - UVA, Sobral - Ceará.

Palavras-chave: Fitoterapia, Plantas medicinais, Atenção primária.

\section{INTRODUÇÃO}

Desde épocas mais antigas, certas comunidades e povos utilizavam-se de plantas com a finalidade de tratar e curar doenças, esses, mesmos não detendo o conhecimento químico e farmacológico das plantas acreditavam no seu poder de cura. $O$ uso de plantas medicinais com ação terapêutica, além de um procedimento antigo, está correlacionado com a própria evolução da humanidade (SANTANA, 2019).

Essas presunções despertam a atenção dos programas de assistência à saúde e de profissionais, pois caracteriza-se em uma forma eficaz de atendimento e assistência primária à saúde. Discussões e debates são levantados em torno da implantação da fitoterapia na rede municipal de saúde ou na atenção primária. $O$ crescimento do trabalho desenvolvido com a fitoterapia apresenta-se com uma alternativa a referência de uso destas, em tratamentos de algumas enfermidades. A crescente tendência de busca, por terapias menos agressivas destinadas ao atendimento primário à saúde, faz com que desperte a atenção para estudos nessas áreas (MACEDO, 2016).

\section{OBJETIVO}

Revisar a utilização da fitoterapia e de plantas medicinais na atenção primária à saúde e ressaltar como esta alternativa pode ajudar a quem carece de medicamentos para tratamentos de enfermidades.

\section{MÉTODO}

A pesquisa foi realizada a partir de uma revisão sistemática. Tendo em vista essa perspectiva, a revisão de literatura foi pautada e fundamentada a partir da análise de artigos, dissertações e revistas científicas obtidas na base de dados, ScienceDirect, PUBMED, SciELO, Portal Capes e Google Acadêmico. Com a utilização de descritores para a pesquisa, como: plantas medicinais, medicamentos fitoterápicos, fitoterapia, medicina, medicina popular, saúde primária. Utilizando como recorte temporal 2016 a 2020, nos idiomas Português e Inglês e foram excluídos artigos que não tinham foco na fitoterapia e artigos fora da delimitação dos anos, ao final, procedeu-se à análise de 5 artigos.

\section{REVISÃO BIBLIOGRÁFICA}

As plantas com propriedades medicinais representam a principal matéria médica utilizada pela conhecida medicina tradicional em suas atividades terapêuticas e a medicina popular sendo a que mais utiliza a maior diversidade de espécies. Embora não se veja a aplicação de plantas medicinais dentro dos centros médicos, o uso destas representa um fator essencial e importante para a manutenção da saúde das pessoas (OLIVEIRA, et al., 2017).

O fator mais relevante para tal crescimento da fitoterapia se resume na evolução dos estudos científicos, que pesquisam tentam cada vez mais elucidar a confiabilidade dos fitoterápicos e que ganham destaque na descoberta da eficácia de plantas medicinais, através dos estudos químicos e farmacológicos, principalmente nas utilizadas pela população com finalidade terapêutica (ZHANG; VIRGOUS, 2019). Notando-se a eficácia 
e o baixo custo da utilização de plantas medicinais nos programas de atenção primária à saúde, pode-se confirmar que esta é uma alternativa bastante viável e útil como uma proposta terapêutica, isso se caracteriza pela forma fácil de adquirir essas plantas (ZENI, et al., 2017).

A possibilidade de fazer uso da fitoterapia no cenário da atenção primária à saúde faz com que seja necessário e imprescindível que se tenha um conhecimento exacerbado sobre plantas medicinais, quais os efeitos que essas causam, dentre esses, seus efeitos benéficos e maléficos, como essa deve atuar no corpo humano e qual o período de tratamento, para isso, observa-se que o número de pesquisas científicas dentro dessa temática tem ganhado cada vez mais atenção e respaldo. Com isso, programas de fitoterapia podem ganhar mais destaque dentro do âmbito da atenção primária à saúde (MACEDO, 2016).

\section{DISCUSSÃO}

Alguns autores afirmam a necessidade da criação de políticas públicas que possam assistir o aumento do uso de terapias alternativas, exemplo de a fitoterapia na atenção primária à saúde ser bastante eminente. Podendo reduzir a gritante diferença em relação à assistência, melhoria e manutenção no setor da saúde para a população, devido à enorme desigualdade social que assola o país, tratamentos medicamentosos para usuários e o acesso ao atendimento proporciona um contexto cada vez mais complexo (ZENI et al., 2017). Portanto, tendo em vista a análise dos artigos a baixa adesão ao processo de fitoterapia, ainda muito associado ao cuidado domiciliar, porém é uma PICS e deve ser compreendido pelos profissionais da saúde e utilizado de forma mais ampla.

\section{CONSIDERAÇÕES FINAIS}

Portanto, demonstrar a relevância no desenvolvimento de pesquisa na perspectiva de inserção de programas de fitoterápicos no país tem um elo com a importância da temática para o desenvolvimento dessa área que tanto cresce nos últimos anos. O efeito do uso de fitoterápicos e plantas medicinais pode contribuir tanto para o acesso a outras opções terapêuticas de cuidado, como para promover assistência na saúde na atenção primária, podendo contribuir efetivamente no tratamento de enfermidades e assim proporcionar a promoção à saúde.

\section{REFERÊNCIAS}

1. MACEDO J. Plantas medicinais e fitoterápicos na atenção primária à saúde: contribuição para profissionais prescritores. Trabalho apresentado à Escola Nacional de Saúde Pública Sérgio Arouca. 2016.

2. OLIVEIRA LP, et al. Eficácia dos métodos alternativos na medicina. III Seminário Científico da FACIG.2017.

3. SANTANA PHR. Plantas medicinais com fins terapêuticos utilizados por gestantes de unidades básicas de saúde. 2019. Monografia apresentada na Faculdade Maria Milza.

4. ZENI ALB, et al. Utilização de plantas medicinais como remédio caseiro na Atenção Primária em Blumenau, Santa Catarina, Brasil. Ciênc. saúde colet. 22 (8) Ago 2017.

5. ZHANG L, VIRGOUS CSIH. Synergistic anti-inflammatory effects and mechanisms of combined phytochemicals. The Journal of nutritional biochemistry, 2019. 
RESUMO EXPANDIDO: Estudo Original

Título: Perfil epidemiológico da sífilis congênita no estado da Bahia, no período de 2010 a 2019

Autor/coautores: Augusto Cesar Costa Cardoso, Manoela Borges Pereira Lacerda.

Instituição: Universidade do Estado da Bahia (UNEB), Salvador-Bahia.

Palavras-chave: Sífilis congênita, Perfil epidemiológico, Pré-natal.

\section{INTRODUÇÃO}

A sífilis é uma doença infectocontagiosa sistêmica, transmitida, principalmente, por via sexual e vertical, que vem sendo alvo de preocupação por todo o mundo. Segundo a Organização Mundial de Saúde (OMS), é a segunda da lista das doenças sexualmente transmissíveis, afetando sobretudo mulheres, em idade reprodutiva, ocasionando a Sífilis Congênita (SC). A SC é a infecção do feto pela bactéria Treponema pallidum. Ela pode causar sérias repercussões, como aborto, sequelas motoras e cognitivas. No Brasil, nos últimos dez anos, houve grande aumento na taxa de incidência da SC. O seu tratamento é feito com penicilina G benzatina e deve ser breve para evitar complicações graves (ANDRADE, 2018).

\section{OBJETIVO}

Compreender o contínuo crescimento dos casos de SC e analisar o perfil epidemiológico dos casos de SC na Bahia, durante o período de 2010 a 2019, refletindo sobre aspectos coletivos e caminhos para a superação da realidade descrita.

\section{MÉTODO}

Estudo ecológico, retrospectivo, descritivo, com dados secundários quantitativos. Os dados foram obtidos no Sistema de Informação de Agravos de Notificação (SINAN), referentes a 2010 até 2019, na Bahia. A coleta ocorreu em setembro de 2019 a março de 2020. Houve análise das variáveis: Casos de gestantes com sífilis (segundo idade gestacional no diagnóstico, faixa etária, escolaridade e raça ou cor) e casos de SC (segundo idade da criança, realização do pré-natal, momento de diagnóstico da sífilis materna, esquema de tratamento da mãe e informações sobre tratamento do parceiro).

O Tabnet do DATASUS foi utilizado para tabulação e os cálculos estatísticos foram obtidos no Programa Excel 2010. A incidência da SC foi feita através da divisão do número de casos novos por ano pelo número de nascidos vivos e multiplicado por 1.000 (obtido do Sistema de Informações sobre Nascidos Vivos). Este estudo avaliza a preservação da identidade dos sujeitos e princípios éticos, estabelecidos pela Resolução do Conselho Nacional de Saúde (CNS) № 466, de 12 de dezembro de 2012.

\section{RESULTADOS}

O Gráfico 1 revela o número de casos de gestantes com sífilis por ano de diagnóstico, entre 2010 e 2019 , na Bahia. Há uma contínua progressão, com pico em 2018 e queda em 2019.

Com relação aos casos de SC em menores de um ano e taxa de incidência por ano de diagnóstico, nos anos de 2010 a 2019, foram notificados 8.842 casos de SC no estado da Bahia, com um aumento significativo da taxa de detecção ao longo dos anos.

A maioria das mulheres tem entre 20 a 29 anos de idade (49.8\%), são pardas (60.2\%) e 20,6\% não concluíram o Ensino Fundamental. Evidenciou-se que $71,9 \%$ das mães fizeram o pré-natal, quando $46 \%$ dessas gestantes foram diagnosticadas e o tratamento materno foi adequado em apenas $3,5 \%$ dos casos. 0 parceiro da mãe não foi tratado em $57,3 \%$ dos casos. No que diz respeito à idade gestacional no momento do diagnóstico, 33,9 \% das gestantes já havia alcançado o terceiro trimestre de gestação, 32,9 \% estavam no segundo e $21,6 \%$ no primeiro. 
Gráfico 1. Casos de gestantes com sífilis por ano de diagnóstico. Bahia, 2010 -2019.

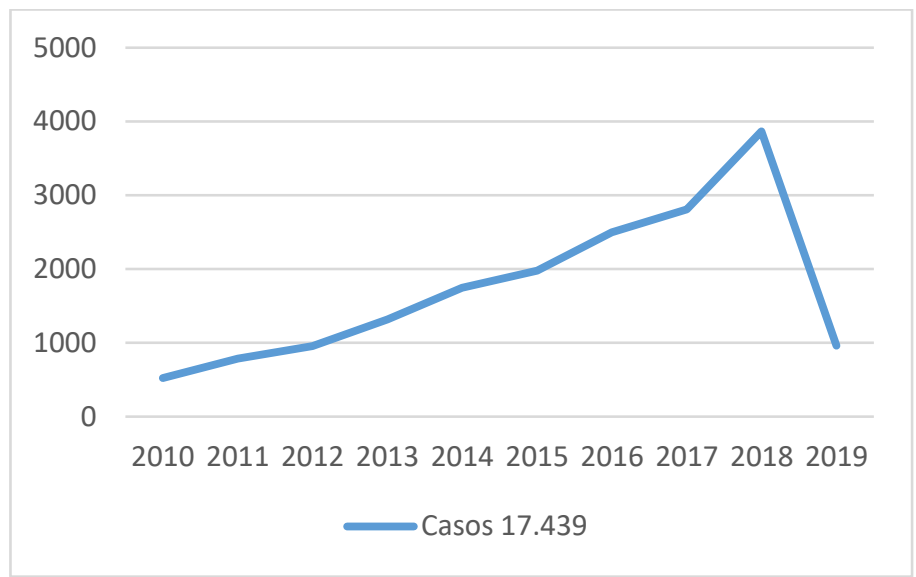

Fonte: LACERDA, 2019 [dados extraídos do SINAN, 2019]

\section{DISCUSSÃO}

Essa crescente notificação não é necessariamente negativa, já que desde 2008 a ONU elabora estratégias para otimizar o registro de casos. O pico em 2018 pode estar associado à crise no fornecimento de penicilina em 2017, assim como ao diagnóstico precoce com testes rápidos implantado pelo governo brasileiro neste ano (ANDRADE, 2018).

As características das gestantes têm raízes em questões socioeconômicas antigas e apontam caminhos para a superação dessa realidade. Investir em medidas socioeducativas e um bom suporte de acompanhamento é eficaz e de baixo custo. A tomada de consciência dos riscos de uma relação desprevenida, sobretudo na gravidez, contribuirá para prevenção e tratamento precoce da SC, evitando prejuízos irreparáveis (NUNES, 2018).

Muitas gestantes tiveram diagnóstico precoce, no entanto, a minoria foi tratada adequadamente. Os fatores podem variar desde a falta de compromisso dos profissionais à evasão do tratamento por parte das pacientes e não rastreio dos parceiros. (REIS, 2018).

\section{CONSIDERAÇÕES FINAIS}

As estratégias de saúde da família adotadas pelo governo da Bahia e Ministério da Saúde contribuíram para aumentar as notificações de SC e diagnóstico precoce, possibilitando o tratamento adequado e evitando complicações irreversíveis. No entanto, ainda há muito para avançar.

Permitiu-se refletir acerca de questões imprescindíveis como perfil socioeconômico das mulheres e fatores associados. Assim, compreendeu-se que o caminho mais eficaz é a educação, qualificação das equipes de saúde e orientação sobre cuidados com a saúde da mulher gestante. Assim, destaca-se a importância do prénatal, durante e após gravidez e de medidas socioeducativas que considerem a realidade da população.

\section{REFERÊNCIAS}

1. ANDRADE ALMB, et al. Diagnóstico tardio de sífilis congênita: uma realidade na atenção à saúde da mulher e da criança no Brasil. Revista Paulista de Pediatria. São Paulo, p. 376-381. jul. 2018. 
2. NUNES PS, et al. Sífilis gestacional e congênita e sua relação com a cobertura da Estratégia Saúde da Família, Goiás, 2007-2014: um estudo ecológico*. Epidemiologia e Serviços de Saúde, [s.I.], v. 27, n. 4, p.1-10, nov. 2018. Instituto Evandro Chagas.

3. REIS GJ, et al. Diferenciais intraurbanos da sífilis congênita: análise preditiva por bairros do Município do Rio de Janeiro, Brasil. Caderno de Saúde Pública. Rio de Janeiro, p. 1-13. abr. 2018. 
RESUMO EXPANDIDO: Estudo Original

Título: Levantamento epidemiológico das internações por tripanossomíase no Brasil durante o período de 2009 a 2019

Autor/coautores: Vanessa Aparecida Pivatto, Gabriela Araujo Moreira, Bárbara Tisse da Silva, Rodrigo Antonio Pivatto.

Instituição: Universidade do Alto Vale do Rio do Peixe (UNIARP), Caçador-SC; Universidade Federal do Paraná (UFPR), Curitiba-PR; Universidade de Vassouras (UV), Vassouras-RJ; Instituto Federal Catarinense (IFC), Concórdia-SC.

Palavras-chave: Trypanosoma cruzi, Internação, Epidemiologia.

\section{INTRODUÇÃO}

A tripanossomíase é uma zoonose causada pelo protozoário Trypanosoma cruzi, parasito de mamíferos que tem como principal hospedeiro o Triatoma infestans, conhecido como barbeiro. A primeira vez que foi detectada a presença desse protozoário no inseto-vetor, pelo pesquisador Carlos Chagas, ocorreu em Minas Gerais no ano de 1908 (REY, 2008).

As formas de transmissão da tripanossomíase compreendem a vetorial, a oral, transplante de órgãos/tecidos e transfusão sanguínea, transmissão congênita e acidental. Algumas das manifestações clínicas em humanos na fase aguda incluem febre, edema subcutâneo, astenia, mal-estar, aumento dos linfonodos, hepatomegalia, esplenomegalia e sinal de Romanã. Caso ocorra persistência parasitária no organismo, pode haver comprometimento no coração, como a cardiopatia chagásica crônica, cujas manifestações clínicas incluem arritmias, insuficiência cardíaca, comprometimentos tromboembólicos sistêmicos e pulmonares. (DIAS, et al., 2016).

A tripanossomíase atinge em torno de 7 a 8 milhões de pessoas em todo o mundo. Em estimativa feita sobre o número de infectados, em 2010, nos países latino-americanos, 5.742 .167 estariam acometidas pela doença sendo que os três países com maior número de casos em ordem decrescente são Argentina (1.505.235), Brasil (1.156.821) e México (876.458) (WHO, 2015).

\section{OBJETIVO}

Realizar um levantamento epidemiológico das internações hospitalares por tripanossomíase no Brasil durante o período de 2009 a 2019 por meio da base de dados DATASUS e analisar as características e tendências dessas internações.

\section{MÉTODO}

Estudo epidemiológico descritivo com dados obtidos por meio de consulta à base DATASUS. Foram observados casos de tripanossomíase diagnosticados no Brasil no período de 2009 a 2019. Para evitar erros de retardo de notificação, optou-se por analisar dados disponíveis até 2019. Variáveis como número de internações, valores de serviços hospitalares, taxa de mortalidade, etnia, caráter de atendimento, tempo de permanência, valor médio, regime de internação e idade foram avaliadas em todas as regiões brasileiras. A partir das informações levantadas foi construído um algoritmo para extração e manipulação de dados por meio do pacote estatístico SPSS 13.0. Por se tratar de um banco de domínio público, não foi necessário submeter o trabalho ao Comitê de Ética em Pesquisa com Seres Humanos.

\section{RESULTADOS}

REAS | Vol. Sup. 54 | e4479 | DOI: https://doi.org/10.25248/anais.e4479.2020 Página 26 de 78 
Foram observadas 6.463 internações por tripanossomíase no Brasil. O Sudeste apresentou o maior percentual de internações $(42,92 \%)$ e o Sul obteve o menor percentual $(5,41 \%)$. Foram despendidos no total $\mathrm{R} \$ 11.651 .425,43$, tendo o máximo ocorrido em $2019(\mathrm{R} \$ 1.855 .561,76)$ e o mínimo em $2012(\mathrm{R} \$ 619.130,49)$.

O caráter de atendimento predominante foi o de urgência (4.928), sendo que o caráter eletivo contou com 1.535 internações. Quanto ao regime de internação, notou-se que a maior parte foi ignorada (2.614), seguido do regime público (2.594) e do privado (1.255).

Houve predominância de internações na faixa etária acima de 50 anos e entre 70 e 79 anos houve mais óbitos (186). Quanto às etnias, 2.325 internações não apresentaram essa informação, seguido de 2.1720 internações de indivíduos pardos.

Em relação à mortalidade, o Brasil apresentou taxa de 9,69\% (626 óbitos). Por fim, analisaram-se as Unidades da Federação e percebeu-se que São Paulo foi o Estado com mais internações (1.174) e óbitos (178). Ademais, Pernambuco ficou em segundo lugar no número de óbitos (81) e Roraima foi o local com menos internações (7).

\section{DISCUSSÃO}

O Sudeste apresentou o maior número de internações, valores de serviços hospitalares e óbitos por tripanossomíase no Brasil. Este resultado pode estar correlacionado com o aumento da urbanização e migração (DIAS, et al., 2016).

Em relação ao sexo mais atingido, constatou-se uma concordância da literatura com o presente estudo, em que a maior prevalência foi encontrada entre indivíduos do sexo masculino (MALTA, 1996).

O caráter de atendimento de urgência predominante no setor público relaciona-se a complicações cardíacas e digestivas, que podem ser reflexo da ausência de intervenções preventivas e elevam os custos terapêuticos (MONTEIRO, 2010).

A faixa etária mais atingida foi adultos acima de 50 anos. O maior número de óbitos entre pacientes de 70 a 79 anos correlaciona-se às comorbidades preexistentes e às complicações da tripanossomíase em longo prazo (PASSOS, 2012).

\section{CONSIDERAÇÕES FINAIS}

O aumento de urbanização e de migração pode ter correlação com os resultados obtidos neste estudo. É de extrema necessidade que se analisem outros contextos interferentes relacionados com a história natural da doença e seus fatores biopsicossociais, como por exemplo o modo de desenvolvimento das cidades, que podem interferir na distribuição da tripanossomíase. Em virtude dessa mudança de perfil sociodemográfico, há tendência de ampliação do número de infectados. Sendo assim, a rede de atenção primária tem papel indispensável no que tange ao fornecimento de informações, assistência de saúde na prevenção, e busca ativa em caso de não adesão ao tratamento.

\section{REFERÊNCIAS}

1. DIAS J, et al. II Consenso Brasileiro em Doença de Chagas, 2015. Epidemiologia e Serviços de Saúde, Brasília, v. 25, n. esp, p. 7-86, jun. 2016.

2. LUÍS R. Parasitologia. 4. ed. Rio de Janeiro: GEN. 2008. 910 p.

3. MALTA J. Doença de Chagas. Ed. Savier. 1996. 202 p.

4. MONTEIRO MW, et al. Série de casos agudos de doença de Chagas atendidos num serviço terciário de Manaus, Estado do Amazonas, de 1980 a 2006. Revista da Sociedade Brasileira de Medicina Tropical 2010; v. 43, n. 2. 2010. 
5. PASSOS, et al. Sobrevivência e infectividade do Trypanosoma cruzi na polpa de açaí: estudo in vitro e in vivo. Epidemiologia e Serviços de Saúde. v. 21. n. 2, p. 223-232. 2012.

6. WHO. World Health Organization. Chagas disease in Latin America: an epidemiological update based on 2010 estimates. Weekly epidemiological record. 2015. fev. n. 6, p. 33-44. 
RESUMO EXPANDIDO: Revisão Bibliográfica

Título: ITAMs e suas funções no sistema imune: uma breve revisão

Autor/coautores: Melaine Lopes, Camilla Lazzaretti.

Instituição: Centro Universitário Cenecista de Osório (UNICNEC), Osório-RS, Porto Alegre-RS.

Palavras-chave: Immune System. ITAMs. ITIMs.

\section{INTRODUÇÃO}

Sabe-se que a atividade das células imunológicas depende do reconhecimento que seus receptores de membrana realizam. Em algumas células de defesa, como linfócitos T e células NK, existem os receptores denominados $\mathrm{Fc \gamma}$, onde desempenham diversos papéis no sistema imunológico. Eles possuem caudas intracelulares denominadas "motivos de ativação com base em imunorreceptores de tirosina (ITAMs)", que são alvos de proteínas tirosinas quinases. Quando fosforilados auxiliam na indução da sinalização intracelular de respostas imunes, o que resulta na transcrição gênica permitindo a diferenciação celular e a secreção de proteínas inflamatórias. O funcionamento deles se dá, a partir da fosforilação de seus resíduos de tirosina (GETAHUN A e CAMBIER JC, 2015).

Desta forma, a função de linfócitos é aprimorada, bem como a apresentação de antígenos, fagocitose e degranulação celular. Além da ativação gerada pelos ITAMs, sua atuação pode atingir um caráter inibitório por meio da atuação da proteína adaptadora conhecida como DAP12. Nestes casos, chamam os ITAMs de ITIMs (motivos de inibição baseados em tirosina por imunoreceptores) (VAN R, et al., 2016). Dadas estas informações, o presente estudo discorre de uma revisão narrativa da literatura, onde realizou-se uma análise crítica-reflexiva relacionada aos ITAMs e sua atuação no sistema imunológico.

\section{OBJETIVO}

Aprofundar os conhecimentos a cerca do papel dos ITAMs e suas variadas faces frente a imunidade inata e a imunidade adaptativa.

\section{REVISÃO BIBLIOGRÁFICA}

Após diversos estudos, nota-se que os ITAMs atuam na imunidade inata e adaptativa, a partir de variados mecanismos, tais como: (i) por meio do desencadeamento da citotoxidade por receptores como FcRy, em células natural killers; (ii) em neutrófilos atuam nas funções efetoras na degranulação e liberação de espécimes reativas de oxigênio (EROs); (iii) nas células $B$ e T os ITAMs entram em atividade na transdução de sinais junto aos receptores de antígenos (GETAHUN A e CAMBIER JC, 2015). Junto disso, percebe-se que os ITAMs podem atuar de forma inibitória, onde inclusive, há relatos na literatura de estudos realizados com camundongos deficientes da proteína DAP12 (um dos componentes de diferentes tipos de ITAMs) que mostraram que seus macrófagos apresentam menos poder inflamatório quando em contato com lipopolissacarídeo (LPS) (HIRSCH I, et al., 2017). Além destas informações, muitos estudos observam que há um crescente interesse na análise do controle da sinalização via ITAM ou ITIM nas funções de neutrófilos, onde um dos tipos de imunoreceptores que medeia essas sinalizações é FcRy (são receptores para as porções Fc de $\lg G$ ), principalmente correlacionando com parâmetro de patologias neoplasicas.

Tabela 1: Mecanismos de atuação de ITAMs.

\begin{tabular}{lc}
\hline ITMs & Mecanismos de Atuação \\
\hline ITAMs & Citotoxidade por receptores como FcRy em células NK
\end{tabular}

REAS | Vol. Sup. 54 | e4479 | DOI: https://doi.org/10.25248/anais.e4479.2020 Página 29 de 78 
Degranulação mediada por função efetora de Neutrófilo
Transdução de sinais junto a receptores de antígenos em células B e T

ITIMs

Atuação antiinflamatória

Fonte: GETAHUN A, et al., 2015. Of ITIMs, ITAMs, and ITAMis: revisiting immunoglobulin Fc receptor signaling. 2015.

\section{DISCUSSÃO}

Os ITAMs e os ITIMs possuem grande potencialidade de estudo acerca da sua possível utilidade clínica e terapêutica, no que concerne, principalmente, o caráter inibitório antiinflamatório. Há diversos apontamentos sobre o possível desenvolvimento de alvos promissores para intervenção terapêutica baseados nas interações propiciadas por imunorreceptores em neutrófilos, segundo estudos encontrados na literatura. Contudo, há muitos mecanismos funcionais a serem elucidados, em relação a sua regulação, onde essas moléculas com base em imunorreceptores de tirosina medeiam. Há uma gama de receptores envolvidos, onde até então o mais comentado e descrito foi o FcY (YOUSEFI Z, et al., 2016).

Outro ponto importante acerca do funcionamento dos ITAMs é sua variabilidade gênica, o que permite sequências de aminoácidos diferenciados. Desta forma, os aminoácidos tirosina da região terminal dos ITAMs, podem estar alterados, o que permite uma maior fosforilação ou a ausência de funcionalidade dos receptores imunológicos (ANTENUCCI L, et al., 2018).

\section{CONSIDERAÇÕES FINAIS}

De acordo com o que foi apresentado, percebe-se que os ITAMs são necessários para a ativação das respostas inatas e adaptativas, por meio de suas sinalizações intracelulares. Sua ação inibitória parece ser antiinflamatória e é amplamente estudada na atualidade em diversos locais do tecido. Desta forma, demonstra-se a necessidade de aprimorar pesquisas dos ITAMs, para que possivelmente sejam desenvolvidos alvos terapêuticos para o tratamento de doenças inflamatórias.

\section{REFERÊNCIAS}

1. ANTENUCCI L, et al. Phosphorylated immunoreceptor tyrosine-based activation motifs and integrin cytoplasmic domains activate spleen tyrosine kinase via distinct mechanisms. Journal of Biological Chemistry, 2018; 293(13).

2. GETAHUN A, CAMBIER JC. Of ITIMs, ITAMs, and ITAMis: revisiting immunoglobulin Fc receptor signaling. Immunological Reviews, 2015; 268(1): 66-73.

3. HIRSCH I, et al. Cross Talk between Inhibitory Immunoreceptor Tyrosine-Based Activation Motif-Signaling and Toll-Like Receptor Pathways in Macrophages and Dendritic Cells. Frontiers in Immunology, 2017; 8(394): 1-12.

4. VAN R, et al. Immunoreceptors on neutrophils. Seminars in Immunology, 2016; 28(2): 94-108.

5. YOUSEFI Z, et al.. Fc Receptor-Like 1 as a Promising Target for Immunotherapeutic Interventions of BCell-Related Disorders. Biomarker Insights, 2019;14:1-9. 
RESUMO EXPANDIDO: Revisão Bibliográfica

Título: Ação antimicrobiana do citronelal

Autor/coautores: David Vitor da Silva Anjos, Paulo Henrique Silva, Suyla Manuelle Leite, Renata Janaína Carvalho de Souza.

Instituição: Centro Universitário Brasileiro (UNIBRA), Recife-PE.

Palavras-chave: Óleo essencial, Leishmania braziliensis, Anti-helmíntico.

\section{INTRODUÇÃO}

A classe farmacológica dos antimicrobianos é a que mais detém índices de resistência dos agentes patológicos ao tratamento, principalmente a nível bacteriano. A propagação de bactérias que apresentam essa resistência aos antibióticos ocorreu de forma notória nos últimos anos, ocorrendo assim a ineficácia da farmacoterapia (OROZCO RC, et al., 2019).

Na busca por novas substâncias que resolvam o problema com a referida resistência, tem-se evidenciado substâncias oriundas de materiais orgânicos e naturais, como as plantas. Como exemplo dessas substâncias, tem-se o monoterpenoide citronelal, que tem sido alvo de pesquisas para a problemática supracitada. Este fitoconstituinte é a substância majoritária em óleos essenciais de plantas, como as do gênero Eucalyptus e Cymbopogon, e sua obtenção isolada pode ser feita decorrente de uma mistura não-racêmica dos enantiômeros $\mathrm{R}$ e $\mathrm{S}$, que apresentam eficácia como antibacteriano, antifúngico e anti-helmíntico. $\mathrm{O}$ mecanismo de ação do citronelal baseia-se em nível de membrana celular, apresentando efeito tóxico (dissipação da força próton motiva), implicando assim na disfunção no que concerne à permeabilidade seletiva da membrana (BEZERRA RV, et al., 2019).

\section{OBJETIVO}

Revisar estudos sobre a ação antimicrobiana do citronelal, em suas diferentes formas de atuação, como antibacteriana, antifúngica e anti-helmíntica, visando apresentar este fitoconstituinte como tratamento alternativo aos antimicrobianos já utilizados no tratamento de algumas patologias.

\section{MÉTODO}

Tratando-se de uma revisão bibliográfica, buscou-se diferentes artigos científicos acerca da temática abordada, publicados em bases de dados Scientific Electronic Library Online - SciELO, Science Direct e U.S. National Library of Medicine - PubMed. Para a busca dos artigos analisados foram utilizadas palavras chaves isoladas e permutadas, como "citronelal", "óleo essencial" e "citronelal antimicrobiano". Os critérios de inclusão foram artigos completos, publicados nos idiomas Inglês ou Português e que tivessem abordando o tema proposto, publicados no período de 2014 a 2019. Enquanto o critério de exclusão foram trabalhos incompletos e que não abordavam o tema proposto.

\section{REVISÃO BIBLIOGRÁFICA}

Em um estudo realizado por Bezerra et al. (2019), foi testada a atividade antibacteriana dos dois enantiômeros do citronelal, o (S)-(-)-citronelal e o (R)-(+)-citronelal, frente à cepa do Bacillus subtilis que é uma bactéria multirresistente. Avaliando-se a concentração inibitória mínima (CIM) dos fitoconstituintes contra a cepa da bactéria. E como resultado da CIM e suas diferentes concentrações graduais, obteve-se a concentração de $256 \mu \mathrm{g} / \mathrm{mL}$ para ambos enantiômeros frente à cepa de $B$. subtilis. Constando-se que óleos essenciais com uma CIM de até $500 \mu \mathrm{g} / \mathrm{mL}$ apresenta uma atividade antimicrobiana classificada como forte/boa.

A ação antifúngica dos enantiômeros citados acima do citronelal também foi testada e comprovada, tanto isoladamente quanto em associação com a nistatina. O fungo utilizado foi a Candia tropicalis, um dos agentes 
causadores da CVV (MEDEIROS CIS, et al., 2018). Os protocolos experimentais utilizados para analisar a capacidade fungicida foram a concentração fungicida mínima (CFM) e a CIM. Os dados obtidos foram que a CIM foi de 16 e $64 \mu \mathrm{g} / \mathrm{mL}$ para (R)-(+)-citronelal e (S)-(-)-citronelal respectivamente. Já a CFM foi de 32 e $64 \mu \mathrm{g} / \mathrm{mL}$ para os mesmos fitoconstituintes, respectivamente.

O controle de microrganismos em animais que fazem parte da cadeia alimentar humana também é importância, em caprinos e ovinos, por exemplo, pode-se perceber a presença de alguns nematoides gastrointestinais, como o parasita Haemonchus contortus, que frequentemente é combatido com antihelmínticos que estão apresentando certa resistência em seu tratamento. Como alternativa a esse tratamento, um estudo buscou testar essa mesma atividade através do óleo essencial (OE) da planta Eucalyptus citriodora, contendo $63,9 \%$ de citronelal em sua composição, onde constatou-se atividade anti-helmíntica satisfatória (ARAÚJO-FILHO JV, et al., 2019). A substância foi testada in vitro utilizando-se o teste de motilidade de vermes adultos (TMVA) e microscopia eletrônica de transmissão (MET). O TMVA mostrou que $2 \mathrm{mg} / \mathrm{mL}$ do óleo essencial inibiram completamente a motilidade do $H$. contortus em $6 \mathrm{~h}$, após a exposição, exibindo modificações estruturais internas no microrganismo. $O$ óleo ainda reduziu os nematoides em ovos por grama de fezes (OPG) de ovelhas aos 14 dias, após o tratamento, em 69,5\%.

\section{DISCUSSÃO}

Apresentando uma atividade antimicrobiana contra o Bacillus subtilis, classificada como forte/boa por Bezerra RV, et al. (2019), foi mostrada a ação do fitoconstituinte com seus enantiômeros isolados. Evidenciando assim, a gama de possibilidades para a ação desejada, não se limitando a análise da mistura racêmica. Como também foi constatado sua ação antifúngica, classificada como forte/boa contra Candida tropicalis por Medeiros CIS et al. (2018). O citronelal, no estudo como anti-helmíntico, mostrou resultados satisfatórios, já que exibiu modificações estruturais internas em $H$. contortus com $2 \mathrm{mg} / \mathrm{mL}$ do óleo essencial de E. citriodora e inibição da motilidade do parasita, ficando evidente a ação antimicrobiana do citronelal (ARAÚJO-FILHO JV, et al., 2019).

\section{CONSIDERAÇÕES FINAIS}

Diante dos todos os estudos apresentados, pode-se observar a capacidade de inibição do citronelal contra diferentes microrganismos. Sendo esses estudos extremamente relevantes diante dos problemas relacionados à resistência aos antimicrobianos convencionais que já são utilizados no tratamento de determinadas patologias.

\section{REFERÊNCIAS}

1. ARAUJO-FILHO JV, et al. Anthelmintic activity of Eucalyptus citriodora essential oil and its major component, citronellal, on sheep gastrointestinal nematodes. Revista Brasileira de Parasitologia Veterinária, 2019; 28(4): 644-651.

2. BEZERRA RV, et al. Atividade antimicrobiana dos monoterpenos (R)-(+)-citronelal, (S)-(-)-citronelal E 7hidroxicitronelal contra cepa de Bacillus subtilis. Revista Uningá, 2019; 56(2): 62-69.

3. CARNEIRO JNP, et al. Avaliação da atividade tripanocida, leishmanicida e citotóxica do geraniol e citronelal. Cadernos de Cultura e Ciência, 2015; 13(2): 29-36.

4. MEDEIROS CIS, et al. Atividade anti-Candida tropicalis dos enantiômeros (R)-(+)- \& (S)-(-)-citronelal em associação com nistatina. Archives of Health Investigation, 2018; 7(1): 40-43.

5. OROZCO RC, et al. Antimicrobial resistance trends in methicillin-resistant and methicillin-susceptible Staphylococcus aureus and Staphylococcus epidermidis isolates obtained from patients admitted to intensive care units. 2010-2015. Revista de la Facultad de Medicina, 2019; 67(3): 409-416. 
RESUMO EXPANDIDO: Revisão Bibliográfica

Título: Ácido Mandélico voltado ao tratamento de manchas e hiperpigmentação da pele

Autor/coautores: Ana Tamires Alves dos Santos, David Pablo Cavalcanti da Fonseca, Marconi Rego Barros Júnior, Maria Luiza Carneiro Moura Gonçalves Rego Barros, Ana Carolina Messias de Souza Ferreira da Costa.

Instituição: Centro Universitário Brasileiro, UNIBRA, Recife-Pernambuco.

Palavras-chave: Acne vulgar, Clareamento, Melasma.

\section{INTRODUÇÃO}

Constantemente aumentam os cuidados tomados com a pele e procura por profissionais, buscando tratamento de manchas de acnes e de Melasma. Essas manchas podem vir a prejudicar a qualidade de vida dos pacientes. Melasmas são manchas hiperpigmentadas adquiridas pelo fotoenvelhecimento, no qual afeta comumente o público feminino. Sua hiperpigmentação varia de marrom claro para a escuro com bordas irregulares e disposição assimétrica. A acne vulgar é uma doença inflamatória crônica, cujo principal mecanismo de desenvolvimento são as glândulas sebáceas relacionadas a hiperseborreia (ZAENGLEIN AL, 2018). A acne começa no início da adolescência, afetando tórax, face, ombros e costas que são ricas em glândulas sebáceas. As mais comuns são de moderada a grave que levam a resultados de cicatrizes e manchas de acnes na pele após a inflamação. Em estudos revelaram que as cicatrizes são evidentes em $95 \%$ dos casos de acnes (LAN T, et al., 2018). A utilização de Ácido Mandélico (AM) promove o tratamento eficaz na remoção ou clareamento das manchas, através de peelings químicos de AM, são mais utilizados por terem como característica suavidade e resultados mais positivos para o clareamento das manchas (NOLASCO IMML, 2020).

\section{OBJETIVO}

Analisar a eficiência do Ácido mandélico no tratamento de manchas e acnes na pele, visando atribuir o método mais seguro e com menos efeitos colaterais, visando prevenir riscos que possa prejudicar o estilo de vida do paciente, com atuação de um profissional capacitado para desenvolver a prática do procedimento estético.

\section{MÉTODO}

Foi realizada uma revisão integrativa, com intuito de coletar informações sobre a efetividade do ácido mandélico no tratamento de melasmas e manchas de pele causadas pela acne vulgar, no qual foi realizado a pesquisa em portais acadêmicos como PubMed e Scielo através das palavras chave: manchas de pele, tratamento estético, ácido mandélico e acne. Dentre o material pesquisado, foi utilizado como critério de inclusão, artigos que relatassem a eficiência do AM e como critério de exclusão, foram descartados documentos que tratasse da utilização do AM para outros fins que não fossem o clareamento de pele. Dentre o material utilizado, estes tiveram suas publicações entre o ano de 2016 a 2020.

\section{RESULTADOS}

O ácido mandélico é um ácido com alto benefício tópico para o tratamento de hiperpigmentação na pele e acnes, além de aprimorar a qualidade de pele envelhecida. Possui penetração lenta na camada do estrato córneo da pele e comumente é suportável em pacientes com pele sensível. Sua molécula possui estruturas grandes, no qual favorece com que sua penetração na pele seja de maneira lenta, além de ser considerada um agente descascador leve e seguro geralmente utilizado na concentração de $20 \%$ a $50 \%$ para o clareamento e efeito rejuvenescedor (KONTOCHRISTOPOULOS G, 2016). Através de estudo comparativo 
realizado por pesquisadores durante 12 semanas, foi observado uma diferença de efetividade entre compostos de mesma finalidade como o ácido mandélico e ácido salicílico, no qual possuem a função de remover manchas causadas pelo melasma e acne da pele, no qual o ácido mandélico obteve $15 \%$ de resultados superiores em comparação ao outro ácido (DAYAL S, et al, 2019).

\section{DISCUSSÃO}

Dentre os métodos com utilização do ácido mandélico mais comum, atualmente se encontram os pellings, nos quais são utilizados para eliminar manchas surgidas de acnes e melasma. $O$ ácido mandélico permanece por mais tempo na superfície da pele por possuir peso molecular maior, e atua com menos queimação e ardor em comparação ao ácido salicílico que possuem baixo peso molecular (SARKAR R, et al, 2016). Em estudos comparativos, o AM teve $45 \%$ de resposta positiva no tratamento de acne comparado ao AS que obteve $30 \%$ ao final do tratamento pelo resultado de redução de pápulas, pústulas e manchas na pele. Nenhum dos pacientes submetidos ao tratamento tiveram efeitos colaterais a exposição ao AM. No Quadro 1 podemos ver a evolução nos resultados de estudo randomizado com 50 pacientes, no qual pode observar melhores resultados na comparação das substancias em 12 semanas (DAYAL S, et al., 2019).

Quadro 1 - Estudo comparativo de efetividade entre AM e AS no tratamento de acne vulgar.

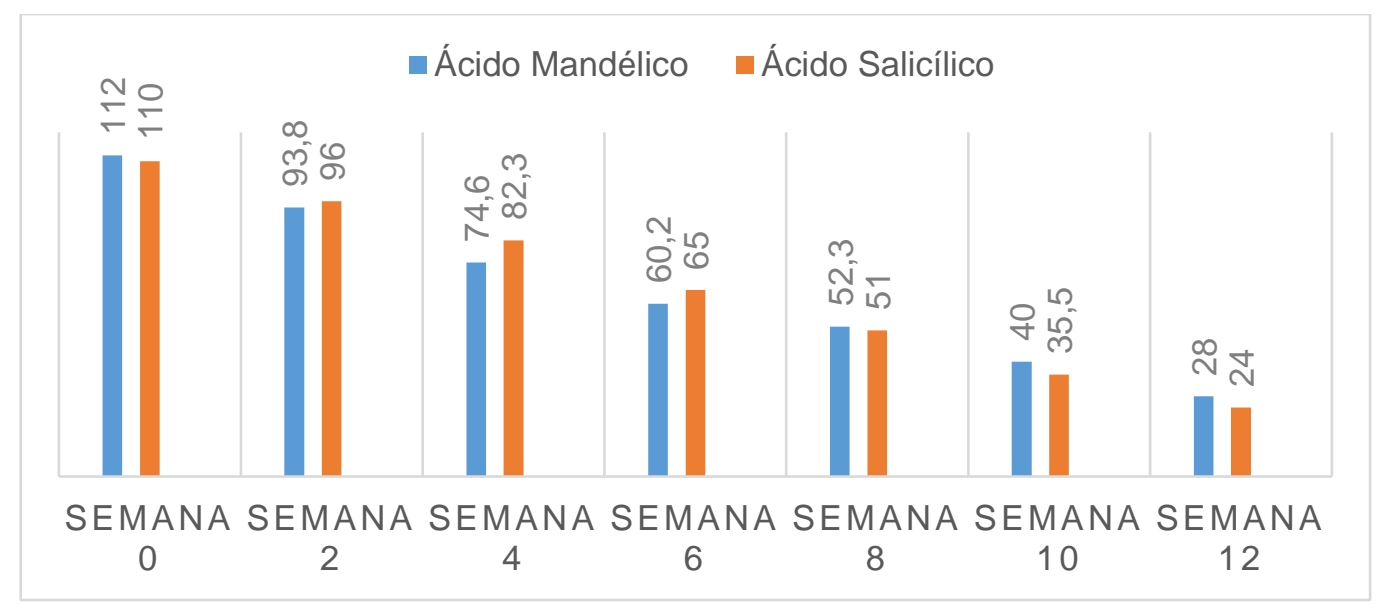

Fonte: Adaptado de DAYAL S, et al., 2019.

\section{CONSIDERAÇÕES FINAIS}

Através dos resultados de estudos do AM, foi observado positividade nos resultados por sua ação ser leve e com ausência de efeitos colaterais no paciente, sendo assim sua aplicação de forma segura, confiável e eficaz. Esse é o meio mais positivos para pacientes com peles sensíveis, no qual visam buscar profissionais responsáveis, para a realização desse tratamento. Contudo, a utilização de pellings com aplicação de AM, possui característica satisfatória, podendo ser um grande marco para as indústrias cosmecêuticas e consultórios estéticos.

\section{REFERÊNCIAS}

1. DAYAL S, et al. Comparative study of efficacy and safety of $45 \%$ mandelic acid versus $30 \%$ salicylic acid peels in mild-to-moderate acne vulgaris. Journal of Cosmetic Dermatology, 2019; 19(2).

2. LAN T, et al. Treatment of Atrophic Acne Scarring with Fractional Micro-Plasma Radio- Frequency in Chinese Patients: A prospective Study. Lasers in Surgery and Medicine, 2018; 50(8). 
3. KONTOCHRISTOPOULOS G, PLATSIDAKI E. CHEMICAL PEELS IN ACTIVE ACNE AND SCARS. Clinics in Dermatology, 2016; 35(2).

4. NOLASCO IMML, RESENDE JR. Use of mandelic acid in the treatment of postinflammatory hyperchromias: a literature review. Scire Salutis, 2020; 10.

5. SARKAR R, et al. Comparative Evaluation of Efficacy and Tolerability of Glycolic Acid, Salicylic Mandelic Acid, and Phytic Acid Combination Peels in Melasma. American Society Dermatologic Surgery, 2016; 42(3).

6. ZAENGLEIN AL. Acne vulgar. The NEW ENGLAND JOURNAL of MEDICINE, 2018; 379(14). 
RESUMOS EXPANDIDO: Revisão Bibliográfica

Título: Impacto dos serviços clínicos farmacêuticos na adesão de pacientes renais crônicos a terapia

Autor/coautores: Izadora Gomes Rodrigues Silva, Jordan Carlos Silva de Medeiros, Ana carolina Messias de Souza Ferreira da Costa, Marconi Rego Barros Junior, Maria Luiza Carneiro Moura Gonçalves Rego Barros.

Instituição: Centro Universitário Brasileiro - UNIBRA, Recife-Pernambuco; Universidade Federal de Pernambuco - UFPE, Recife-Pernambuco.

Palavras-chave: Doença renal crônica, Medicamentos, Farmacêutico clínico.

\section{INTRODUÇÃO}

A doença renal crônica (DRC) é a diminuição lenta e progressiva da capacidade dos rins filtrar os resíduos metabólicos do sangue. Existe evidência na transição epidemiológica de sua prevalência, dos custos envolvidos no tratamento, e a alta taxa de morbimortalidade. Em sua fase mais avançada, necessita de uma Terapia Renal Substitutiva. De acordo com o Censo da Sociedade Brasileira de Nefrologia, a prevalência de pacientes em diálise está na faixa de 544 por milhão de pessoas (pmp), com incidência anual de 180 casos pmp. Estima-se que 111.303 indivíduos se encontrem em tratamento dialítico por ano, destes, aproximadamente, 92,8\% são submetidas à hemodiálise (PEREIRA CV e LEITE IC, 2019).

Os serviços clínicos farmacêuticos, impactaram de forma positiva o tratamento de pacientes com DRC na alta prevalência de Problemas Relacionados a Medicamentos (PRMs) em todos os estágios da doença. Os PRMs mais observados, são o uso de medicamentos contraindicados ou em doses inadequadas, que interferem negativamente na função renal e no desfecho clínico. Então, a detecção e resolução dos PRMs contribui para a prevenção de complicações e redução dos custos com cuidados em saúde por meio da melhoria da qualidade de vida do paciente (MARQUITO AB, et al., 2020).

\section{OBJETIVO}

Abordar os serviços clínicos farmacêuticos no intuito de identificar os PRMs em pacientes portadores da $\mathrm{DRC}$ e analisar seus respectivos impactos na qualidade de vida relacionada à saúde e à adesão ao regime terapêutico.

\section{MÉTODO}

Trata-se de uma revisão integrativa em que as buscas foram realizadas nas bases de dados PubMed, ScienceDirect e Scielo segundo os descritores: "farmacêutico", "nefrologia" e "acompanhamento farmacoterapêutico". Dos 14 artigos selecionados, 8 foram excluídos por apresentarem divergências. 6 foram selecionados de acordo com os critérios de inclusão como: artigos publicados no período de 2019 a 2020 nos idiomas português e inglês que apresentam clareza nos aspectos analisados sobre o acompanhamento farmacoterapêutico em pacientes com DRC. Assim, foram incluídos estudos observacionais e transversais.

\section{RESULTADOS}

$\mathrm{Na}$ análise de CHELSEA E, et al., (2019) onde os residentes de farmácia realizaram 118 consultas para 87 pacientes (idade média de 73 anos, $97 \%$ do sexo masculino) com doença renal sem diálise ( $89 \%$ estágios III-V), polifarmácia ( $87 \%$ dos pacientes que tomavam $>10$ medicamentos) e uma carga de comorbidade pesada (85\% hipertensão, $80 \%$ dislipidemia, 59\% diabetes mellitus tipo II) de janeiro a outubro de 2017 . Os farmacêuticos identificaram 344 discrepâncias de medicamentos e 301 problemas de terapia medicamentosa, resultando em 398 alterações no processo de atendimento. 
Então, os farmacêuticos recomendaram 228 substituições de medicamentos, forneceram 76 dispositivos de adesão, facilitaram 24 consultas ou encaminhamentos, e realizaram comunicados com a equipe de atenção primária em 70 ocasiões. Todos os membros da equipe interprofissional concordaram plenamente que os pacientes e a equipe se beneficiaram do envolvimento dos farmacêuticos. Dessa forma, os serviços farmacêuticos ocasionaram a reconciliação de medicamentos que resultou na identificação dos problemas da terapia medicamentosa (CHELSEA E, et al.,2019).

Em um estudo observacional longitudinal retrospectivo conduzido em clínica ambulatorial de nefrologia, na cidade de Juiz de Fora/MG, a prevalência de PRMs no período pré-intervenção foi de 126, com média de $1,26 \pm 0,96$ PRM por paciente. Somente $20 \%$ dos pacientes não apresentaram nenhum PRM. As categorias de PRMs mais prevalentes foram "interação e medicamento administrado inadequadamente" $(34,1 \%)$, "uso inadequado por dose inapropriada ou medicamento contraindicado" (33,3\%), "pressão arterial inadequada" $(30,2 \%)$ (MARQUITO AB, et al., 2020).

\section{DISCUSSÃo}

Dentre os principais fatores de risco para a DRC estão Diabetes Mellitus e Hipertensão Arterial Sistêmica, responsáveis por dois terços dos casos da doença renal crônica. Dessa forma, o uso de medicamentos é explicado pela complexidade no tratamento das comorbidades, que precisam ser atendidas, impactando o aumento potencial no número de medicamentos prescritos (KLEIN KB, et al., 2020). Então, o principal risco identificado foram os PRMs ocasionando à redução da efetividade terapêutica. Diante disto, o acompanhamento farmacoterapêutico com os portadores da DCR é de grande relevância, na contribuição na adesão ao tratamento, minimização dos PRMs e fornecer as informações sobre a terapia, facilitando a adesão ao tratamento hemodialítico e farmacológico, melhorando assim a qualidade de vida dos pacientes portadores da DRC (SILVA SK e BANDEIRA IC, 2019).

\section{CONSIDERAÇÕES FINAIS}

Diante do exposto, conclui-se que o acompanhamento farmacoterapêutico torna-se primordial para que o plano terapêutico contemple as necessidades individuais dos pacientes. Portanto, os serviços clínicos farmacêuticos na nefrologia, contribui para a melhoria do processo de uso dos medicamentos, a redução dos riscos, a qualidade dos serviços prestados ao paciente e o manejo dos PRMs frequentes nessa população e consequentemente proporcionar uma melhor qualidade de vida aos pacientes frente ao tratamento hemodialítico e farmacológico.

\section{REFERÊNCIAS}

1. BARBOSA D, et al. Processo de análise da qualidade de vida dos doentes renais crônicos submetidos à hemodiálise. Revista Uniabeu. v. 12, n. 30, 2019.

2. KLEIN KB, et al. Adherence to drug treatments in patients with chronic kidney disease on hemodialysis. O Mundo da Saúde, São Paulo. 2019;43: 800-813.

3. HAWLEY CE, et al. The missing piece: Clinical pharmacists enhancing the interprofessional nephrology clinic model. Journal of the American Pharmacists Association. 2020; 59: 727-735.

4. MARQUITO A, et al. Avaliação da farmacoterapia na doença renal crônica: validação do instrumento PAIR para uso no Brasil. Brazilian Journal of Nephrology, n. AHEAD, 2020.

5. PEREIRA CV, LEITE IC. Qualidade de vida relacionada à saúde de pacientes em terapêutica hemodialítica. Acta Paulista de Enfermagem, v. 32, n. 3, p. 267-274, 2019.

6. SILVA SKM, BANDEIRA IZ. Terapia hemodialítica sob uma abordagem farmacoeconômica e farmacoterapêutica. Mostra Científica da Farmácia, v. 5, 2019. 
RESUMO EXPANDIDO: Revisão Bibliográfica

Título: Importância do controle da coleta de amostras de refeições fornecidas por unidades hospitalares

Autor/coautores: Cássia Thaís Pessoa de Albuquerque Ferreira, Joerika Batista Ciqueira, Marcos Garcia Costa Morais, Maysla Rayssa Silva Costa, José Thiago Alves de Sousa.

Instituição: Universidade de Pernambuco (UPE), Garanhuns-PE; Centro Universitário Maurício de Nassau (UNINASSAU), Campina Grande-PB; Universidade Federal de Campina Grande (UFCG), Cuité-PB.

Palavras-chave: Amostras de Alimentos, Serviços de Alimentação, Doenças Transmitidas por Alimentos.

\section{INTRODUÇÃO}

O setor de Unidade de Alimentação e Nutrição (UAN) hospitalar é denominado como um estabelecimento localizado no hospital que realiza o papel técnico-administrativo das refeições. Estas refeições passam por um processo de manipulação, preparação, armazenamento e distribuição. Nesse contexto, é evidente que é de suma responsabilidade da UAN hospitalar em englobar os serviços de apoio ao tratamento, nos quais está inserida a terapia nutricional (MARMENTINI, et al., 2015; VIENCZ, et al., 2016).

A alimentação hospitalar tem como princípio o fornecimento de refeições seguras, livres de contaminantes de qualquer espécie, com boa apresentação e nutricionalmente equilibradas, respeitando as necessidades calóricas, constatando assim a importância deste estudo para a saúde hospitalar como um todo, buscando garantir uma refeição que agrade ao paladar dos pacientes, acompanhantes e funcionários, auxiliando na recuperação total do estado nutricional do enfermo, sendo a refeição um dos principais pontos que favorecem a alta hospitalar (VIENCZ, et al., 2016; SIRTOLI e CAMARELLLA, 2018).

Para que o fornecimento do alimento não sofra nenhum tipo de risco contaminante, a unidade deve ser responsável pela sua inocuidade, para preservar a integridade e as condições higiênicas do produto (SILVA e BITELLO, 2016).

\section{OBJETIVO}

Analisar a importância de se fazer diariamente a coleta de amostras em unidades hospitalares, relatando sua relevância para a garantia da qualidade do alimento para os comensais, pincipalmente os enfermos.

\section{MÉTODO}

Trata-se de uma revisão bibliográfica, realizado através de artigos indexados nas bases de dados Scielo, PubMed, livros e cartilhas. Como critérios de inclusão, foram escolhidos artigos relevantes acerca do tema, possuindo como descritores da BVS: Amostras de Alimentos. Serviços de Alimentação. Doenças Transmitidas por Alimentos.

\section{REVISÃO BIBLIOGRÁFICA}

Os alimentos que passaram por um processo de manipulação inapropriados e sem adoção das Boas Práticas representa uma das principais formas de confirmação de uma infecção alimentar, pois quanto menor for a quantidade de micróbios presentes no alimento, menores serão os riscos de DTA's, principalmente para o mais debilitado (MENDONÇA, et al., 2016).

Os resultados da análise laboratorial podem indicar falhas no processo de Boas Práticas de Manipulação, como a inadequada higienização de frutas e hortaliças, temperatura inadequada durante a distribuição e armazenamento e na manipulação de alimentos crus, visando para que não ocorra contaminação cruzada; 
observar para que os alimentos não sejam coletados com os mesmos talheres de forma a reutilizar a mesma colher, por exemplo (MARMENTINI, et al., 2015).

De acordo com a Instrução Normativa DIVISA/SVS N 16 de 23/05/2017, definiu na seção VII, do Art.66 que a guarda de amostras nas cozinhas hospitalares devem guardar amostras dos alimentos prontos distribuídos para o consumo, com a finalidade de esclarecer alguma ocorrência de patologia alimentar, devendo ser coletadas após 1 hora do tempo de distribuição ou imediatamente antes do consumo, utilizando dos mesmos utensílios que estão sendo servidos na distribuição, identificação criteriosa das embalagens de primeiro uso, com todas as informações escritas no ato da coleta, como nome do estabelecimento, produto, data, horário e do responsável pela colheita (DIÁRIO OFICIAL DO DISTRITO FEDERAL, 2017).

A Resolução da Diretoria Colegiada - RDC n²16, de 15 de setembro de 2004, foi criada para contemplar os procedimentos eficazes que devem ser adotados por cada serviço de alimentação, visando a proteção à saúde da população, sendo aplicável em todo o território nacional, e a falta desta conformação é configurada como infração de natureza sanitária (BRASIL, 2004).

\section{DISCUSSÃO}

Deste modo, é de suma importância que nesses ambientes esteja presente, pelo menos, um responsável técnico (RT) inscrito no órgão do conselho regional que regulariza a aptidão do profissional, de acordo com a Portaria CVS1/DITEP de 13 de janeiro de 1998. É necessário que o manipulador de alimentos (nutricionista, auxiliar de nutrição, copeira) realize a coleta respeitando as legislações de coleta e armazenamento, com uma planilha de controle diária, e se não estiverem deve-se descobrir, realizar treinamentos para que esta situação não ocorra e procurar sempre corrigir qualquer problema (SECRETARIA DE SAÚDE DO ESTADO DE SÃO PAULO, 1998; SIRTOLI e CAMARELLLA, 2018).

A implementação de regras contribui para a diminuição de erros e na análise prévia dos possíveis riscos, prevalecendo o padrão do estabelecimento. Para que isto ocorra, se faz necessário a contribuição massiva dos colaboradores (manipuladores), com treinamento reforçado sobre todos os parâmetros de conformidade. (VIENCZ, et al., 2016).

\section{CONSIDERAÇÕES FINAIS}

Pôde-se observar que prevenir os erros no momento da coleta, que objetiva a principal causa de doenças oriundas da alimentação é um fator essencial na cozinha hospitalar, para identificar a preparação coletada e armazenar de maneira correta, apontando para a garantia da qualidade higiênico-sanitária da alimentação hospitalar, obtida através de medidas importantes, como a capacitação oriunda de treinamentos específicos com os manipuladores, um ponto chave de promoção de um alimento sem contaminação, já que este fator pode estar relacionado à falta de informação ou negligenciamento do funcionário.

\section{REFERÊNCIAS}

1. DIÁRIO OFICIAL DO DISTRITO FEDERAL. Ano XLVI, Edição n 103, Brasília-DF, 31 de maio de 2017.

2. MARMENTINI RP, et al. A importância das boas práticas de manipulação para os estabelecimentos que manipulam alimentos. Revista Facimed, v.40, n.8, p. 263-2015.

3. MENDONÇA EP, et al. Características de virulência, resistência e diversidade genética de sorovares de Salmonella com impacto na saúde pública, isolados de frangos de corte no Brasil. Tese (doutorado). Universidade Federal de Uberlândia, Programa de Pós-Graduação em Ciências Veterinárias, 2016.

4. SILVA VM, BITELLO AR. Verificação da presença de salmonellaspp em alimentos minimamente processados em um Município do interior do Rio Grande do Sul. Revista Destaques Acadêmicos, Lajeado, v. 8, n. 3, 2016.

5. SIRTOLI DB, CAMARELLA L. O papel da vigilância sanitária na prevenção das doenças transmitidas por alimentos (DTA). Revista Saúde e Desenvolvimento, vol.12, n.10, 2018. 
6. VIENCZ TV, et al. Avaliação do cardápio do almoço oferecido por uma unidade de alimentação e nutrição hospitalar. Visão Acadêmica, Curitiba, v. 17, n.2, Abr-Jun, 2016. 
RESUMO EXPANDIDO: Revisão Bibliográfica

Título: Os impactos e desafios da COVID-19 em gestantes, lactantes e recém-nascidos durante a pandemia

Autor/coautores: Izadora Gomes Rodrigues Silva, Geovanna Oliveira Carneiro, Rennaly Sabrina da Silva Santana, Ana Carolina Messias de Souza Ferreira da Costa, Maria Luiza Carneiro Moura Gonçalves Rego Barros.

Instituição: Centro Universitário Brasileiro - UNIBRA, Recife-Pernambuco; Universidade Federal de Pernambuco - UFPE, Recife-Pernambuco.

Palavras-chave: SARS-CoV-2, Amamentação, Gravidez.

\section{INTRODUÇÃO}

Inicialmente chamada de Wuhan-Hu-1-CoV, a Covid-19 teve sua pandemia declarada pela Organização Mundial de Saúde (OMS) em março de 2020, tendo 1.272 .630 casos confirmados no Brasil, com total e 495.326 mortes (última atualização em 26.06.2020). Alguns fatores biológicos podem explicar o aumento do risco de infecção por coronavírus durante a gravidez, como diabetes, seguido pela imunossupressão relativa da resposta TH1, aumentando susceptibilidade para infecções virais e expressão da enzima conversora de angiotensina (proteína de membrana e receptor para SARS-Cov-2) relativamente aumentada na gestação (ZENG L, et al., 2020).

A Covid-19 tem um amplo espectro clínico, variando de quadros assintomáticos a graves. Os casos sintomáticos se caracterizam principalmente pelo aparecimento de fadiga, febre e tosse seca, mas outros sintomas podem estar presentes. Quadros de maior gravidade se manifestam como Síndrome Respiratória Aguda Grave. Os impactos e desafios vivenciados durante a pandemia estão relacionado também a fatores psicológicos, pela tensão natural desse momento e o medo de contrair o vírus (MS, 2020).

\section{OBJETIVO}

Identificar o impacto da Covid-19 na gestação e no processo da amamentação durante a pandemia, avaliar a segurança dos recém-nascidos durante o aleitamento materno e destacar os cuidados necessários.

\section{MÉTODO}

Trata-se de uma revisão sistemática onde a busca foi realizada nas plataformas PubMed e ScienceDirect, com os descritores "SARS-CoV-2", "Breastfeeding", "Pregnancy". Dos 15 artigos que corresponderam à busca, 10 artigos foram excluídos por não terem como foco principal o impacto da Covid-19 em gestantes ou envolverem o tratamento, o que não será abordado neste trabalho. Os 5 artigos incluídos, foram selecionados de acordo com os critérios como: apresentação de clareza nos aspectos analisados, idioma em Inglês e publicados em 2020. Foram incluídos estudos retrospectivos, prospectivos, revisões sistemáticas, metaanálises e diretrizes clínicas.

\section{RESULTADOS}

Existem dados limitados sobre o atual impacto do Covid-19, nas mulheres infectadas durante a gravidez, lactantes e nos recém-nascidos. Os relatórios disponíveis e analisados mostraram resultados semelhantes, nos quais não há evidências que da transmissão vertical do Covid-19. 6 estudos relataram recém-nascidos infectados por Covid-19 positivos (confirmados em 36 horas - 17 dias após o parto) e aqueles encontraram apenas 13 recém-nascidos infectados dentre 222 expostos à SARS-CoV-2. Na lactação a determinação de separar ou não a mãe suspeita ou confirmada com COVID-19 de seu bebê deve ser baseada na tomada de decisão compartilhada entre a mãe e a equipe clínica (DURAN, et al., 2020). Em estudos limitados, o vírus 
não foi detectado no leite materno, e além disso, alguns especialistas especulam que anticorpos específicos para SARS-CoV-2 passam para o bebê alguns dias após o início da doença, possivelmente moderando a expressão clínica da infecção do bebê (GIULIANI, et al., 2020).

Relatórios iniciais informam que as manifestações clínicas da Covid-19 na população grávida são semelhantes às descritas para adultos não grávidas com infecções por Covid-19 (aproximadamente $80 \%$ de doenças leves, $15 \%$ graves e $5 \%$ críticas). No estudo realizado, a taxa de cesariana foi relatada como variando de $42,9 \%$ a 91 - 92\% dos casos clínicos (GILLIAN, et al., 2020). Dessa forma, é fundamental os conhecimentos apresentados na tabela 1. de acordo com as orientações do Ministério da Saúde.

Tabela 1. Orientações sobre coronavírus a gestantes e lactantes.

\section{Gravidez}

- Lavar as mãos com álcool em gel ou água e sabão;

- Manter um espaço seguro entre as outras pessoas;

- Se tiver febre, tosse ou dificuldade para respirar, procurar assistência médica. Telefone antes de ir para a unidade e siga as instruções da autoridade sanitária local.
Amamentação

Pré-natal

Lactantes infectadas ou com suspeita de infecção, ainda não há comprovação de que o vírus seja transmitido através do leite. Então, é imprescindível a adequada lavagem das mãos antes e depois da amamentação ou da ordenha do leite materno.

\section{- Durante} amamentação, todas, infectadas, devem usar máscara para proteger o bebê de gotículas de saliva que possam ser transmitidas da mãe para o filho.
- A regra é de que o - O principal alerta pré-natal seja é de que é direito mantido normalmente, tomando cuidados de higiene e evitando contato e aglomerações.

- Caso a gestante apresente sintomas de gripe, as consultas e exames de rotina devem ser adiados em 14 dias e, quando necessário, realizados em locais isolados de outras pacientes.
Parto da mulher ter um acompanhante durante todo 0 trabalho de parto e internação hospitalar, mas, em quadros de riscos de transmissão para a saúde das mulheres, esse direito pode ser restringido, sem que configure negativa de direito.

\section{Cuidados necessários}

- Higiene: a forma de prevenção é a mesma recomendada para todas as demais pessoas: lave sempre as mãos com água e sabão, evite aglomerações, evite tocar os olhos e a boca. Caso precise sair de casa, utilize máscara de proteção e capriche na higienização.

-Recomenda-se que haja distância de dois metros entre o berço do bebê e o leito da mãe.

Fonte: SILVA IGR, et al., 2020. Tabela criada a partir das informações do Ministério da Saúde, 2020. 


\section{DISCUSSÃO}

Para os profissionais de saúde, as mulheres grávidas não parecem ser mais suscetíveis às consequências do coronavírus do que a população em geral. Contudo, apesar das gestantes não configurarem no grupo de maior risco, elas devem redobrar os cuidados para evitar contaminação, pois seu adoecimento grave, pode comprometer a saúde fetal, e aumentar os riscos associados ao parto prematuro (STUMPFE, et al., 2020). Então, o procedimento padrão do manejo da Covid-19 na gravidez inclui isolamento precoce, controle de infecção, detecção de outras infecções virais, aplicação precoce de ventilação mecânica em pacientes com insuficiência respiratória progressiva e administração de antibióticos em casos de risco de infecção bacteriana. Monitoramento do feto e contrações uterinas devem ser considerados. Qualquer planejamento para o parto dessas pacientes e de suas condições clínicas deve ser feitos através de decisões especializadas (ZENG, et al., 2020).

\section{CONSIDERAÇÕES FINAIS}

Atualmente os dados ainda são limitados em relação à gestação e COVID-19. Na lactação, depende do quadro clínico da lactante. Para os recém-nascidos a amamentação é a fonte primordial de alimento e anticorpos, que fortalece o sistema imunológico deste. Nesta época, os impactos e desafios vivenciados aumenta a tensão e ansiedade, muitas mães que tinham como rede de apoio seus familiares, em razão do isolamento, encontram-se como protagonistas dessa situação delicada em que o apoio familiar é fundamental para puerpério saudável física e psicologicamente. A psicoterapia via telemedicina é uma boa alternativa nesses casos.

\section{REFERÊNCIAS}

1. DURAN P, et al. COVID-19 and newborn health: systematic review. Rev Panam Salud Publica. 2020.

2. GILLIAN A, et al. Clinical update on COVID-19 in pregnancy: A review article. Obstetrics and Gynecology Researsh. 2020.

3. GIULIANI C, et al. Breastfeeding during the COVID-19 pandemic: suggestions on behalf of Woman Study Group of AMD. Diabetes Research and Clinical Practice, 2020.

4. STUMPFE FM, et al. SARS-CoV-2 Infection in Pregnancy - a Review of the Current Literature and Possible Impact on Maternal and Neonatal Outcome. 2020.

5. ZENG L, et al. Neonatal early-onset infection with SARS-CoV-2 in 33 neonates born to mothers with COVID-19 in Wuhan, China. JAMA pediatrics, 2020. 
RESUMO EXPANDIDO: Revisão Bibliográfica

Título: O acesso da pessoa idosa aos serviços de saúde da atenção básica

Autora: Cidianna Emanuelly Melo do Nascimento

Instituição: Universidade Estatual do Ceará (UECE), Fortaleza-Ceará.

Palavras-chave: Envelhecimento, Acesso, Atenção Básica.

\section{INTRODUÇÃO}

O envelhecimento populacional é consequência da diminuição da taxa de fecundidade, ampliação da expectativa de vida, uso de novas tecnologias médicas e melhorias no serviço de saúde. Contudo, à medida que a população envelhece surgem fragilidades. As causas que levam os idosos a procurarem a atenção primária à saúde são diversas, entre elas as doenças crônicas degenerativas. Com isso procuram a Estratégia Saúde da Família (ESF) para diagnóstico, tratamento e reabilitação (SILVA AR, 2015).

Assim, percebe-se o aumento da visibilidade dos agravos comuns da terceira idade, gerando aumento da demanda no setor saúde. Desse modo, é importante compreender como ocorre o acesso aos serviços de saúde compreende como acesso os meios utilizados para se obter o atendimento no posto de saúde e se eles encontram alguma dificuldade na busca pelo serviço de saúde. Devido a necessidade de implementar a promoção, prevenção, tratamento e reabilitação para que os idosos deem continuidade aos serviços de saúde, se fez necessário descrever o envelhecimento populacional e suas consequências além das políticas voltadas a essa faixa etária e identificar os problemas que dificultam esse acesso dos idosos ao sistema público de saúde.

\section{OBJETIVO}

Discutir sobre os fatores associados ao acesso dos idosos aos serviços de saúde; descrevendo o envelhecimento populacional e suas consequências além das políticas voltadas a essa faixa etária e identificando os problemas que dificultam esse acesso dos idosos ao sistema público de saúde.

\section{REVISÃO NARRATIVA}

Trata-se de uma pesquisa bibliográfica narrativa, baseada em artigos publicados em português no período de 2015 a 2020, por meio dos Descritores em Ciências da Saúde (DCS): acesso aos serviços de saúde e idosos. Inicialmente foram lidos os resumos dos artigos, e caso se enquadrassem nos critérios, eles foram gerados na íntegra para análise. Após a análise dos artigos para construção do estudo e para melhor exposição foram agrupados dois tópicos: envelhecimento populacional e suas consequências diretas ao idoso; e, políticas públicas voltadas ao acesso aos serviços de saúde pela pessoa idosa.

Sobre o envelhecimento suas consequências diretas ao idoso, percebe-se que os desafios do envelhecimento são as mudanças físicas, sociais e imagem do corpo, os déficits do organismo que pode levar limitações as atividades de vida diária (AVD), alta prevalência de doenças crônicas e doenças músculos esqueléticas que muitas vezes trazem disfunção total do corpo (SILVA AR, 2015).

Essas modificações causadas pelo envelhecimento podem demandar um aumento de hospitalizações (DE ALMEIDA AN, 2015). Frente a uma análise de custo de internações hospitalares de idosos no Brasil, no decorrer de uma década, estudos inferiram que os gastos hospitalizações são onerosos e poderiam ser 
reduzidos com investimentos e implementação de políticas de promoção, prevenção e tratamento adequado. Sendo este, o papel principal da atenção primária à saúde (ALMEIDA APSC, et al., 2017).

As políticas públicas voltadas ao acesso aos serviços de saúde pelas pessoas idosas preveem a participação de todos, tanto nas discussões, quanto nas ações assistenciais. Entretanto com o crescimento acelerado da população idosa, tais políticas encontram dificuldades para acompanhá-lo, fazendo assim com que ocorram consequências, relacionadas as responsabilizações sobre o idoso, fazendo com que as mesmas sejam assumidas por seus familiares como um problema individual ou familiar, devido ou a ausência, ou a precariedade, da ajuda do Estado.

\section{DISCUSSÃO}

A acessibilidade envolve dimensões sociais, organizacionais e geográficas. Como direito regulamentado prevê acesso ao local, livre barreiras e obstáculos que impeçam a dificuldade de locomoção do usuário. A acessibilidade constitui-se em ganho visível para a humanização dos serviços de saúde, com ampliação do acesso de qualidade (AUSTREGÉSILO SC, et al., 2015).

As principais dificuldades na assistência ao idoso são: a fragilidade do acesso, a impossibilidade da garantia do atendimento integral e a descontinuidade do cuidado (MAGALHÃES KA, et al., 2015). A pessoa idosa que busca por atendimento enfrenta diversas barreiras, entre elas a descentralização do local da UBS, a dificuldade de transporte, o desnivelamento das calçadas e ruas esburacadas (SOUSA FTL, et al., 2019).

Cabe aos gestores do SUS estabelecer, abranger e implantar serviços que permitam o deslocamento do cidadão idoso, sobretudo àqueles que já apresentem dificuldade de locomoção, com auxílio, apoio e manutenção para uma independência funcional.

\section{CONSIDERAÇÕES FINAIS}

As políticas de atenção à pessoa idosa demonstram nítidos avanços, entretanto, ainda se observa falhas no seu desenvolvimento. O acesso aos serviços públicos de saúde apresenta uma descontinuidade do cuidado no que diz respeito a marcação de consultas, a mudanças de equipes de saúde e a carência de acompanhamento domiciliar. Por outro lado, a dimensão geográfica escancara fragilidades específicas de cada região. Nesse sentindo é importante ressaltar a atuação da equipe multiprofissional na implementação de estratégias que avalizem a continuidade do cuidado do idoso visando garantir um acesso integral e equânime dos idosos, em conformidade com os pilares do SUS.

\section{REFERÊNCIAS}

1. AUSTREGÉSILO SC, et al. Acessibilidade a serviços de saúde bucal por pessoas idosas: uma revisão integrativa. Rev. bras. Geriatr. Gerontol; v.18, n.1, p.189-99, 2015.

2. DE ALMEIDA AN. O acesso aos serviços de saúde pelos idosos no Brasil com base na Pesquisa Nacional por Amostra de Domicílios (PNAD) entre 1998 e 2008. Jornal Brasileiro de Economia da Saúde, 2015, 7(1), 43-52.

3. MAGALHÃES KA, et al. A visita domiciliária do agente comunitário de saúde a família com idosos frágeis. Ciência \& Saúde Coletiva, 2015; 20, 12, p. 3787-96.

4. SILVA AR. Doença crônicas não transmissíveis e sinais e sintomas de depressão e de declínio cognitivo em idosos na atenção primaria à saúde. [Dissertação]. Pontifica Universidade Católica do Rio Grande do Sul, Porto Alegre, 2015. 
5. SOUSA FTL, et al. Projeto terapêutico singular: uma ferramenta de promoção da saúde do idoso. Revista Eletrônica Acervo Saúde, 2019;(24), e659. 
RESUMO EXPANDIDO: Revisão Bibliográfica

Título: Políticas Públicas de saúde e ações estratégicas na erradicação da Tuberculose Pulmonar

Autor/coautores: Izadora Gomes Rodrigues Silva, Bruno Sant'Anna Rodrigues da Silva, Ana Carolina Messias de Souza Ferreira da Costa, Marconi Rego Barros Júnior, Maria Luiza Carneiro Moura Gonçalves Rego Barros.

Instituição: Centro Universitário Brasileiro - UNIBRA, Recife-Pernambuco; Centro Universitário Mauricío de Nassau - UniNassau.

Palavras-chave: Tuberculose, Estrátegias, Sistema de saúde.

\section{INTRODUÇÃO}

A Tuberculose Pulmonar (TBP) é uma doença infectocontagiosa causada pela bactéria Mycobacterium tuberculosis. A forma pulmonar é a mais frequente e de maior relevância para a saúde pública. No entanto, a tuberculose pode ocorrer em outras partes do corpo (tuberculose extra-pulmonar). A Organização Mundial de Saúde (OMS) revisou as diretrizes de vacinação com a vacina BCG (Bacilo de Calmette-Guérin) em bebês, incorporando recentes avanços no conhecimento da tuberculose, fornecendo orientações sobre a imunização de lactentes (OMS, 2020).

A TBP é particularmente prevalente em países com sistemas de saúde vulneráveis e afeta desproporcionalmente comunidades frágeis (DE MESQUITA GN, et al., 2020). A transmissão desta doença, também inclui as deficiências subjacentes do sistema de saúde como: instalações com escassez, longos tempos de espera pessoal, falta de cultura organizacional, suporte inadequado de educação e treinamento contínuo e práticas precárias de saúde e segurança ocupacional. Então, a estratégia para erradicação da TBP, possui o apoio às Políticas Públicas de Saúde (PPS) na ações preventivas e de controle, em relação transmissão nos subgrupos de risco presentes (WESTHUIZEN, et al., 2020).

\section{OBJETIVO}

Analisar o impacto da tuberculose pulmonar, abordar as ações para suprimir esta doença no sistema de saúde e avaliar suas estratégias, para busca de melhores resultados e diminuição desta doença no Brasil.

\section{MÉTODO}

Trata-se de uma revisão integrativa realizada a partir de buscas nas bases de dados PubMed, SciELO e ScienceDirect nos idiomas português e inglês, utilizando os descritores "tuberculose pulmonar" "estratégias" e "políticas públicas." Foram analisados doze artigos científicos de acordo com o tema relacionado. Ao final da análise, foram selecionados 6 artigos publicados em 2019 a 2020 de acordo com critérios de inclusão, que apresentaram clareza nos aspectos analisados.Os critérios de exclusão foram artigos que não estavam relacionados com os dados do atual estudo e publicados no período de 2006 a 2018.

\section{RESULTADOS}

Em 2014, a OMS aprovou o Plano Global para erradicação da TBP. Prevê-se que seus estágios intermediários ocorram em 2020 (20\%, <85/100.000), 2025 (50\%, <55/100.000 habitantes) e 2030 (80\%, $<20 / 100.000$ habitantes) e exige maior comprometimento da parte dos governos, e com foco na prestação de melhores serviços às populações vulneráveis. O Brasil tem as taxas mais baixas da lista de 30 países com alta carga da TBP. O Programa Nacional de Controle da Tuberculose do Brasil reconhece a importância da horizontalização da atenção à TBP visando à integração do controle da mesma, principalmente na atenção primária à saúde (APS), que inclui o Programa de Agentes Comunitários de Saúde e o Programa de Saúde 
da Família (PSF), expandindo acesso ao diagnóstico e tratamento. Vale ressaltar que, a prevenção ainda é a estratégia fundamental para a eliminação da TBP nos casos de primeiro contato, reinfecção ou reativação latente da doença (MELO MC, et al., 2020). Dessa forma, é necessário instruir-se sobre a doença, sintomas, diagnóstico, prevenção e tratamento. Diante disto, na tabela 1. apresentam as informações sobre a TBP de acordo com o Ministério da Saúde (MS, 2020).

Tabela 1. Compreensão da TBP e as orientações.

\begin{tabular}{|c|c|c|c|c|c|}
\hline Sintomas & Transmissão & Diagnóstico & Tratamento & Prevenção & $\begin{array}{l}\text { Populações } \\
\text { vulneráveis }\end{array}$ \\
\hline $\begin{array}{l}\text {-Tosse seca ou } \\
\text { produtiva; } \\
\text {-febre vespertina; } \\
\text {-sudorese } \\
\text { noturna; } \\
\text {-emagrecimento; } \\
\text {-cansaço/fadiga. }\end{array}$ & $\begin{array}{l}\text {-Transmissão } \\
\text { aérea e se instala } \\
\text { a partir da } \\
\text { inalação } \\
\text { aerossóis de } \\
\text { oriundos das vias } \\
\text { aéreas, durante a } \\
\text { fala, espirro ou } \\
\text { tosse das } \\
\text { pessoas com } \\
\text { tuberculose ativa, } \\
\text { que lançam no ar } \\
\text { partículas em } \\
\text { forma de } \\
\text { aerossóis de } \\
\text { contendo bacilos. }\end{array}$ & $\begin{array}{l}\text { Baciloscopia; } \\
\text {-teste rápido } \\
\text { molecular } \\
\text { para } \\
\text { tuberculose; } \\
\text {-cultura para } \\
\text { micobactéria; } \\
\text {-radiografia } \\
\text { de tórax. }\end{array}$ & $\begin{array}{l}\text {-São utilizados } \\
\text { quatro fármacos } \\
\text { que utilizam o } \\
\text { esquema básico: } \\
\text { rifampicina, } \\
\text { isoniazida, } \\
\text { pirazinamida e } \\
\text { etambutol. } \\
\text { Observação: o } \\
\text { Tratamento dura } \\
\text { no mínimo seis } \\
\text { meses, é gratuito e } \\
\text { está disponível no } \\
\text { SUS, devendo ser } \\
\text { realizado, } \\
\text { preferencialmente, } \\
\text { em regime de } \\
\text { Tratamento } \\
\text { Diretamente } \\
\text { Observado (TDO). }\end{array}$ & $\begin{array}{l}\text { - A vacina BCG; } \\
\text {-o emprego de } \\
\text { medidas de controle } \\
\text { de infecção também } \\
\text { faz parte das ações de } \\
\text { prevenção da doença, } \\
\text { tais como: manter } \\
\text { ambientes bem } \\
\text { ventilados e com } \\
\text { entrada de luz solar; } \\
\text { proteger a boca com o } \\
\text { antebraço ou com um } \\
\text { lenço ao tossir e } \\
\text { espirrar (higiene da } \\
\text { tosse). }\end{array}$ & $\begin{array}{l}\text {-Indígenas; } \\
\begin{array}{l}\text {-privados } \\
\text { liberdade; }\end{array} \\
\begin{array}{l}\text {-pessoas } \\
\text { vivem } \\
\text { HIV/aids; }\end{array} \\
\begin{array}{r}\text { que } \\
\text { com }\end{array} \\
\begin{array}{l}\text {-pessoas } \\
\text { situações em } \\
\text { ruas/precárias. }\end{array}\end{array}$ \\
\hline
\end{tabular}

Fonte: Ministério da Saúde (MS), 2020.

O diagnóstico precoce da tuberculose é o primeiro componente fundamental do pilar da OMS, sendo destacados os avanços no diagnóstico como a implantação do Teste Rápido Molecular para Tuberculose (TRM-TB), bem como a detecção de resistência à rifampicina. Dessa forma, o investimento em pesquisa e capacitação desses profissionais melhorou o processo de trabalho da equipe do laboratório, das vigilâncias estaduais e municipais e acelerou o início do tratamento dos pacientes (DA SILVA KO, et al., 2020).

\section{DISCUSSÃO}

A estrátegia eficaz de controle da TBP, inclui prevenção primária, detecção e tratamento precoce. Esses fatores contribuem para o tratamento e a redução da mortalidade, com ênfase em locais com alta vulnerabilidade social. Então, mudanças no sistema de notificação, desde a implementação de novas políticas de atendimento, não permitem o compartilhamento de variáveis entre os sistemas de informação, que dificulta a análise mais ampla dos dados nacionais da doença. (MELO MC, et al., 2020). Há fortes evidências de que os profissionais de saúde têm risco maior de desenvolver TBP, então, o controle da infecção hospitalar deve também estar associado a estratégias de prevenção de infecções, tanto na prevenção da transmissão, quanto no desenvolvimento de habilidades para lidar com surtos (WESTHUIZEN, et al., 2020).

\section{CONSIDERAÇÕES FINAIS}

Diante do exposto, conclui-se que a negligência da tuberculose pulmonar continua sendo uma lacuna importante na prestação de cuidados de alta qualidade, porém, trata-se de um grande desafio, sendo necessário aprimorar essas táticas do ponto de vista da promoção e prevenção, principalmente quando se trata de ações educativas por meio de publicidade. Portanto, o apoio às políticas públicas de saúde, possui evidências positivas nas ações preventivas e de controle da doença, ampliado em relação à dinâmica da transmissão nos subgrupos de risco presentes nos contextos regionais brasileiros. 


\section{REFERÊNCIAS}

1. BRASIL. MINISTÉRIO DA SAÚDE. Guia de vigilância em saúde. 2019.

2. DA SILVA KO, et al. Análise das metas de controle da tuberculose no Brasil: uma revisão narrativa. Revista Eletrônica Acervo Saúde, v. 12, n. 5, p. e3063-e3063, 2020.

3. DE MESQUITA GN, et al. Estratégia de combate à tuberculose na atenção primaria/Strategies to combat tuberculosis in primary care. Brazilian Journal of Health Review, v. 3, n. 2, p. 2182-2189, 2020.

4. JUNGES JR, et al. Directly Observed Therapy for treating tuberculosis: critical analysis of decentralization. Interface-Comunicação, Saúde, Educação, v. 24, 2020.

5. MELO MC, et al. Temporal trend of tuberculosis in Brazil. Cadernos de Saúde Pública, v. 36, p. e00081319, 2020.

6. WESTHUIZEN, et al. The high-quality health system 'revolution': Re-imagining tuberculosis infection prevention and control. Journal of Clinical Tuberculosis and Other Mycobacterial Disease. V. 17, 2019. 
RESUMO EXPANDIDO: Revisão Bibliográfica

Título: Síndrome de Peutz-Jeghers: um acometimento raro

Autor/coautores: Cleber Queiroz Leite, Laís Silva Sousa, Kimberlly Nava Flores, Grícia Aparecida Rodrigues de Souza.

Instituição: Centro Universitário São Lucas (UNISL), Porto Velho-RO.

Palavras-chave: Síndrome de Peutz-Jeghers, Pólipos intestinais, Diagnóstico.

\section{INTRODUÇÃO}

A Síndrome de Peutz-Jeghers (SPJ) foi identificada pela primeira vez por Peutz em 1921. Essa síndrome caracteriza-se por um acometimento relativamente raro, porém bem reconhecido (RESANO RU, et al., 2018). Ela é uma enfermidade autossômica dominante, manifestada pelo aparecimento de pólipos hamartomatosos nas localidades do trato gastrointestinal, associada à pigmentação melânica cutânea mucosa (CONRADO AK e CHANIS R, 2018). Além disso, possui um risco elevado com cerca de 37 a $93 \%$ de chances de desenvolver neoplasias (LEITE ACG e SANTOS EVL, 2019), tendo uma prevalência entre 1:50.000 e 1:200.000 nascidos vivos (OKIDA LFA, et al., 2017). Cursa com múltiplos pólipos hamartomatosos localidados no trato gastrointestinal e máculas hipercrômicas mucocutânea, principalmente nas áreas de região labial, plantar e palmar (PEREIRA CM, et al., 2018). A síndrome atinge mulheres e homens igualmente e na mesma intensidade, no entanto não há predominância de um grupo étnico ou racial (SANTAMARÍA AZ, et al., 2017).

\section{OBJETIVO}

Revisar sobre a Síndrome de Peutz-Jeghers, esclarecendo a importância em reconhecer a sintomatologia apresentada pelo paciente, bem como realizar o seu diagnóstico precoce e a instituição do devido tratamento e acompanhamento.

\section{MÉTODO}

Trata-se de uma revisão integrativa, cuja base de dados foram a Scientific Electronic Library On-line (SciELO), Latino-Americana e de Caribe em Ciências da Saúde (LILACS). Utilizaram-se como critérios os seguintes descritores e suas combinações: "Síndrome de Peutz-Jeghers", "Pólipos Intestinais", "Diagnóstico", obtendo-se como resultados 123 publicações. Empregando-se o filtro "texto completo", o número reduziu para 80 publicações, dentre elas regidas nas línguas portuguesa, inglesa e espanhola. Além disso, dispondo-se como critério de inclusão os artigos publicados a partir do ano de 2015 a 2020, sendo excluídos os artigos anteriores a 2015 e os que não abordavam o tema. Portanto, foram descartados 57, pois tratava-se de publicações anteriores a 2015, e 17 publicações que se repetiam nas bases de dados reduzindo para 6 , que foram objetivo de pesquisa para este trabalho.

\section{REVISÃO BIBLIOGRÁFICA}

A síndrome Peutz-Jeghers (SPJ) é um distúrbio hereditário dominante atribuído à mutação genética no gene STK11/LKB1, localizado na região 13 do braço curto do cromossomo 19 (CONRADO AK e CHANIS R, 2018). Esse gene codifica a serina treoninaquinase 11, proteína facilitadora da apoptose, que resulta na perda da função e no crescimento celular incontrolado (LEITE ACG e SANTOS EVL, 2019).

A síndrome é clinicamente observada por pólipos hamartomatosos intestinais, associado a uma forma distinta de deposição de melanina macular da mucosa e da pele (PEREIRA CM, et.al, 2018).Quanto às lesões dermatológicas, o armazenamento de melanina, pode ser encontrado na infância, no nascimento ou primeiros meses de vida (OKIDA LFA, et al., 2017). Em compensação, os primeiros acometimentos clínicos são 
resultantes dos pólipos nas regiões gastrointestinais e acabam variando entre episódios frequentes de dores abdominais, devido a quadros de obstrução intestinal ou intussuscepção (PEREIRA CM, et al., 2018). Além disso, sangramentos intestinais incompreensíveis geram irregularidade menstrual, prolapso de pólipo retal e tumor de cordão sexual (CONRADO AK e CHANIS R, 2018).

A existência de pólipos hamartomatosos nas regiões gastrointestinais são fundamentais para a comprovação de SPJ (OKIDA LFA, et al., 2017). Desse modo, 90\% dos portadores iniciam entre os 11 aos 13 anos de idade, sendo o intestino delgado a área mais comum, seguido por cólon, reto e estômago (LEITE ACG e SANTOS EVL, 2019). A grande maioria dos pólipos se torna sintomático em uma idade precoce, necessitando de laparotomias emergentes e ressecções nas regiões do trato gastrointestinal (SANTAMARÍA AZ, et al., 2017).

\section{DISCUSSÃO}

O diagnóstico da SPJ é clínico, apoiado por teste genético (OKIDA LFA, et al., 2017). Há grande variabilidade quanto à sintomatologia, de quadros leves a graves com necessidade de cirurgias (PEREIRA CM, et al., 2018). Indivíduos que apresentam SPJ possuem maior vulnerabilidade às neoplasias em colo do útero, trato gastrointestinal, ovários e testículos (SANTAMARÍA AZ, et al., 2017). O risco do paciente com SPJ desenvolver câncer gastrointestinal é de $37 \%$ a $93 \%$ e a idade média no momento do diagnóstico é 42 anos (LEITE ACG e SANTOS EVL, 2019). O tratamento, se intussuscepção ou obstrução intestinal, é cirúrgico, através de endoscopia digestiva alta e/ou colonoscopia, procedimentos para retirada e avaliação do intestino delgado, a fim de prevenir futuras complicações (RESANO RU, et al., 2018). Assim, é necessário acompanhamento entre dois e cinco anos por meio de gastroduodenoscopia e retossigmoidoscopia para pacientes até 20 anos ou colonoscopia se acima (PEREIRA CM, et al., 2018).

\section{CONSIDERAÇÕES FINAIS}

Enfatiza-se a importância de suspeitar clinicamente de entidades raras como a síndrome de PeutzJeghers, utilizando-se de anamnese adequada, na qual a história pessoal e hereditária contribui com mais de $50 \%$ para a patologia atual do paciente. Visto a baixa ocorrência desse quadro de sintomas e sua alta taxa de complicações, salienta-se a importância do diagnóstico precoce, do acompanhamento multidisciplinar e da expansão do conhecimento sobre a temática, objetivando um tratamento apropriado e ampliação da qualidade de vida aos pacientes.

\section{REFERÊNCIAS}

1. CORONADO AK, CHANIS R. Síndrome de peutz-jeghers como causa de invaginación intestinal em niño. Revista Pediátrica de Panamá, 2018; 47(3): e2428.

2. LEITE ACG, SANTOS EVL. Síndrome de peutz-jeghers: abordagem na atenção básica-relato de experiência. Revista Journal of Medicine and Helth Promotion, 2019; 4(1): e11221129.

3. OKIDA LFA, et al. Síndrome de peutz-jeghers e acalásia: relato de caso e revisão da literatura. Revista de Medicina, 2017, 96(3): e197203.

4. PEREIRA CM, et al. Síndrome de peutz-jeghers: relato de caso clínico. Revista Journal of Health Sciences Institute, 2018; 36(3): e193196.

5. RESANO RU, et al. Tratamiento quirúrgico conservador en un paciente comn invaginación yeyunoyeyunal secundaria a síndrome de peutz-jeghers. Reporte de un caso. Revista Acta Pediátrica de México, 2017; 39(3): e244249.

6. SANTAMARÍA AZ, et al. Poliposis hamatomatosa gastrointestinal com intususcepción instestinal, em paciente com síndrome de peutzjeghers: Presentación de um caso. Revista Colombiana de Radiología, 2017; 28(1): e46464649. 
RESUMOS EXPANDIDO: Revisão Bibliográfica

Título: O risco da automedicação em meio a uma pandemia.

Autor/coautores: Suyla Manuelle da Silva Leite, Paulo Henrique da Silva, David Vitor da Silva Anjos, Maria Luiza Carneiro Moura Gonçalves Rego Barros, Ana Carolina Messias de Souza Ferreira da Costa.

Instituição: Centro Universitário Brasileiro; Instituto de Gestão e Marketing - UNIBRA, Recife, Pernambuco.

Palavras-chave: Isolamento, Corona Vírus, Farmácia.

\section{INTRODUÇÃO}

Automedicação é o uso irracional de medicamento na intenção de resolver um problema de saúde por conta própria, esta ação preocupa os profissionais de saúde, dentre eles o farmacêutico, inserido nas farmácias, busca mudar a situação junto a aconselhamento farmacoterapêutico e consulta farmacêutica clínica. O processo da automedicação possui influência do comercio, mídias digitais e familiares com informações de garantia da ação benéfica dos produtos (MATOS, et al., 2018).

No início de 2020 a prática de automedicar teve aumento nas farmácias, graças a doença viral causada pelo SARS-Cov-2 ou Covid19, com sintomas parecidos a resfriados e gripe, devido a informações sem bases cientificas comprovadas de medicações, chás e vitaminas que teriam a ação de eliminar o vírus ou garantir a proteção de contágio. Fazendo assim, comércios farmacêuticos escassos de medicações, pois a prática em torno do vírus cresceu e com ele os riscos de piora dos casos para problemas cardíacos e renais. O farmacêutico possui deveres na atenção direta ao paciente para os cuidados contra o Corona vírus na recomendação de medidas de prevenção, hábitos físicos e alimentares saudáveis, o isolamento social e informar sobre os medicamentos envolvidos no tratamento (LIMA C, 2020; NETO, et al., 2020).

\section{OBJETIVO}

Demostrar os efeitos da automedicação em uma população com acesso livre, e, quais são as medicações mais utilizadas e informar o papel do farmacêutico contra o uso irracional de medicamentos em especial contra o Covid19.

\section{MÉTODO}

O presente resumo trata-se de uma revisão bibliográfica sem critério explicito retirados de portais digitais Scielo e Lilacs. Para a busca dos materiais utilizou-se palavras chaves isoladas e permutadas, como "automedicação", "automedicação e risco", "farmacêutico na automedicação", "farmacêutico contra o Covid19" e "automedicação para Covid19". Os critérios de exclusão de materiais foram para as teses e monografias. Reunidos em uma janela de tempo entre 2018 a 2020. Responsável por 3 referências em idioma português do Brasil e 1 em língua estrangeira, inglês e 1 em espanhol. A coleta de dados para a revisão foi realizada em junho de 2020.

\section{REVISÃO BIBLIOGRÁFICA}

A automedicação preocupa profissionais de saúde, inclusive farmacêuticos, com o dever de aconselhamento e prevenção, visto que são os profissionais que lidam direto com medicamento de livre acesso ou não. O destaque para o risco da automedicação é a piora no estado da saúde como, intoxicação, alergias, intolerância medicamentosa, resistência, dependência e interação. Foi realizado um levantamento com 40.000 pessoas pelo Brasil em 2016 para demostrar os subgrupos terapêuticos mais consumidos de forma própria racional, destacando os analgésicos em $1^{\circ}$ lugar e em seguida relaxantes musculares, antiinflamatórios, preparações para tosse, suplementos, vitaminas, plantas e antibacteriano para uso sistêmico (CENTENERA-JARABA J, 2019; MATTOS, et al., 2018). 
Após 4 anos do levantamento, o mundo se encontra infectado por um vírus de doença com sintomas simples e que podem se agravar, são eles, isolados ou em conjunto: hiposmia, ageusia, tosse leve ou moderada, febre persistente, dor de garganta, encefálica, diarreia e falta de ar. Estes sintomas são da Covid19, causada pelo SARS-Cov-2, possuem semelhança a gripe, muitas vezes tratada em casa, mas não são doenças iguais. Com isso e com a ajuda das fake News para os possíveis tratamentos da Covid19, tornouse escassa medicação, como: analgésicos, vitaminas e antibióticos nas farmácias, em geral, esses medicamentos não há comprovação de efeito para a doença, piorando os casos e sendo responsável por mortes. A maioria dos da doença melhoram com 14 dias, alguns necessitam de internação hospitalar e Tratamento em Unidade Intensiva, sendo a automedicação um dos mediadores responsáveis pela gravidade do caso (LIMA C, 2020; ROSA S e SANTOS W, 2020).

\section{DISCUSSÃO}

Apesar que a maioria dos subgrupos mencionados são Medicamentos Isentos de Prescrição (MIP), qualquer ação racional de administração de algum medicamento necessita de orientação farmacêutica para os possíveis efeitos, dos destacados na pesquisa, quanto para os demais encontrados em farmácia comercial. O risco da automedicação em meio a uma pandemia é crítico e pode causar: arritmias cardíacas, intoxicação renal, paralisação dos rins, trombose, paralisação dos pulmões, edemas e a perda dos movimentos. $O$ farmacêutico precisa estar disposto de frente como serviço essencial para minar e equilibrar os efeitos, as adversidades e as incoerências populacionais que acredita no autodiagnóstico e na eficácia da automedicação sem ter importância para o perigo (NETO, et al., 2020; ROSA S e SANTOS W, 2020).

\section{CONSIDERAÇÕES FINAIS}

Em suma o farmacêutico tem importante papel na prevenção e orientação sobre a prática da automedicação, com objetivo de informar riscos pré-dispostos, bem como aconselhar sobre tal irracionalidade. Inesperadamente em 2020 houve aumento da automedicação devido a pandemia pelo Corona Vírus, levando a piora dos casos e a causa de mortes pela complicação da doença. Com o propósito de diminuir estes acontecimentos esse profissional deve aconselhar o paciente que se automedica em meio a uma pandemia com os possíveis riscos de causar problemas cardíacos, renais etc.

\section{REFERÊNCIAS}

1. CENTENERA-JARABA J, LOPEZ-GUZMAN J. Reflexión acerca del desarrollo de la bioética en las organizaciones profesionales farmacéuticas. La excelencia profesional. pers.bioét., Chia, v. 23, n. 1, p. 49-63, June 2019.

2. LIMA C. Informações sobre o novo coronavírus (COVID-19). Radiol Bras, São Paulo, v. 53, n. 2, p. V-VI, abril de 2020.

3. MATOS J, et al. Prevalência, perfil e fatores associados à automedicação em adolescente e servidores de uma escola pública profissionalizante. Cad. Saúde Coletiva. 26(1) 76-83. Rio de Janeiro, 2018.

4. NETO M, et al. Fake news no cenário da pandemia de Covid-19 / Fake news in the Covid-19 pandemic scenario / Noticias falsas en el escenario de la pandemia de Covid-19. Cogitare enferm ; 25: e72627, 2020.

5. ROSA S, SANTOS W. Clinical trials on drug repositioning for COVID-19 treatment. Rev. panam. salud pública ; 44(40) 2020. 
RESUMO EXPANDIDO: Revisão Bibliográfica

Título: Uso do canabidiol como auxílio ou alternativa terapêutica para manejo da dor em pacientes com câncer

Autor/coautores: David Pablo Cavalcanti da Fonseca, Ana Tamires Alves dos Santos, Marconi Rego Barros Junior, Maria Luiza Carneiro Moura Gonçalves Rego Barros, Ana Carolina Messias de Souza Ferreira da Costa.

Instituição: Centro Universitário Brasileiro, UNIBRA, Recife - PE.

Palavras-chave: Alternativa terapêutica, Cannabis, Oncologia.

\section{INTRODUÇÃO}

A definição da dor está relacionada a um sentimento fisiológico, no qual o indivíduo passa por uma experiencia de união de sentimentos, sensações, emoções e componentes sociais, no qual está relacionado a algum dano tecidual. Porém, ainda não há uma definição exata e precisa da dor, no que está previamente estabelecida por um sentimento espontâneo causado por alguma lesão fisiológica que possa levar ao desenvolvimento do sentimento (WILLIAMS ACC e CRAIG KD, 2016). Durante a internação e tratamento oncológico, comumente o paciente é submetido a terapia analgésica devido a dores constante distribuídas pelo corpo. Embora diversos fármacos sejam utilizados para manejar a dor, ainda há necessidade de estudos para desenvolver fármacos inovadores com menos riscos e mais efeitos benéficos para os pacientes em tratamento quimioterápico (NEUFELD NJ, et al., 2017). Visando aprimorara a terapêutica, foi desenvolvido a implementação de fitoterápicos, aprimorando a terapêutica da dor em pacientes oncológico com auxílio de Canabidiol, composto derivado da Cannabis sativa administrado em diversas formas farmacêuticas, obtendo positividade terapêutica comparativa a opioides convencionais. Deste modo, observa-se no uso do canabidiol propriedades sedativas eficientes para o manejo da dor em pacientes com câncer (BYARS T, et al., 2019).

\section{OBJETIVO}

Abordar sobre a implantação do uso do canabidiol no manejo da dor em pacientes com câncer, submetidos à quimioterapia, visando sugerir a importância da alternativa terapêutica para o tratamento da dor destes pacientes.

\section{MÉTODO}

Foi realizado uma revisão integrativa, através de portais acadêmicos como Scielo, PubMed e ERIC com a utilização de palavras-chaves como: canabidiol, cannabis, câncer e dor, no qual foi levado em considerações para critério de inclusão, artigos relacionados a efetividade terapêutica da Cannabis para tratamento da dor e utilizando como critério de exclusão, artigos nos quais elucidavam o mecanismo de ação e tivessem publicação realizada antes do ano de 2016. Para a elaboração deste trabalho, foi realizada uma pesquisa durante o mês de junho de 2020, no qual dentre os artigos utilizados, foram pesquisados nas línguas portuguesa e inglesa, artigos publicados entre o ano de 2016 a 2019.

\section{RESULTADOS}

A Cannabis, popularmente conhecida por maconha, é uma planta com efeitos entorpecentes, no qual promove efeito sedativo através da sua ingestão, inalação e aplicação tópica. Embora seja restrita o uso da planta em diversos países, nos EUA o uso para consumo próprio recreativo é permitido em algumas regiões do país. O material utilizado para fins terapêuticos médicos, através de estudos realizados, foi identificado a eficácia para o tratamento de dores através da utilização inalante da droga. Pacientes com câncer, passam por diversas comorbidades e dificuldades devido a alterações fisiológicas da doença, inclusive dores crônicas e intensas. Em estudos realizados, observa-se a possibilidade do tratamento destes pacientes com a 
alternativa terapêutica da utilização da Cannabis, para favorecer o alívio de dores durante a internação. No estudo realizado em comparação as formas farmacêuticas sublingual e inalante, onde pode ser observado na Tabela 1, melhor efetividade da pela forma inalante quando tratar-se de tempo de ação (ROMEROSANDOVAL EA, et al., 2017).

Tabela 1 - Comparação de aspectos entre formas farmacêuticas Sublingual e Inalante.

\begin{tabular}{|c|c|c|}
\hline Tempo até o pico plasmático & De 2 a 4 horas & Inalante \\
\hline Duração de efeito & Alternado entre 8 a 20 horas & De 3 a 5horas \\
\hline $\begin{array}{c}\text { Evidências científicas para } \\
\text { manejo da dor }\end{array}$ & $\begin{array}{c}\text { Moderadamente comprovada } \\
\text { para efeito sedativo/ sono }\end{array}$ & $\begin{array}{c}\text { Conclusivo ou substâncial para } \\
\text { tratamento de dor crônica }\end{array}$ \\
\hline
\end{tabular}

Fonte: Adaptado de ROMERO-SANDOVAL EA, et al., 2017.

\section{DISCUSSÃO}

A forma farmacêutica inalante de Canabidiol, promove benefícios que interessam a pesquisa na saúde, uma vez que facilita a administração a pacientes idosos, em que encontram-se em estado de saúde crítica e com dificuldade de administração de medicamentos convencionais, além de promover um tempo de início de efeito breve, podendo auxiliar o manejo da dor em pacientes com câncer. Embora trata-se de um entorpecente ilegal, o uso medicinal do Canabidiol, possui segurança comprovada por cientistas, para o tratamento da dor crônica, devido suas características químicas do material vegetal, tendo bastante aceitação e tolerância dos pacientes submetidos a tratamento partes da planta (HÄUSER W, et al., 2019).

\section{CONSIDERAÇÕES FINAIS}

O tratamento alternativo com canabidiol, pode promover diversos benefícios ao paciente, uma vez que a utilização via inalante promove mais facilidade na administração e maior conforto ao paciente, com tempo de efeito relativamente baixo e efetividade cientificamente comprovada. Podendo assim, tornar o uso do material vegetal, um grande aliado para a medicina no futuro, através de seus benefícios para o manejo da dor crônica em pacientes oncológicos, promovendo segurança, efetividade, praticidade e tolerância terapêutica.

\section{REFERÊNCIAS}

1. BYARS T, et al. Using Cannabis to treat Cancer-related Pain. Seminars in Oncology Nursing, 2019; 35(3).

2. HÄUSER W, et al. Efficacy, tolerability and safety of cannabis-based medicines for cancer pain. Der Schmerz, 2019; 33(5).

3. NEUFELD NJ, et al. Cancer pain: a review of epidemiology, clinical quality and value impact, Future Oncology, 2017; 13(9).

4. ROMERO-SANVOVAL EA, et al. Cannabis and Cannabinoids for Chronic Pain. Current Rheumatology Reports, 2017; 19(11).

5. WILLIAMS ACC e CRAIG KD. Updating the definition of pain. The Journal of the international Association for the Study of pain, 2016; 157(11). 
RESUMO EXPANDIDO: Revisão Bibliográfica

Título: Utilização da Calendula officinalis L. e Punica granatum L. na saúde bucal

Autor/coautores: Bianka Carlla Vicente da Silva, Suzana de Paula Figueiredo, Renata Janaína Carvalho de Souza.

Instituição: Centro Universitário São Miguel (UNISÃOMIGUEL), Recife - Pernambuco.

Palavras-chave: Plantas Medicinais, Fitoterapia, Cárie.

\section{INTRODUÇÃO}

Em 1998, o Conselho Nacional de Saúde aprovou a Política Nacional de Medicamentos e de Práticas Integrativas e Complementares, que propuseram a inserção das plantas medicinais e fitoterapia como alternativas terapêuticas a serem empregadas pelo sistema público de saúde. O uso de plantas medicinais traz grandes vantagens na promoção da saúde bucal, sendo eficientes no tratamento e apresentando baixo custo de produção (OLIVEIRA FGS e LEHN CR, 2015).

Cárie e gengivite estão entre as principais afecções que atingem a saúde bucal dos indivíduos. Diversos estudos vêm demonstrando eficiência dos fitoterápicos na prevenção e combate a estas patologias, surgindo como alternativa para o restabelecimento da saúde oral. Neste contexto, já foram encontradas 132 espécies de plantas que também podem ser utilizadas na produção de enxaguantes bucais naturais, importantes no tratamento dessas e outras afecções que podem acometer a mucosa oral (ALELUIA CM et al., 2015).

A partir de estudos científicos, algumas plantas são indicadas como antibacterianas, cicatrizantes e antiinflamatórias do trato bucal, como exemplo pode-se citar a Calendula officinalis L. (calêndula) e Punica granatum L. (romã). Entretanto a maioria dos estudos se concentram na atividade antibacteriana dessas plantas (BOHNEBERGER G, et al., 2019).

\section{OBJETIVO}

Revisar estudos sobre a utilização Calendula officinalis L. (calêndula) e Punica granatum L. (romã) na prevenção e tratamento de patologias bucais, com a finalidade de demonstrar a importância dos vegetais como fontes de substâncias farmacologicamente ativas para produção de produtos bucais.

\section{MÉTODO}

Tratando-se de um estudo descritivo, do tipo revisão integrativa da literatura, buscou-se artigos científicos nas bases de dados do Scientific Electronic Library Online - SciELO, Science Direct e U.S. National Library of Medicine - PubMed. Utilizando-se como critérios de inclusão artigos completos, publicados nos idiomas espanhol, inglês e português, e que tivessem relação com o tema proposto, publicados no período de 2010 a 2020. Os critérios de exclusão foram estudos incompletos e que não abordavam o tema proposto.

\section{REVISÃO BIBLIOGRÁFICA}

Em um estudo de levantamento dos principais produtos de origem vegetal para a saúde bucal, realizado por Monteiro MHDA e Fraga SAPM (2015), foi observado que a Calendula officinalis L. (calêndula) e Punica granatum L. (romã) estão entre as plantas mais utilizadas, isoladas ou em associação com outros agentes químicos, assim como as doenças periodontais e gengivite foram mencionadas como as afecções bucais mais comuns.

Em um teste in vitro, analisando-se o extrato natural da casca de romã, foi observada a formação de um halo de inibição de $25 \mathrm{~mm}$ e $30 \mathrm{~mm}$, que impediu o desenvolvimento da bactéria Streptococcus mutans, que é um dos principais patógenos responsáveis por afecções bucais (SILVA GG, et al., 2020). 
Um outro estudo que avaliou colutórios comercializados e disponíveis no mercado (RIBEIRO ASC, et al., 2015), apontaram que o colutório contendo $C$. officinalis possuiu a melhor eficácia contra o microrganismo $S$. mutans, desenvolvendo um halo de inibição de $3,5 \mathrm{~mm}$, após 48 horas da aplicação do colutório no ensaio in vitro.

Em um estudo de revisão, Bohneberger G, et al., (2019) mostram comprovação de atividade antiinflamatória de $100 \%$ da calêndula e da romã, $70 \%$ de ação antibacteriana da romã, $40 \%$ de ação antisséptica da romã, $40 \%$ de ação cicatrizante da calêndula e $20 \%$ de ação antifúngica da romã, baseadas em ensaios clínicos.

\section{DISCUSSÃO}

Aleluia CM, et al., (2015) apresenta a $P$. granatum como uma das plantas medicinais mais utilizadas na composição de fitoterápicos, possuindo ação antibacteriana e anti-inflamatória comprovadas por testes clínicos e laboratoriais. Assim como a C. officinalis que mostra atividade antibacteriana comprovada (RIBEIRO ASC, et al., 2015).

Algumas vantagens são atribuídas aos fitoterápicos em comparação a produtos sintéticos, como o baixo custo e menos efeitos colaterais (OLIVEIRA FGS e LEHN CR, 2015).

Desde que se conheça suas ações farmacológicas, acredita-se que plantas que possuem atividades biológicas podem ser utilizadas na formulação de enxaguantes bucais, pomadas e creme dental. Podendo também estar em associação com outras substâncias químicas para tratar ou prevenir patologias bucais. Entretanto existe uma carência de estudos sobre a utilização de fitoterápicos na odontologia, salientando-se que há várias possibilidades de pesquisas nessa área fitoterápica, com a finalidade de aperfeiçoamento do conhecimento sobre o uso de plantas medicinais na saúde bucal (MONTEIRO MHDA e FRAGA SAPM, 2015).

\section{CONSIDERAÇÕES FINAIS}

Plantas como $C$. officinalis e $P$. granatum apresentam importantes atividades farmacológicas, como ação antibacteriana, para tratar afecções bucais. A fitoterapia pode ser citada como uma opção eficiente para o tratamento e prevenção de patologias bucais, apresentando como vantagens o fácil acesso, baixo custo e menos efeitos colaterais em relação aos medicamentos e outros produtos de necessidade farmacêutica sintéticos. Sendo importante a realização de mais pesquisas para o aprofundamento dessa área do conhecimento.

\section{REFERÊNCIAS}

1. ALELUIA CM, et al. Fitoterápicos na odontologia. Revista de Odontologia da Universidade da Cidade de São Paulo, 2015; 27(2): 126-134.

2. BOHNEBERGER G, et al. Fitoterápicos na odontologia, quando podemos utilizá-los?. Brazilian Journal of Health Review, 2019; 2(4): 3504-3517.

3. MONTEIRO MHDA, FRAGA SAPM. Fitoterapia na odontologia: levantamento dos principais produtos de origem vegetal para saúde bucal. Revista Fitos, 2015; 9(4): 253-303.

4. RIBEIRO ASC, et al. Atividade antimicrobiana de diferentes colutórios fitoterápicos. Ensaios e Ciência: Ciências Biológicas, Agrárias e da Saúde, 2015; 19(4): 178-183.

5. SILVA GG, et al. Atividade Antimicrobiana de substâncias fitoterápicas utilizadas no tratamento de afecções bucais: Estudo in vitro. Revista Ciência Plural, 2020; 6(2):113-124. 
RESUMO EXPANDIDO: Revisão Bibliográfica

Título: Atividades biológicas das cascas da Aroeira do sertão (Myracrodruon urundeuva).

Autor/coautores: Elvis Bezerra Santos, Jessica Alves de Lima, Vanessa da Silva Rocha, Nabuêr Francieli da Silva e Rosângela Estevão Alves Falcão.

Instituição: Universidade de Pernambuco (UPE), Garanhuns-PE; Universidade Federal de Pernambuco (UFPE), Recife - PE.

Palavras-chave: Aroeira do sertão, Atividades biológicas, Cascas.

\section{INTRODUÇÃO}

Os produtos naturais se constituem como métodos para a síntese medicamentosa em larga escala, mostrando-se promissores na busca por novos fármacos, por apresentar elevado índice de terapeuticidade. Nos últimos anos, cerca de $30 \%$ dos medicamentos comumente utilizados, são provenientes de espécies botânicas ou dos compostos provenientes do metabolismo secundário (NEWMAN e CRAGG, 2016).

Myracrodruon urundeuva se configura como uma planta árborea pertencente à família Anacardiaceae de ocorrência nos biomas do Cerrado, Mata Atlântica e Caatinga, sendo conhecida no Brasil por aroeira, aroeira do cerrado, aroeira do sertão, gibão e urundeuva (SILVA-LUZ; PIRANI, 2015). Possui uso frequente, abrangendo atividades biológicas tais como antiinflamatórias e cicatrizantes (GALVÃO, et al., 2018).

Em um estudo realizado por Pereira (2018) foi realizada a identificação fitoquímica dos compostos encontrados nas cascas da aroeira, focando nas substâncias fenólicas, substâncias as quais apresentam inúmeras propriedades farmacológicas, tais como anti-inflamatória e antimicrobiana. O estudo citado será debatido com mais detalhes nos resultados e discussão do presente estudo, onde foi avaliado, ademais, a atividade antioxidante de $M$. urundeuva.

\section{OBJETIVO}

Revisar e caracterizar atividades biológicas das cascas de Myracrodruon urundeuva, pautando-se como um exemplar associado à farmacologia dos produtos naturais, em ensaios in vitro, reforçando a necessidade de ensaios in vivo.

\section{MÉTODO}

O seguinte trabalho foi realizado por meio de revisão sistemática, analisando artigos que exploravam o tema proposto e que se enquadravam no limite de anos de 2015-2020. De caráter qualitativo, para a qual foi consultada a base de dados o Google Acadêmico, na língua inglesa e portuguesa. Os descritores utilizados foram: atividades biológicas da aroeira, atividades biológicas de Myracrodruon urundeuva, atividades biológicas da casca de Myracrodruon urundeuva.

\section{REVISÃO BIBLIOGRÁFICA}

No estudo de Pereira (2018) se realizou a identificação fitoquímica e avaliação da atividade antioxidante de Myracrodruon urundeuva, na determinação deste potencial, utilizou-se o método do sequestro do radical livre (DPPH) in vitro, nas concentrações de 10,15, 20, 25 e $30 \mathrm{mg} / \mathrm{ml}$ do extrato etanólico bruto. As triagens fitoquímicas prove do extrato metanólico das cascas do caule, onde obteve-se 42 substâncias, a maioria isoméricas, dentre as quais: "trigaloil glicose, ácido gálico, digaloil glicose, catequin galato, galato de etila, dicafeoil e urundeuvina", sugeriu-se que o efeito antioxidante da casca prové deles. Na avaliação da atividade citada, verificou-se que a menor concentração obteve maior êxito na atividade. Ademais, notou-se que a planta apresenta um alto teor de compostos fenólicos associados à sua alta atividade antioxidante. 
Em outro estudo (CASTRO, 2016) foi avaliada a citotoxicidade do extrato etanólico das cascas de $M$. urundeuva, frente a células oncológicas. As linhagens descritas foram:

- Colon humano;

- Glioblastoma;

- Leucemia;

- Próstata.

A concentração do extrato testada foi de $20 \mathrm{mg} / \mathrm{ml}$, que inibiu significativamente o crescimento e desenvolvimento das células oncológicas, isso foi atribuído, segundo o autor, a compostos químicos não voláteis, apresentando uma alta citotoxicidade. E se verificou que o extrato foi mais eficaz frente às células leucêmicas.

Em outra pesquisa, avaliou-se a atividade anti-inflamatória do extrato glicólico das cascas de $M$. urundeuva. Para tal avaliação foram testadas as seguintes concentrações: $3,13 \mathrm{mg} / \mathrm{mL}$ e $12,5 \mathrm{mg} / \mathrm{mL}$, em células de macrofagos RAW 264.7, estimuladas por lipopolisscarídeos de $E$ coli, um método de avaliação in vitro, pois analisa se o extrato conseguiu induzir a síntese de derivados inflamatórios. $O$ extrato provocou o aumento da produção de citocinas pró-inflamatórias, onde a concentração de $12,5 \mathrm{mg} / \mathrm{mL}$ gerou o dobro da produção das citocinas que a concentração de $3,13 \mathrm{mg} / \mathrm{mL}$ desse extrato, dessa forma, a primeira se mostrou mais eficaz (CRISTIANE, 2016).

\section{DISCUSSÃO}

A partir do exposto, verificou-se que os extratos das cascas de Myracrodruon urundeuva apresentam atividades biológicas notórias, como comprovadas nos ensaios in vitro, todavia, destaca-se que são escassos os estudos com a casca das plantas, abrangendo mais a folha e a semente nas pesquisas.

Dessa forma, incentiva-se a realização de outros estudos, visando a importância das cascas de $M$. urundeuva nas atividades citadas, ressaltando a importância de que sejam realizados ensaios in vivo, pois, a maioria dos ensaios não chegaram nas fases préclinicas, algumas vezes, por falta de interesse e incentivo na pesquisa ( PEREIRA, 2018; CASTRO, 2016; CRISTIANE, 2016)

Portanto, torna-se necessário ensaios posteriores, para fins de verificação das atividades_biológicas, com diferentes compostos, com ensaios em modelos experimentais in vivo, reforçando a necessidade de testagem e de mais identificações fitoquímicas, pois, mais compostos não identificados nos estudos, podem ser os responsáveis pelos efeitos farmacológicos estudados.

\section{CONSIDERAÇÕES FINAIS}

Diante do exposto, verifica-se que a casca de Myracrodruon urundeuva se configura como um exemplar pouco estudado, diante de outros componentes da referida planta, como semente e folha, mas que abrange atividades biológicas eficazes conforme os estudos revisados. Dessa forma, a contribuição deste trabalho é o incentivo às pesquisas in vivo com os compostos das cascas desta espécie que apresentaram resultados promissores, pois, é de suma importância que existam estudos que atestem essas atividades em modelos experimentais animais, logo, contribuindo para a saúde pública.

\section{REFERÊNCIAS}

1. CASTRO CB. Perfil químico e atividade citotóxica de extratos de folha, galho e casca de aroeira-do-sertão (myracrodruon urundeuva all): abordagem metabolômica e quimiométrica. Monografia submetida à Coordenação do Curso de Bacharelado em Química da Universidade Federal do Ceará, 2016.

2. CRISTIANE KH. Atividade anti-inflamatória e citotoxicidade dos extratos glicólicos de cynara cardunculus var. scolymus (I.) fiori (alcachofra), myracrodruon urundeuva allemão (aroeira-do-sertão) e camellia 
sinensis (I.) kuntze (chá verde). Tese apresentada ao curso de Odontologia do Instituto de Ciência e Tecnologia, UNESP - Univ Estadual Paulista, Campus de São José dos Campos, 2016.

3. GALVÃO WRA, et al. Gastroprotective and anti-inflammatory activities integrated to chemical composition of Myracrodruon urundeuva Allemão - A conservationist proposal for the species. Elsevier, Journal of Ethnopharmacology 222 (2018) 177-189, April 2018.

4. NEWMAN DJ, CRAGG GM. Natural Products as Sources of New Drugs from 1981 to 2014. J. Nat. Prod., v. 79, p. 629-661, 2016.

5. PEREIRA DPS. Caracterização de compostos fenólicos por espectrometria de massas e potencial antioxidante das cascas de Myracrodruon urundeuva (aroeira-do- sertão) do cariri paraibano. Dissertação apresentada ao Programa de Pós- Graduação em Produtos Naturais e Sintéticos Bioativos do Centro de Ciências da Saúde da Universidade Federal da Paraíba, 2018.

6. SILVA-LUZ CL, PIRANI JR. Anacardiaceae in Lista de Espécies da Flora do Brasil. Jardim Botânico do Rio de Janeiro, 2015. 
RESUMO EXPANDIDO: Revisão Bibliográfica

Título: Atividades biológicas dos frutos do noni (Morinda citrifolia Linn).

Autor/coautores: Elvis Bezerra Santos, Jessica Alves de Lima, Vanessa da Silva Rocha, Nabuêr Francieli da Silva e Rosângela Estevão Alves Falcão.

Instituição: Universidade de Pernambuco (UPE), Garanhuns-Pernambuco; Universidade Federal de Pernambuco (UFPE), Recife - Pernambuco.

Palavras-chave: Atividades biológicas, Fruto, Noni.

\section{INTRODUÇÃO}

Plantas medicinais são consideradas de suma importância para as bases farmacológicas associadas à saúde, onde, diversos fármacos derivam de compostos encontrados nessas espécies botânicas, nesse contexto, o conjunto de substâncias ativas é bem promissor no que diz respeito à cura das enfermidades (CASANOVA e COSTA, 2017).

Morinda citrifolia Linn (noni) é uma espécie botânica amplamente utilizada como alimento e tem sido pesquisada devido aos seus efeitos terapêuticos na saúde humana. Sendo investigada como um agente que atua em células oncológicas, e tem eficácia antimicrobiana, utilizada para tratar também desordens gastrintestinais (ABOU, et al., 2015), embora, existem poucos estudos realizados em seres humanos.

O seu fruto também merece destaque no campo da terapêutica farmacológica, onde o mesmo já foi testado em ensaios in vivo e in vitro, em um estudo onde foi avaliada a atividade moduladora de fármacos e antimicrobiana, sendo debatida com mais detalhes nos resultados, onde o mesmo obteve resultados medianos (TINTINO, et al., 2015).

\section{OBJETIVO}

Abordar e caracterizar atividades biológicas dos frutos de Morinda citrifolia Linn, em ensaios in vitro, pautando-se como um trabalho associado à farmacologia de produtos provenientes de plantas.

\section{MÉTODO}

O seguinte trabalho foi realizado por meio de revisão sistemática, analisando artigos que exploravam o tema proposto e que se enquadravam no limite de anos de 2015-2020. A pesquisa tem caráter qualitativo, para a qual foram consultadas as seguintes bases de dados: Google Acadêmico, SciELO e PubMed. Na língua inglesa e portuguesa. Os descritores utilizados foram: atividades biológicas do noni (Google Acadêmico e SciELO), atividades biológicas de Morinda citrifolia (Google Acadêmico e Scielo), Morinda citrifolia Linn (Google Acadêmico, SciELO e PubMed).

\section{REVISÃO BIBLIOGRÁFICA}

Em um estudo realizado por Tintino et al., (2015) foi avaliada a capacidade antimicrobiana (contra bactérias e fungos) e a atividade moduladora frente a fármacos antimicrobianos comumamente utilizados ( antibacterianos: amicacina gentamicina, impenem e a oxacilina; antifúngicos: Benzoilmetronidazol, Mebendazol, Anfotericina B e a Nistatina), para tanto foi utilizado $10 \mathrm{mg} / \mathrm{ml}$ do extrato etanólico do fruto de Morinda citrifolia L. contra Escherichia coli ATCC 11105, Pseudomonas aeruginosa ATCC 15442 e cepas do fungo Candida krusei ATCC 2538, onde foi mostrado que o extrato, não apresentou uma atividade antimicrobiana muito eficaz, todavia, o mesmo teve resultados mais significativos na atividade moduladora dos fármacos antibacterianos, ademais, a atividade moduladora em fármacos antifúngicos não foi significativa. 
Em outra pesquisa realizada por Teixeira (2015) foi avaliado o potencial antiproliferativo de extratos e frações do fruto do noni ( $M$. citrifolia Linn), em linhagens de interesse tumoral. A atividade antiproliferativa foi testada por meio do uso dos extratos etanólicos $(100 \mathrm{mg} / \mathrm{ml})$, $\mathrm{n}$-hexânicos $(50 \mathrm{mg} / \mathrm{ml})$ e acetato de etila $(50 \mathrm{mg} / \mathrm{ml})$ nas linhagens tumorais de:

- Mama;

- Ovário com fenótipo de resistência a múltiplos fármacos;

- Rim;

- Pulmão;

- Próstata;

- Ovário não resistente a múltiplos fármacos;

- Leucemia.

Mediante os testes realizados, o extrato etanólico foi ativo e seletivo nas linhagens dos ovários (-resistentes e não resistentes), e ainda inibiu a proliferação da linhagem de ovário com fenótipo de resistência a múltiplos fármacos, e não apresentou efeito citostático contra nenhuma linhagem tumoral.

A fração n-hexânica obteve efeito citostático sobre todas as linhagens testadas, sendo a fração mais eficaz evidenciada no estudo, sendo seletiva para a linhagem de ovário não resistente, seguida das linhagens de pulmão, leucemia, ovário resistente e mama.

A fração acetato de etila obteve potencial citotástico contra todas as linhagens citadas, tendo maior seletividade para a linhagem de ovário não resistente e mama.

\section{DISCUSSÃO}

Diante dos resultados analisados neste estudo, verificou-se que o fruto do noni foi eficaz em situações de interesse tumoral e na atividade moduladora de fármacos antimicrobianos, todavia, os autores registram nos seus trabalhos a necessidade de estudos posteriores, com diferentes concentrações dos extratos do fruto e suas frações, para verificação dos resultados obtidos naqueles trabalhos, confirmando ou não os resultados encontrados.

Poucos trabalhos realizam as investigações farmacológicas do fruto desta planta, se constituindo na maioria, de artigos de revisão, e poucos artigos originais, reforçando a importância da planta para as enfermidades, logo, o porquê de ser realizado mais pesquisas nesse sentido.

Aqui também é reforçada a importância da sucessão dos ensaios realizados, dos ensaios in vitro, para in vivo, e posteriormente ensaios clínicos, pois, algumas atividades, que obtiveram resultados satisfatórios, muitas das vezes, não possuem continuidade, por falta de incentivo, em algumas situações (TINTINO, et al., 2015; TEIXEIRA, 2015).

\section{CONSIDERAÇÕES FINAIS}

Diante do exposto, verifica-se que o fruto do noni apresenta uma comprovada ação moduladora de fármacos antimicrobianos, e antiproliferativa em algumas linhagens tumorais, todavia, fica registrado neste trabalho a importância da realização de ensaios in vivo, e a posterior sucessão para os ensaios clínicos, pois, a planta é considerada promissora, e dessa forma, a contribuição deste trabalho é incentivar a realização de ensaios com modelos animais experimentais, para validação das suas atividades biológicas estudadas, e contribuir para a saúde pública.

\section{REFERÊNCIAS}


1. $A B O U$ AR, et al. Morinda citrifolia (noni): A comprehensive review on its industrial uses, pharmacological activities, and clinical trials. Arab. J. Chem. 2015; 10.1016.

2. CASANOVA ML, COSTA SS. Interações Sinérgicas em Produtos Naturais: Potencial Terapêutico e Desafios. Rev. Virtual Quim, 2017, 9 (2), 575-595.

3. TEIXEIRA DG. Isolamento químico e avaliação de bioatividade de frações do fruto de noni (Morinda citrifolia L.). Tese apresentada ao Programa de Pós-Graduação em Biologia Comparada do Centro de Ciências Biológicas da Universidade Estadual de Maringá, 2015.

4. TINTINO SR, et al. Atividade antimicrobiana e efeito combinado sobre drogas antifúngicas e antibacterianas do fruto de Morinda citrifolia L. Acta biol. Colomb. 2015;20(3):193-200. 
RESUMO EXPANDIDO: Revisão Bibliográfica

Título: Sarcopenia e seus impactos no estado nutricional em pacientes oncológicos em cuidados paliativos

Autor/coautores: Joerika Batista Ciqueira, Cássia Thaís Pessoa de Albuquerque Ferreira, Marcos Garcia Costa Morais, Maysla Rayssa Silva Costa, José Thiago Alves de Sousa.

Instituição: Centro Universitário Maurício de Nassau (UNINASSAU), Campina Grande-PB; Universidade de Pernambuco (UPE), Garanhuns-PE; Universidade Federal de Campina Grande (UFCG), Cuité-PB.

Palavras-chave: Neoplasia, Atrofia Muscular, Estado Nutricional.

\section{INTRODUÇÃO}

As doenças crônicas não transmissíveis são as principais causas de morte no mundo, dentre as quais destaca-se o câncer, afetando indivíduos das diferentes faixas etárias e condições socioeconômicas e os induz a apresentar diversos desfechos clínicos que interferem no seu estado nutricional, como por exemplo, a má nutrição, devido a uma diminuição na ingestão alimentar. Assim, causando complicações devastadoras a pacientes em estados terminais contribuindo para maiores casos de óbitos nesta população. Desse modo, o suporte nutricional adequado é de grande relevância, evidencia-se um melhor prognóstico quando associado a cuidados paliativos, que de acordo com Organização Mundial de Saúde, é um cuidado que prioriza a autonomia do paciente, enfatizando o cuidado global, daqueles que não apresentam mais respostas ao tratamento curativo, objetivando aliviar os sintomas provenientes da fase terminal da doença (ARAÚJO, 2019). A nutrição é um assunto favorável aos cuidados paliativos, pois apresenta um papel importante na promoção e prevenção do câncer. Assim, contribuindo para que seja possível reverter os efeitos adversos provocados pela redução da massa muscular, sarcopenia, promovendo maior conforto e bem-estar para estes pacientes (UBACHS, et al., 2019).

\section{OBJETIVO}

Analisar a produção científica disseminada em periódicos nacionais e internacionais a respeito dos impactos ocasionados pela sarcopenia e suas consequências no estado nutricional e comprometimento da qualidade de vida em pacientes oncológicos em cuidados paliativos.

\section{MÉTODO}

Trata-se de uma revisão bibliográfica a qual usufruiu como base de dados as plataformas PUBMED, SciELO e LILACS, a partir dos descritores: cuidados paliativos, qualidade de vida e atrofia muscular. Foram selecionados 22 artigos completos, publicados entre os anos de 2017-2020, escritos em inglês ou português, excluindo-se 18 que não abordavam a temática em questão.

\section{REVISÃO BIBLIOGRÁFICA}

O câncer provoca diversas alterações no organismo humano, desde alterações metabólicas, capacidade física e bem-estar psicossocial que, consequentemente, apresentam influências significativas no estado nutricional, provocando maiores impactos no avançar da doença. Desse modo, uma condição trivial e que pode acarretar desfechos negativos para a qualidade de vida destes pacientes é a sarcopenia, termo utilizado para descrever a redução de massa muscular esquelética, podendo interferir negativamente no comprometimento da hospitalização e morte dos pacientes com câncer em ascensão (JUBY e MAGER, 2019). O câncer em seu estado avançado conduz o paciente a ceder aos cuidados paliativos, cuja abordagem, visa proporcionar o alívio e prevenção do sofrimento, uma abordagem voltada para o ser humano em sua integralidade. Vale advertir, que o cuidado paliativo visa preservar a autonomia do paciente, colaborando para que este usufrua de sua vitalidade o máximo possível, desde que, dentro dos seus limites. Com isso, à 
aplicação dos cuidados paliativos tem se tornado cada vez mais frequente em países em desenvolvimento, como o Brasil. Contudo, é de suma importância a ampliação do número de profissionais capacitados e unidades de saúde que apresentem estrutura apropriada para esse atendimento. A atuação de um nutricionista é primordial para pacientes oncológicos no fim da vida, devido a ser um público que apresenta grande recusa pelos alimentos, agravando ainda mais os casos de sarcopenia. Desse modo, ele é o responsável pela evolução do quadro nutricional, bem como, proporcionar uma alimentação nutricional adequada priorizando a autonomia e satisfação do paciente valorizando os alimentos preferenciais dele. Sendo assim, o acompanhamento nutricional em cuidados paliativos reduz os impactos ocasionados pela sarcopenia refletindo em uma melhoria na qualidade de vida.

\section{DISCUSSÃO}

Após análise dos estudos abordados para a presente revisão, foi possível constatar a prevalência dos impactos associados a sarcopenia em pacientes oncológicos, nos mais variados tipos de câncer, que estão em tratamento paliativo. Entre os impactos que podem levar esta população a piores desfechos clínicos ligados a sarcopenia, ressalta-se a idade avançada, depleção do estado nutricional relacionado ao menor índice de massa corporal, dispneia e anorexia. Estes fatores corroboram na menor ingestão alimentar, resultando em menor percentual de massa muscular esquelética que pode variar de $31 \%$ a $87 \%$, prejudicando a qualidade de vida e causando maior progressão da doença (FARIAS, 2017). Dessa maneira, a atuação do nutricionista nos cuidados paliativos é indispensável, pois além de contribuir para a manutenção da qualidade de vida, proporcionará uma sobrevida digna, por meio da sensibilidade, respeito pela autonomia do paciente e em conjunto com os recursos terapêuticos oncológicos globais.

\section{CONSIDERAÇÕES FINAIS}

Portanto, a sarcopenia está associada a uma série de desfechos clínicos que contribuem negativamente para o bem-estar dos pacientes. Diante disso, é necessário a aplicação de protocolos padronizados para a identificação do diagnóstico nutricional e abordagens interdisciplinares, a fim de reduzir e prevenir os impactos da sarcopenia em pacientes oncológicos em fase terminal, para que assim possam desfrutar de uma melhor qualidade de vida, uma vez que, este é o principal objetivo do cuidado paliativo.

\section{REFERÊNCIAS}

1. ARAÚJO RG. Sarcopenia em pacientes oncológicos em cuidados paliativos: uma revisão integrativa. Repositório Institucional da UFPB, 2019.

2. FARIAS TND. Terapia nutricional nos cuidados paliativos: a importância do nutricionista nesta temática. Repositório Institucional da UFPB, 2017.

3. JUBY AG, MAGER DR. A review of nutrition screening tools used to assess the malnutrition-sarcopenia syndrome (MSS) in the older adult. Clinical nutrition ESPEN, v. 32, p. 8-15, 2019.

4. UBACHS J, et al. Sarcopenia and ovarian cancer survival: a systematic review and meta-analysis. Journal of cachexia, sarcopenia and muscle, v. 10, n. 6, p. 1165-1174, 2019. 
RESUMO EXPANDIDO: Revisão Bibliográfica

Título: Uso de benzodiazepínicos em área rural

Autor/coautores: Carine Machado Pereira, Stéphane Rossi de Melo, Denise Krieger.

Instituição: Universidade do Planalto Catarinense (UNIPLAC), Lages-Santa Catarina.

Palavras-chave: Receptores de GABA-A, Uso indevido de medicamentos, População rural.

\section{INTRODUÇÃO}

O uso crônico de benzodiazepínicos é deletério tanto para o utilizador quanto para o Sistema Único de Saúde (SUS). Em relação ao indivíduo seu uso leva a diversos efeitos prejudiciais, a saber: alteração na coordenação motora, sonolência excessiva, perda de memória, tontura e dependência química ao fármaco (NALOTO DCC, et al., 2016). Estes efeitos colaterais, muitas vezes, são negados ou ignorados pelo indivíduo que utiliza o medicamento. Ademais, a correlação entre o uso crônico do medicamento e suas consequências potencialmente graves (acidentes de trânsito, fratura em idosos) é difícil de ser observada (FEGADOLLI C, et al., 2019).

É importante constatar que o medicamento é disponibilizado gratuitamente para a população, portanto fica evidente o aumento de gasto público gerado pela dependência do fármaco em questão, além de não prover melhora da saúde do indivíduo no seu contexto mais amplo (FEGADOLLI C, et al.,2019).

Apesar de conhecida malignidade do tema no contexto urbano, poucos são os estudos que o abordam na área rural fato que sensibilizou a formação dessa revisão bibliográfica.

\section{OBJETIVO}

Revisar e analisar os fatores de risco e causas associadas ao uso abusivo de benzodiazepínicos em população rural, comparado com a população urbana e identificando a prevalência entre os gêneros.

\section{MÉTODO}

Realizou-se uma revisão de literatura, utilizando as bases de dados SCIELO e LILACS. A busca foi realizada com os descritores: Uso Indevido de Medicamentos AND Fármacos do Sistema Nervoso Central, Transtornos Mentais AND População Rural. Foram incluídos artigos completos publicados em Português ou Inglês, datados entre 2016 e 2020 e que abordaram o abuso de benzodiazepínicos e os transtornos mentais da população rural. Excluiu-se artigos duplicados, sem relevância ao tema e que não se enquadraram nos critérios de inclusão.

\section{REVISÃO BIBLIOGRÁFICA}

Encontrou-se 6.850 obras, sendo 9 no SCIELO e 6.841 no LILACS, sendo que onze foram selecionadas para a formulação desse estudo.

A maioria dos artigos utilizados mostraram relevância de diferentes fatores de risco populacionais para a explicar o uso abusivo de benzodiazepínicos pela população. O que pode ser observado foi a maneira como todos se complementam. Uma malha de dificuldades sociais envolve pessoas da área rural, as quais não têm perspectiva de melhora das condições de vida (PARREIRA, et al., 2017). Com efeito, inicia-se processos patológicos que culminam na prescrição de benzodiazepínicos como uma saída também para o profissional de saúde que não obtém outras vias de tratamento (psicoterapia, grupos de apoio e prevenção). Cria-se, dessa forma, um ciclo vicioso que compromete a saúde do indivíduo e leva a custos excessivos para o sistema único de saúde (SILVA PA, et al., 2019). 
A problemática que envolve o abuso de benzodiazepínicos permeia diversos problemas referentes a carências sociais e aos dilemas da saúde pública em relação à atenção aos transtornos mentais (FEGADOLLI C, et al., 2019).

Desde a década de 1960 os benzodiazepínicos são prescritos, sendo que antigamente seus usuários se concentravam em áreas urbanas. Isso estava correlacionado com os fatores de estresse que surgiram junto com uma revolução tecnológica em cidades mais desenvolvidas (PARREIRA, et al., 2017). Contudo, essa manifestação se modificou durante os anos, sendo que os estudos da atual década relatam a prevalência do uso de benzodiazepínicos em ambiente rural, principalmente em mulheres (NALOTO DCC, et al., 2016). Apesar de considerável conteúdo sobre o tema há ainda poucos estudos que medeiam essa problemática na população rural.

\section{DISCUSSÃO}

A prevalência de abuso de benzodiazepínicos pela área rural foi pouco avaliada pelos estudos, sendo mais observado o perfil de risco que acarreta dependência de benzodiazepínicos. A população com maior risco de dependência foi mulheres entre 56 a 74 anos (SILVA PA, et al., 2019). Ainda, houve maior prevalência de transtornos mentais comuns (TCM) em mulheres da área rural, as quais, normalmente, estão mais expostas a violência, a baixa renda e a dependência financeira (PARREIRA, et al., 2017).

A complexidade dos problemas sociais que envolvem os TMCs causa dificuldade do profissional da saúde de criar estratégias para enfrentamento do problema. Esse fator associado a certa resistência da população a terapias alternativa geram o sentimento de inabilidade do profissional em lidar com essa situação $O$ profissional, então, encontra-se acuado por um problema profundo o que torna a prescrição de benzodiazepínicos a única alternativa no momento (FEGADOLLI C, et al., 2019).

\section{CONSIDERAÇÕES FINAIS}

Percebeu-se que a população feminina é a mais afetada pelos transtornos mentais comuns sendo evidente o maior uso de benzodiazepínicos nessa população. Além disso, foi observada maior prevalência do seu uso entre as mulheres residentes na área rural. De mais a mais, os problemas sociais que envolvem os TMC e a resistência a terapias alternativas fortalecem o uso indiscriminado de benzodiazepínicos. A carência de estudos referentes a prevalência do uso de benzodiazepínicos em área rural foi observada nesse estudo de forma a demonstrar a importância do tema perante a atenção básica e ao Sistema Único de Saúde.

\section{REFERÊNCIAS}

1. FEDAGOLLI $C$, et al. Uso e abuso de benzodiazepínicos na atenção primária à saúde: práticas profissionais no Brasil e em Cuba. Caderno de Saúde Pública, 2019.

2. NALOTO DCC, et al. Prescrição de benzodiazepínicos para adultos e idosos de um ambulatório de saúde mental. Ciênc. saúde col.,2016, 1.

3. PARREIRA BDM, et al. Transtorno Mentais Comuns e fatores associados: Estudo em mulheres em área rural. Common mental disorders and associated factors: a study of women from a rural area. Rev Esc Enferm USP. 2017.

4. SILVA PA, et al. The use of benzodiazepines by women cared for at a Family Health Unit. Rev Esc Enferm USP. 2019. 
RESUMO EXPANDIDO: Revisão Bibliográfica

Título: Impacto do seguimento farmacoterapêutico realizado em pacientes com insuficiência renal crônica

Autor/coautores: Adriana Araújo de Oliveira Souza, Alan Damião Queiroz, Renata Freitas de Araujo-Calumby.

Instituição: Unidade de Ensino Superior de Feira de Santana, UNEF, Feira de Santana- Bahia.

Palavras-chave: Doença renal crônica, Farmácia clínica, Gerenciamento de terapia medicamentosa.

\section{INTRODUÇÃO}

A doença renal crônica (DRC) está entre as doenças mais prevalentes na escala mundial, afetando mais de 750 milhões de pessoas em todo o mundo (CREWS, et al., 2019). Os pacientes com DRC em terapia renal substitutiva ou em acompanhamento ambulatorial sem realização de terapia renal substitutiva, necessitam de uma variedade de medicamentos para controlar os distúrbios metabólicos provenientes da disfunção renal. Assim, é comum a prescrição concomitante de vários fármacos. Essas associações podem gerar interações medicamentosas (IMs) ocasionando efeitos inesperados, com ocorrência de eventos adversos graves e até a ineficácia do tratamento. As IMs são eventos que podem ocorrer, mas que são consideradas evitáveis, possibilitando intervenção e ações de prevenção (MATETI, et al., 2017). Assim, a necessidade de se realizar o seguimento farmacoterapêutico é de fundamental importância aos cuidados do paciente com DRC, pois a função do farmacêutico juntamente com a equipe multiprofissional, transcende os aspectos técnicos. Logo, a filosofia de prática profissional do farmacêutico se fundamenta na promoção de uma melhor qualidade de vida dos pacientes, através do vínculo da Atenção Farmacêutica, promovendo o autogerenciamento da sua saúde e a reabilitação das comorbidades.

\section{OBJETIVO}

Descrever o impacto do seguimento farmacoterapêutico realizado em pacientes com insuficiência renal crônica e de suas contribuições no auxílio da avaliação clínica.

\section{MÉTODO}

O presente trabalho trata-se de uma revisão sistemática realizada através da busca de artigos científicos. As estratégias utilizadas para a realização da pesquisa bibliográfica foram, a utilização de periódicos provenientes dos bancos de dados: Scientific Electronic Library Online (SciELO), Biblioteca Virtual em Saúde (BVS) e National Library of Medicine (PubMed). Os descritores utilizados na pesquisa foram: doença renal crônica e farmácia clínica, doença renal crônica e atenção farmacêutica, doença renal crônica e seguimento farmacoterapêutico, farmacêutico em hemodiálise e farmacêutico e pacientes renais crônicos. Em relação aos critérios de inclusão, foram admitidos artigos publicados em Inglês, Português, Espanhol e Francês com resumos disponíveis nas bases de dados citadas, além de serem artigos originais com texto completo, publicados dentro de um período de 2010 a 2019 e que possuem como tema principal a atuação do farmacêutico no acompanhamento de pacientes com DRC. Os critérios de exclusão foram: artigos fora do período citado; artigos repetidos e de revisão; artigos que não incluem a população de interesse e que não retratam o papel do farmacêutico na área nefrológica ou que avaliam somente a doença em si, fugindo ao tema proposto nesse trabalho.

\section{DISCUSSÃO}

Após a aplicação dos termos de busca descritos anteriormente, foram selecionados 16 artigos. A maioria dos artigos selecionados demonstraram impactos significativos na assistência à saúde de pacientes com DRC que foram acompanhados por farmacêuticos, apontando, assim, a importância da inclusão do farmacêutico na equipe de assistência no ambiente ambulatorial, hospitalar ou na comunidade abordando cuidados 
fundamentais para o gerenciamento e monitorização da terapia medicamentosa desses pacientes, detectando possíveis reações adversas e interações medicamentosas. Outro papel fundamental do farmacêutico clínico é a prevenção e avaliação de efeitos iatrogênicos na DRC. A prevenção de efeitos iatrogênicos é uma preocupação importante do sistema de saúde. O paciente transplantado apresenta um maior risco de apresentar iatrogenicidade, principalmente como resultado de alterações farmacocinéticas associadas à insuficiência renal, a polimedicação e a prescrição de medicamentos com margens terapêuticas estreitas, essenciais para garantir a não rejeição ao tecido transplantado. Assim, esses estudos também ressalta a importância do gerenciamento da terapia medicamentosa na admissão, juntamente com o monitoramento semanal de prescrições e conciliação medicamentosa na alta desses pacientes (FLAMME-OBRY, et al., 2018; MONTERROZA, BOLIVAR, 2017; GHIMIRE, et al., 2019).

\section{CONSIDERAÇÕES FINAIS}

A maioria dos estudos envolvidos neste trabalho relataram impactos positivos resultante da implantação de serviços de Farmácia Clínica prestados a pacientes com DRC, demonstrando sua importância no processo do cuidar, seja na dispensação dos medicamentos, no seguimento da farmacoterapia, na análise da prescrição e principalmente na promoção da adesão. O farmacêutico inserido na equipe multiprofissional do atendimento ao paciente com DRC desempenha um importante papel no seguimento farmacoterapêutico, auxiliando na avaliação clínica, no ajuste de dose, na duração do tratamento, na escolha dos tipos de medicamentos que podem ser utilizados, além de ajudar no processo de administração dos mesmos, estimulando o autogerenciamento e consequentemente melhorando a qualidade de vida dos mesmos.

\section{REFERÊNCIAS}

1. CREWS DC, et al. Burden, access and disparities in kidney disease. World Kidney Day Steering Committee. Journal of Renal Care, 2019; 45(1): 4-8.

2. FLAMME-OBRY F, et al. Impact du pharmacien clinicien sur la iatrogénie médicamenteuse chez le patient greffé renal. Néphrologie \& Thérapeutique, 2018:1-8.

3. GHIMIRE S, et al. Adherence assessment practices in haemodialysis settings: A qualitative exploration of nurses and pharmacists' perspectives. Clinical Nursing, 28: 2197-2205.

4. MATETI UV, et al. Impact of pharmaceutical treatment on health-related quality of life among hemodialysis patients - A multicenter randomized controlled trial. Saudi Journal of Kidney Diseases and transplantation, 2017; 28(6): 1293-1306.

5. MONTERROZA DAA, BOLIVAR JFC. Pharmaceutical care practice in patients with chronic kidney disease. Revista de Farmacia Hospitalaria, 2017; 41(2): 137-149. 
RESUMO EXPANDIDO: Revisão bibliográfica

Título: Biocurativo de selante de fibrina no tratamento de úlceras dos membros inferiores e venosa

Autor/coautores: Suyla Manuelle da Silva Leite, Paulo Henrique da Silva Santos, David Vitor da Silva Anjos, Maria Luiza Carneiro Moura Gonçalves Rego Barros, Ana Carolina Messias (Orientador).

Instituição: Centro Universitário Brasileiro, Instituto de Gestão e Marketing - UNIBRA, Recife, Pernambuco.

Palavras-chave: Biotecnologia, Cicatrizante, Úlceras varicosas.

\section{INTRODUÇÃO}

As úlceras localizadas nos membros inferiores, sendo elas conhecidas por úlceras venosas, úlceras arteriais, úlceras por pressão, pé diabético e deiscência cirúrgica, são ferimentos crônicos de má cicatrização e recorrências de uma nova inflamação no local. Esses ferimentos são mais comuns em adultos que tenham previsivelmente alguma patologia que atinja as veias, artérias e até mesmo em estágio avançado e maltratado da diabetes (CORNÉLIO, 2015).

Para cicatrização de ferimentos de pele, em considerações normais, o organismo irá formar um novo tecido através de um evento celular e molecular e garantir que tal esteja cicatrizado. No entanto uma pessoa com ferimentos crônicos e/ou pré-disposição a má cicatrização, a interação do evento pouca vez dará o efeito esperado. Pensando nisso a Universidade Estadual de Paulista/SP (Unesp) está engajado na produção de um novo curativo com técnica biotecnológica totalmente brasileira, o selante de fibrina, para o auxílio no tratamento de úlceras de perna e úlceras crônicas, e assim poder disponibilizá-lo em hospitais privados e principalmente públicos (CUTER Q, 2017).

\section{OBJETIVO}

Abordar sobre a biotecnologia utilizada na produção do biocurativo para o tratamento de úlceras de perna dentro da pesquisa farmacêutica brasileira na formulação do potencial cicatrizante e entender as combinações bioativas para a produção do biocurativo selante de fibrina.

\section{MÉTODO}

O presente resumo trata-se de uma revisão bibliográfica sem critério explicito retirados de portais digitais Scielo e Lilacs. Para a busca dos materiais utilizou-se palavras chaves isoladas e permutadas, como "selante de fibrina", "biocurativo" e "Veneno de cobra para úlceras". Os critérios de exclusão de materiais foram para as teses e monografias. Reunidos em uma janela de tempo entre 2015 a 2019. Responsável por 4 referências em idioma português do Brasil e 1 em língua estrangeira, inglês e 1 em espanhol. A coleta de dados para a revisão foi realizada em junho de 2020.

\section{REVISÃO BIBLIOGRÁFICA}

Dentro da Unesp a Doutora em farmácia, Rosana Rossi Ferreira, do Departamentos de Ciências Biológicas junto a professora Doutora e médica da Faculdade de Medicina de Botucatu, Elenice Deffune, são responsáveis pela pesquisa e desenvolvimento de um Biocurativo de Selante de Fibrina capaz de cicatrizar as úlceras inferiores com sucesso utilizando plasma sanguíneo e veneno de serpente. Os primórdios para esse desenvolvimento começaram em 1989, mas apenas na atualidade os novos recursos e manejos para a fabricação obtiveram as devidas atualizações (JUNIOR R, 2017).

A produção deste medicamento é realizada a partir de uma enzima substancial do veneno da cascavel, enzima serino protease, extraída cautelosamente e de maneira protocolada das serpentes encontradas no criadouro do Centro de Estudos de Venenos e Animais Peçonhentos (Cevap) também da Unesp. A pequena porção do veneno junto ao sangue de Búfalo, chamado de Crio precipitado, misturados em solução se 
transformam em uma rede de fibrina com propriedades, de acordo com estudos, a adesão, enxertos, a adesividade, capacidade hemostática na diminuição de sangramento e cicatrização (LEITE, 2018).

O animal búfalo depois de vários testes em outros animais é o mais ideal para o efeito de Rede de fibrina, pois o Crio precipitado é encontrado na porção do sangue do animal. A cascavel por outro lado também foi a melhor escolhida e ideal por ter um tipo de veneno que favorece a retirada da enzima que participa diretamente no processo fisiológico de coagulação juntamente com o fibrinogênio, proteína solúvel do plasma sanguíneo, sendo a ação do medicamento baseada nos princípios naturais de coagulações (DE LA PORTÍLLA F, 2019).

\section{DISCUSSÃO}

Após as comprovações do uso do medicamento laboratorialmente, a Agência de Vigilância Sanitária liberou para que continuasse as fases de testes, inclusive a $3^{\circ}$ em humanos que obteve o resultado no hospital das clinicas de São Paulo, pela Unesp, resposta positiva em $71,1 \%$ dos casos, sendo $38,8 \%$ responsável pela cicatrização completa das úlceras e 33,3\% em melhora da aparência das feridas. Logo gerando efeito na produção biotecnológica. No entanto o Selante de Fibrina ainda não pode ser comercializado, pois é necessária a autorização da Anvisa. O medicamento nacional passou por todos os testes, inclusive de farmacovigilância, ou fase 4, e obteve resultados positivos para o tratamento de úlceras de membros inferiores e venosas (PAVÃO D, 2019).

\section{CONSIDERAÇÕES FINAIS}

Em suma O biocurativo selante de fibrina é produzido através de uma técnica biotecnológica da mistura de uma pequena enzima coletada do veneno da cobra Cascavel e o Fibrinogênio do sangue do búfalo, com a propriedade de formar uma rede de fibrina capaz de acelerar, coagular, melhorar e diminuir os ferimentos causados pelas ulcerações. Com o intuito de tratar as ulcerações do sistema público, a pesquisa que já passou por todos os testes, agora espera apenas da liberação da Anvisa para também ser comercializado e produzido em larga escala.

\section{REFERÊNCIAS}

1. CORNÉLIO R. Biocurativo usa sangue e veneno de cobra para super cicatrizante. Jornal da cidade de Botucatu.

2. CUTER Q. Selante de fibrina extraído do veneno da cascavel entra na sua terceira fase. Jornal online Alpha Noticias de Botucatu. Botucatu, 2017.

3. DE LA PORTÍLLA F, JIMÉNEZ-SALIDO A. Papel de la medicina regenerativa y los sellantes en la enfermedad de Crohn perianal / Role of regenerative medicine and sealants in perianal Crohn's disease. Rev. argent. coloproctología ; 30(2): 43-50, Jun. 2019. ilus

4. JUNIOR R, et al. Heterologous fibrina sealant derived from snake venom: from bench to bedside - an overview. Rev J. Venom. Anim. Toxins incl. Trop. Dis Vol.23. Botucatu, 2017.

5. LEITE A. Comparação entre o uso de sutura e sutura associada ao selante de fibrina (CEVAP) na interação neuromuscular após Lesão Nervosa Periférica. Dissertação de mestrado da Universidade Estadual Paulista. Botucatu, 2018.

6. PAVÃO D, et al. Rospective Study on the Impact of the Use of Human Fibrin Sealant free of ClotStabilizing Agents in Total Knee Arthroplasty / Estudo prospectivo sobre o impacto do uso do selante de fibrina humano livre de agentes estabilizadores de coágulo na artroplastia total de joelho. Rev. bras. ortop ; 54(3): 322-328, May-June 2019. tab, graf 
RESUMO EXPANDIDO: Relato de Experiência

Título: Alterações anatômicas na mulher gestante versus infecção urinária: uma estratégia de educação em saúde.

Autor/coautores: Thaise Farias Rodrigues, Beatriz Mella Pessoa Soares, Carlos Eduardo Colares Soares, Janaína de Oliveira e Castro, Quelly Christina Alves Schiave.

Instituição: Universidade Federal do Amazonas (UFAM), Manaus/Amazonas.

Palavras-chave: Prevenção, Infecção urinária, Gestantes.

\section{INTRODUÇÃO}

Durante o período gestacional, ocorrem mudanças anatômicas e funcionais no assoalho pélvico, vísceras e períneo, desencadeadas pelo crescimento de útero gravídico e fatores hormonais. $O$ incremento do peso corporal materno e o peso do útero gravídico aumentam a pressão sobre a musculatura do assoalho pélvico na gestação a longo prazo, podendo evoluir para o surgimento de sintomas urinários (ANDRADE e TAVARES, 2017).

A infecção urinária é uma das infecções mais frequentes entre as gestantes, constituindo importante causa de morbidade gestacional. As condições de parada do fluxo urinário, redução da atividade antibacteriana da urina, hiperestrogenismo gestacional, além de alterações imunológicas próprias da gravidez favorecem o crescimento bacteriano e a instalação da infecção urinária (PAGNONCELI \& COLACITE, 2016).

Uma assistência qualificada durante as consultas de pré-natal é fundamental, uma vez que o diagnóstico precoce e o tratamento adequado são essenciais para o melhor prognóstico materno-fetal (LACERDA, et al., 2018). A realização do Pré-Natal é imprescindível para a identificação de risco gestacional e redução da morbidade e mortalidade materna e infantil, devendo ser iniciado precocemente, realizado de forma periódica e proporcionar cobertura universal (ALMEIDA, 2019).

\section{OBJETIVOS}

Relatar a experiência na promoção de saúde a gestantes abordando sobre anatomia da mulher durante a gravidez e surgimento de patologias como a infecção urinária. Enfatizar a importância da identificação, rastreio e prevenção precoce da infecção urinária, através do ensino de práticas adequadas de higienização, na saúde do binômio mãe-filho.

\section{RELATO DE EXPERIÊNCIA}

Trata-se de um estudo qualitativo do tipo relato de experiência desenvolvido através de oficinas de discussão em maternidade de referência de Manaus. As atividades foram realizadas por acadêmicos de medicina em caráter mensal, durante 3 meses em 2019, em acordo com os gestores da Unidade de Saúde, abordando sobre anatomia da pelve da mulher e suas transformações no período gravídico vinculado a implicações da patologia mais recorrente nessa etapa da vida reprodutiva, a infecção urinária, para as gestantes presentes.

As pacientes foram divididas conforme as suas alas na enfermaria e o debate do tema central foi apresentado por grupos de alunos através de panfletos ilustrativos e palestras de curta duração explicando conceitos, fatores de risco e maneiras eficientes de higienização íntima, dentro da perspectiva da Saúde da Mulher e do Programa de Humanização do Pré-Natal e Nascimento. Os alunos foram capacitados sobre a Política Nacional de Atenção Integral à Saúde da Mulher e metodologias ativas antes da realização das oficinas a fim de garantir um melhor entendimento e transmissão do assunto. 
Durante a execução do projeto foram alcançadas mais de 100 pacientes, buscando através do diálogo entre alunos e gestantes identificar as principais dúvidas, receios e vivências destas a respeito da infecção urinária. A maneira em que a forma de orientação e promoção de saúde foi abordada e correspondida pelas parturientes possibilitou uma construção coletiva do conhecimento visando medidas de prevenção e rastreio da doença.

\section{DISCUSSÃO}

O projeto alcançou mulheres no pré-parto e no pós-parto. Dessa forma, auxiliou na prevenção de um parto prematuro em mulheres no pré-parto, já que cedeu informações necessárias para prevenção da infecção urinária com uma higienização íntima adequada, além de abordar sobre os principais indícios dessa infecção. Ademais, auxiliou na prevenção de outras complicações durante o pós-parto e em futuras gestações, visto que as informações compartilhadas, e especialmente dúvidas sobre essa temática respondidas pelos acadêmicos, serão guardadas pelas parturientes.

Por ter tido uma duração de apenas 3 meses, o tempo pode ser considerado a principal limitação dessa experiência, com alcance de mais de 100 mulheres. Uma repetição do projeto com a mesma abordagem, em um período maior, teria possivelmente um alcance maior de mulheres e consequentemente um maior impacto dessa iniciativa de promoção de saúde, abrindo oportunidades a novas oportunidades de educação em saúde.

\section{CONSIDERAÇÕES FINAIS}

A realização de práticas educativas abordando as mudanças anatômicas que ocorrem durante o período gestacional mostra-se como uma estratégia necessária de educação materna no contexto de fortalecimento do pré-natal. A interação entre gestantes e estudantes de medicina proporcionou um ambiente de troca de conhecimentos acerca da prevenção da infecção urinária, patologia frequente durante a gravidez, associada a complicações maternas quando não identificada e tratada adequadamente.

\section{REFERÊNCIAS}

1. ALMEIDA RN, et al. Atenção à mulher no pré-natal: Análise da assistência versus direito à saúde. Revista Arquivos Científicos. 2019:41-47.

2. ANDRADE CC; TAVARES MCC. Avaliação da Função Muscular Abdominal e Sintomas Urinários no Puerpério. Trabalho de Conclusão de Curso apresentado ao Curso de Fisioterapia da Universidade São Francisco como requisito parcial para obtenção do título de Bacharel em Fisioterapia. Bragança PaulistaSP, 2017.

3. LACERDA ED, et al. Importância da assistência qualificada para detecção das infecções do trato urinário em gestantes. International Journal of Sex Research. 2018:1-2.

4. PAGNONCELI J, COLACITE J. Infecção urinária em gestantes: revisão de literatura. Revista Uningá Review, [S.I.], v. 26, n. 2, 2016. 


\section{Resumos Simples}

RESUMO SIMPLES: Revisão Bibliográfica

Título: Epidemiologia dos casos de câncer de gengiva no Brasil de 2016 a 2020

Autor/coautores: Pedro Henrique Batista da silva1, Renaly Gabriely de Araujo Rodrigues ${ }^{2}$.

Instituição: Universidade Federal do Tocantins, Palmas-Tocantins ${ }^{1}$; UNINASSAU, Campina Grande-

Paraiba².

Palavras-chave: Epidemiologia, Neoplasias Gengivais, Incidência.

\section{INTRODUÇÃO}

O câncer bucal está nos principais problemas de saúde pública de acordo com o Instituto Nacional do Câncer (INCA). A origem da maioria dos casos de Câncer na cavidade bucal está na má alimentação e na má higiene oral, fatores como: escovação dentária inadequada e o não uso de fio dental levam ao surgimento da doença. Das Neoplasias Malignas Bucais foi escolhido o Câncer Gengival para um recorte epidemiológico, por meio do DataSUS, o qual visa fazer um mapeamento dos casos da patologia no território brasileiro. Os principais sintomas das pessoas com essa doença são: Dificuldade de mastigar e engolir e o aparecimento de placas brancas ou vermelhas na gengiva que não cicatrizam (GUEDES, 2017).

\section{OBJETIVO}

Determinar o perfil epidemiológico dos casos de internação por Câncer de Gengiva no Brasil de 2016 a 2020 de maneira a auxiliar no desenvolvimento de políticas que favoreçam a prevenção e o diagnóstico precoce.

\section{MÉTODO}

Trata-se de um estudo epidemiológico, quantitativo e retrospectivo com coleta de dados no Departamento de Informática do Sistema Único de Saúde (SUS) - DATASUS. A pesquisa foi realizada mediante informações Epidemiológicas e Morbidade com consulta ao Sistema de Informações de Agravos de Notificação SUS (SINAN NET) do Ministério da Saúde do Brasil. Foram analisados os dados disponíveis no sistema, como: região predominante, faixa etária etc.

\section{REVISÃO BIBLIOGRÁFICA}

De 2016 a 2020 foram identificados 936 casos clínicos de Neoplasia Maligna na Gengiva. A região Sudeste, representou $49 \%$ dos casos clínicos da doença. O recorte epidemiológico aponta que a patologia é predominante no sexo masculino (61\%) e, em relação a idade, a maioria dos casos ocorre em idosos, a faixa etária com maior porcentual foi a localizada entre 60 e 64 anos representando 16\%. Em relação as modalidades terapêuticas, a predominante foi a radioterapia (33\%) seguido da quimioterapia (30\%) e, por fim, a cirurgia (15\%). No ano de 2019 ocorreu um relevante aumento de $39 \%$ no número de casos.

\section{CONSIDERAÇÕES FINAIS}

A maioria das ocorrências estar nos idosos mostra a necessidade de maior atenção em relação a higiene bucal e alimentação, uma vez que grande parte dos casos da doença surge a partir da falta de cuidado nesses quesitos. O aumento dos casos em 2019 e possivelmente até o fim de 2020 indica a importância da educação na realização da higiene bucal correta e na criação de hábitos alimentares saudáveis. 


\section{REFERÊNCIAS}

1. GUEDES AV. A importância da educação como estratégia na prevenção e no diagnóstico precoce do câncer bucal. Repositório UFPB, João Pessoa, 23/11/2017.

2. OLIVEIRA LK. Câncer bucal: uma abordagem sobre os fatores de risco, diagnóstico e prevenção. Archives of health investigation, 2018. 
RESUMO SIMPLES: Revisão Bibliográfica

Título: Causas relacionadas à pielonefrite com ênfase no seu diagnóstico e tratamento

Autor/Coautores: Paulo Henrique Santos da silva, David Vitor da Silva anjos, Suyla Manuelle da Silva Leite, Ana Carolina Messias de Souza Ferreira da Costa, Ruany Cristyne de Oliveira Silva.

Instituição: Centro Universitário Brasileiro (UNIBRA), Recife-Pernambuco.

Palavras-chave: Sistema renal, Infecção do trato urinário, Refluxo urinário.

\section{INTRODUÇÃO}

A pielonefrite aguda surge de forma inesperada levando o comprometimento dos rins, ocasionada por bactérias gram-negativas, decorrente da microbiota normal do intestino. A infecção pela Escherichia coli é responsável por $80 \%$ dos casos registrados como pielonefrite (COSTA IAC, et al., 2019). A pielonefrite crônica é caracterizada por casos de infecções bacterianas repetidas, quando não se tem o tratamento correto, com o sistema urinário debilitado; o diagnóstico é realizado pelos sinais e sintomas que o paciente apresenta como febre, vômitos, mal-estar, sudorese, dor lombar e também pélvica (SILVA ACS, et al., 2015).

\section{OBJETIVO}

Revisar sobre as causas que possam promover a infecção urinaria, relacionada à pielonefrite, tendo em vista os seus diagnósticos presentes para a confirmação e o seu método de tratamento adequado.

\section{MÉTODO}

O presente resumo trata-se de uma revisão bibliográfica sem critério explicito retirados de portais digitais como o SciELO e revistas digitais. Para a busca dos materiais utilizou-se palavras chaves isoladas e permutadas, como "medicamentos para pielonefrite", e "causas da pielonefrite". Os critérios. Reunidos em uma janela de tempo entre 2010 a 2019. Responsável por três referências em idioma português do Brasil. A coleta de dados para a revisão foi realizada em junho de 2020.

\section{REVISÃO BIBLIOGRÁFICA}

A pielonefrite aguda é caracterizada como resultado de uma breve infecção do trato urinário, que acomete principalmente mulheres. Os sintomas podem variar de acordo com o grau da infecção, podendo ser febre, mal-estar, calafrios, vômitos, diarreias e fadigas. O método de diagnóstico é feito pelo exame de urina do tipo 1. O exame de hemocultura geralmente é recomendado para pessoas que estão com suspeitas de bacteriúria. Podendo ser feito também o exame de imagem como a ultrassom ou a tomografia, exames recomendados para pacientes que apresentam muita febre, ou algum outro sintoma que seja persistente após as $72 \mathrm{~h}$ do tratamento com antibiótico (SILVA ACS, et al., 2015).

O tratamento da pielonefrite vai depender do grau da infecção e os medicamentos utilizados, na maioria dos casos, são antibióticos. O uso dos medicamentos não pode ser interrompido, tem que ser realizado de forma correta e no seu horário, para que a bactéria não crie resistência (OLIVEIRA ALD, et al., 2018).

\section{CONSIDERAÇÕES FINAIS}

Diante do que foi exposto, é importante que as pessoas procurem orientação profissional quando surgem os primeiros sintomas e façam o tratamento correto, sem interrupção, para evitar a resistência bacteriana e que a infecção evolua para uma forma mais grave. 


\section{REFERÊNCIAS}

1. COSTA IAC, et al. Infecção do trato urinário causada por Escherichia coli: revisão de literatura. SALUSVITA, 2019; 38(1):155-193.

2. OLIVEIRA ALD, et al. Mecanismos de resistência bacteriana a antibióticos na infecção urinária. Revista Uningá, 2018; 20(3): 65-71.

3. SILVA ACS, et al. Atualização da abordagem de infecção do trato urinário na infância. Jornal de Pediatria, 2015; 91(6): 2-10. 


\section{AGRADECIMENTOS}

\section{Patrocinadores}
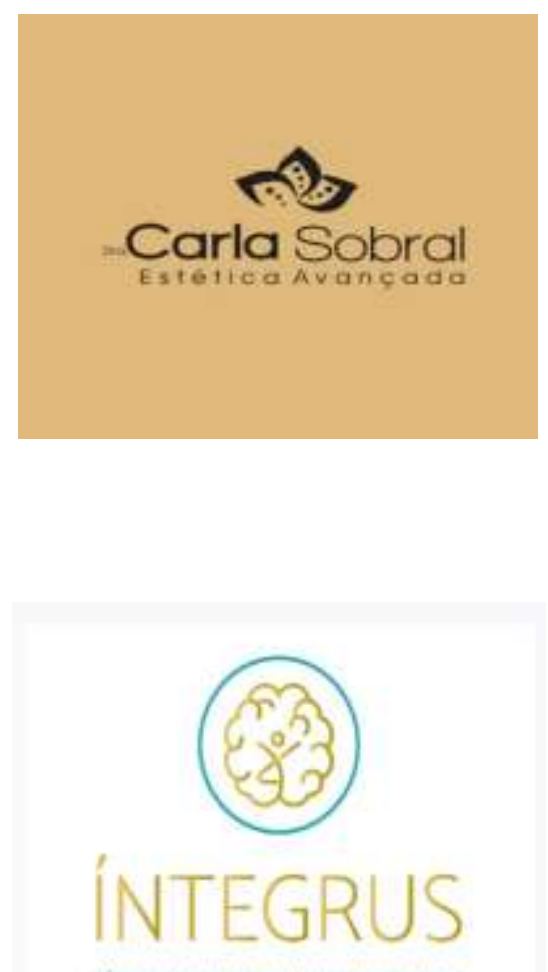

CGREAROE EOMMORTAMENTO NTEGRADOS 